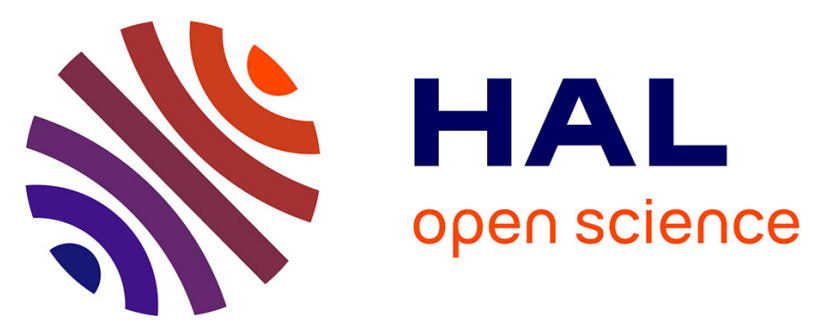

\title{
L'habitat Villeneuve-Saint-Germain du Haut-Mée (Saint-Étienne-en-Coglès, Ille-et-Vilaine)
}

Serge Cassen, Claude Audren, Stéphan Hinguant, Gaelle Chancerel, Grégor Marchand

\section{- To cite this version:}

Serge Cassen, Claude Audren, Stéphan Hinguant, Gaelle Chancerel, Grégor Marchand. L'habitat Villeneuve-Saint-Germain du Haut-Mée (Saint-Étienne-en-Coglès, Ille-et-Vilaine). Bulletin de la Société préhistorique française, 1998, 95 (1), pp.41-76. 10.3406/bspf.1998.10734 . hal-01907100

\section{HAL Id: hal-01907100 https://hal.science/hal-01907100}

Submitted on 4 Dec 2020

HAL is a multi-disciplinary open access archive for the deposit and dissemination of scientific research documents, whether they are published or not. The documents may come from teaching and research institutions in France or abroad, or from public or private research centers.
L'archive ouverte pluridisciplinaire HAL, est destinée au dépôt et à la diffusion de documents scientifiques de niveau recherche, publiés ou non, émanant des établissements d'enseignement et de recherche français ou étrangers, des laboratoires publics ou privés.

\section{(ㄷ)(1) $\$$}

Distributed under a Creative Commons Attribution - NonCommercial| 4.0 International 


\title{
L'habitat Villeneuve-Saint-Germain du Haut-Mée (Saint-Étienne-en-
} Coglès, Ille-et-Vilaine)

\author{
Serge Cassen, Claude Audren, Stéphan Hinguant, Gaëlle Lannuzel, Grégor Marchand
}

\section{Résumé}

Résumé Une fouille préventive menée en 1996 sur le tracé de l'autoroute Rennes- Avran- ches a permis la découverte de structures d'habitat du Villeneuve-Saint- Germain, à l'Est de Fougères, sur les terrains granitiques du Coglais. Des fosses simples (dont l'une d'entre elles, couverte d'une dalle taillée et piquetée, est interprétée comme sépulture) et des couples de fosses allongées (à comblement systématiquement contrasté) accompagnent un bâtiment à plan trapézoïdal prononcé. Le placage lœssique et le contexte géologique typique d'un métamorphisme de contact sont des éléments qui ont en partie déterminé le choix de l'implantation du site.

\begin{abstract}
Abstract Rescue excavations along the planned Rennes-Avranches motorway led to the discovery of dwelling structures (dated to Villeneuve-Saint-Germain) to the East of Fougères on the granitic Coglais terrain. Simple pits (one of which, covered with a cut and picked stone slab, is interpreted as a grave) and pairs of elongated pits (with systematically contrasted in-fill) are found with a house of marked trapezoidal plan. The loess cover and the geological context typical of contact metamorphism are elements which may have determined, at least in part, the choice of site.
\end{abstract}

\section{Citer ce document / Cite this document :}

Cassen Serge, Audren Claude, Hinguant Stéphan, Lannuzel Gaëlle, Marchand Grégor. L'habitat Villeneuve-Saint-Germain du Haut-Mée (Saint-Étienne-en-Coglès, Ille-et-Vilaine). In: Bulletin de la Société préhistorique française, tome 95, n¹, 1998. pp. 41-76;

doi : https://doi.org/10.3406/bspf.1998.10734

https://www.persee.fr/doc/bspf_0249-7638_1998_num_95_1_10734

Fichier pdf généré le 13/04/2018 


\title{
L'habitat \\ Villeneuve-Saint-Germain \\ Serge CASSEN. du Haut-Mée \\ Claude AUDREN, \\ Stéphan HINGUANT, \\ Gaëlle LANNUZEL, \\ Gregor MARCHAND \\ (Saint-Etienne-en-Coglès, \\ Ille-et-Vilaine)
}

\begin{abstract}
Résumé

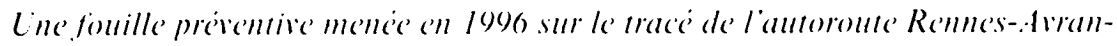
ches a permis la decourerte de structures dihabitat du lillenewe'saintGermain. a l Est de Houseress sur les rerrains granitiques du Coglais. Des fosses

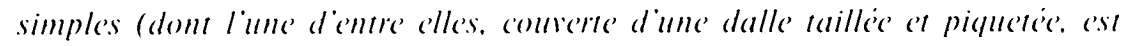

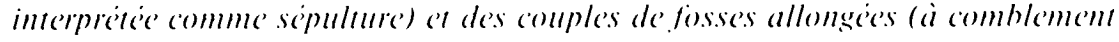

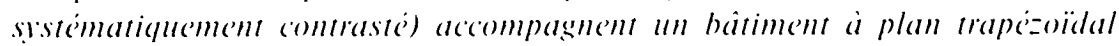

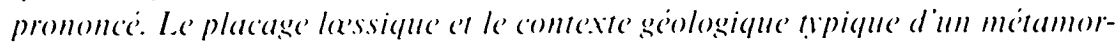
phisme de contact som de's ciliments qui ont en partie determine le choix de limplantation du site.
\end{abstract}

\begin{abstract}

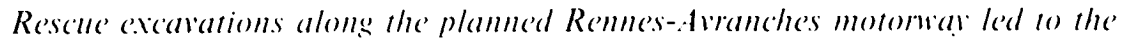
discovery of dwelling structures (dated to l'illenewere-Saim-(iermain) to the East of Fougeres on the granitic Coglais terrain. Simple pits (one of which. covered with a cut and picked stonc slat). is interpreted as a grave) and pairs of elonsated pits (with sistematically contrasted in-fill) are found with a house of marked trapezoidal plan. The loess cover and the geological context trpical of contact motamorphism are eleme'nts which mal have determined, at least in part, the choice of site.
\end{abstract}

\section{LA}

construction de lautoroute des estuaires (A.84) et particulièrement son tracé entre Rennes et Avranches sont à loorigine d'un certain nombre de découvertes archéologicues dans une région septentrionale peu connuc du Massif armoricain. Les conditions de la collaboraltion ayant présidé a la fouille préventive concernée par est article furent déjà évoquées dans une note d'actualité (Cassen. Ilinguant. 1996): on retiendra que les engagements du C.N.R.S., du S.R.A. do Bretagne, de IA.F.A.N. et des universités se sont naturellement inscrits dans les travaux de l'U.M.R. 6.566. Par ailleurs, un plan densemble du décapage fut publié à loceasion de la journée Internéo et ne sera done pas repris ici (Cassen ot al. 1996).

Durant les campagnes d’évaluations menées a laalutomne 1995 sur le tracé de la future voie, une quinzaine de kilomètres à louest de Fougères, la découverte d'une fosse riche d'un matériel néolithique (Leroux. 1996) permit lagrandissement de la zone repérée et donna fort opportunément l'occasion de déceler trois fosses alignées plus petites que nous devions interpréter par la suite comme des trous de poteaux en liaison possible avec une unité d'habitation contemporaine des vestiges céramiques. Une fouille extensive fut alors décidéc pour les mois de mars et avril 1996, dirigee sur le terrain par S. Cassen en collaboration avec $\mathrm{S}$. Hinguant.

En accord avec D. Marguerie, les données paléoenvironnementales du site (palynologie, anthracologie) seront abordées dans une étude ultérieure qui proposera une ș̣nthèse pour l'ensemble des milieux analysés sur le tracé de lautoroute. 


\section{LE CADRE GÉOLOGIQLE}

Sans vouloir à tout prix expliquer limplantation de l'habitat néolithicpue du Ilaut-Mée par le biais de raisons déterministes liés a la qualité des sols ou du soussol, il apparaît néanmoins nécessaire de bien saisir lenvironnement géologicue au sens large pour se laire une idé la plus complic possible des contraintes et des potentialités d’une région touchée, peut-être pour la première fois. par des sociétés d’agriculteurs-éleseurs. La carte géologique qui nous servira de guide est colle du territoire de Saint-Hilaire-du-Harcouët au $1 / 50(000)$ (B.R.(j.M. n" 247. Didet et al. 1984) qui sötend sur une region de bocigge assoz accidentéc. Mis a part lextrême Nord-Ouest draine directement vers la mer. k réseau hydrographique est partagé par une diagonale. situie entre le bassin du Coucsnon au Sud-Ouest et celui de la Sélune au Nord-Fst. Les zones hautes plus accidentés sont directement en rapport avec le massil granitique au bord duquel est situe le Hatut-Mic. Les terrasses fluviatiles. les loess et sables coliens largement Épandus, témoignent d’un environnement périglaciaire qualternatire.

Dans le détail, les formations sédimentatires détriticues dâge briovérien. dans lesquelles les granitö̈des sont intrusils, ont etć thermometamorphisies par celte intrusion. Des schistes tachetés constituent lauréole de métamorphisme de contact la plus externe, des cornéennes en formant lauróle la plus interne. Ces cornéennes sont des roches que la résistance à l'érosion place souvent en position dominante dans la topographie. La limite avec les schistes tachetés est marquée par une rupture de pente franche tres continue. Les vallées encaissées dans les cornéennes, a llanes abrupts. š̉argissent en général des quelles pénètrent dans la zone des schistes tachetés. A laftleurement, les cornénnes se reconnaissent à leur aspect plus eristallin et micalcí a leur durcti ou bien à leur altération rougeàtre.

En ce qui concerne les roches filoniennes. il sagit avant tout de dolérite el de quart\%. De nombreux filons de puissance et de continuite tris diverses ont pris placesurtout à leest du Haut-Mec et non ligurés sur la carte (lig. 1) - dans les fissures du vieux domaine stable continental au cours de son histoire. Les plus importants des filons de dolerite ressortent bien dans la morphologic ear ils forment des reliefs allongés tress nets, alors que diatres ne sont connus que par les blocs a boules éparses qui en proviennent. La roche, noir verdâtre, il grain fin, homogène, dure, se dibite en boules et saltice en un produit argileux d'un rouge violacé caractéristique.

Les formations quaternaires, importantes pour notre propos, sont des lœss weichséliens-würmiens. Ces limons coliens de facies normand sont bruns a brun jaune, miciacés, non carbonatés, frécuemment lites. Co facies se distingue surtout lorsque le loess est épais:

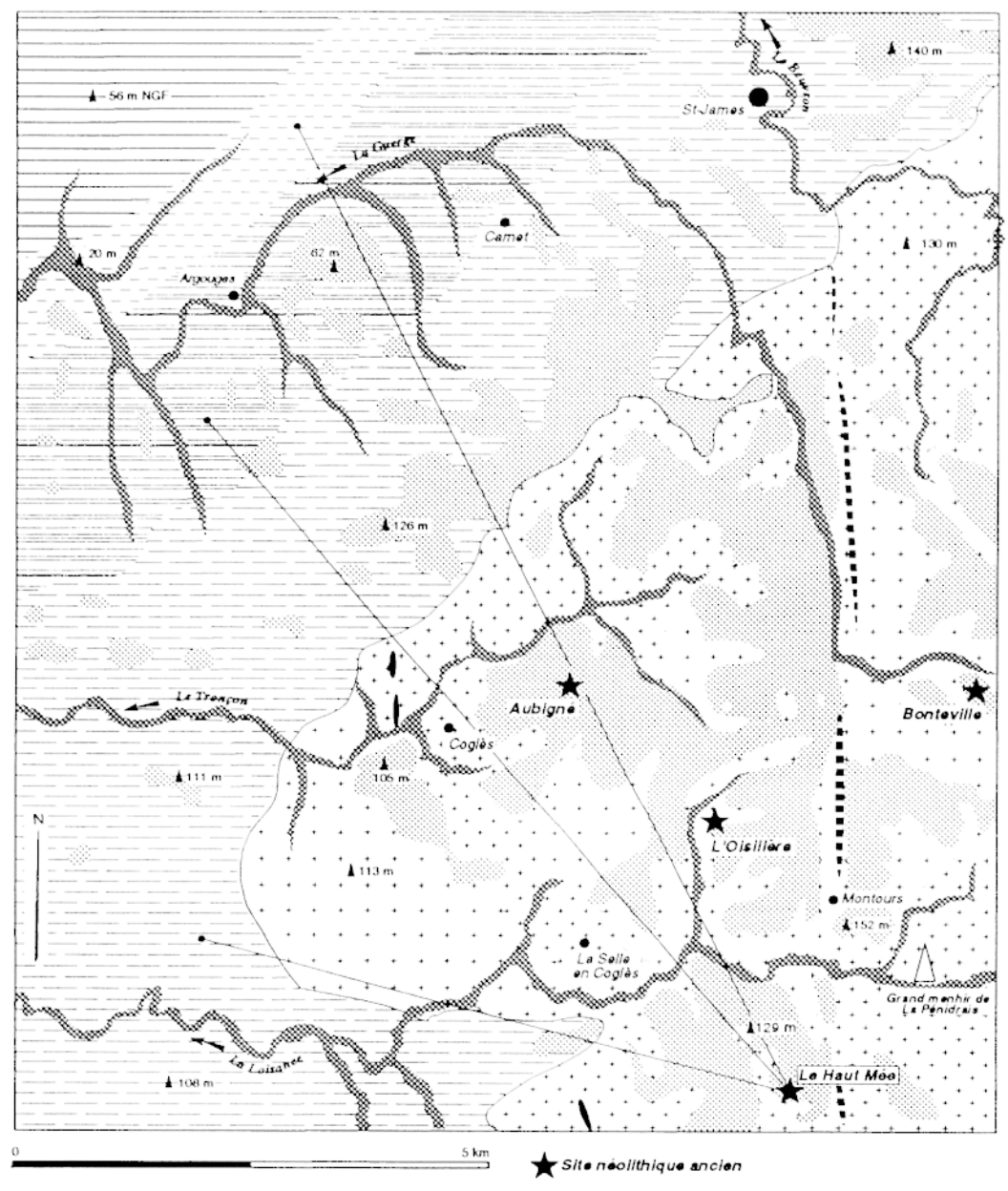

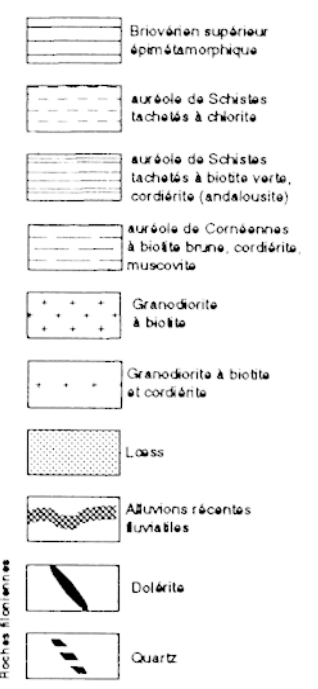

Fig. 1 - Carte geologique simplitise de lougeres ()uest (d'apres Dadel at al., 1984): origine des bracelets (I).A.(O. C. Boujol). 


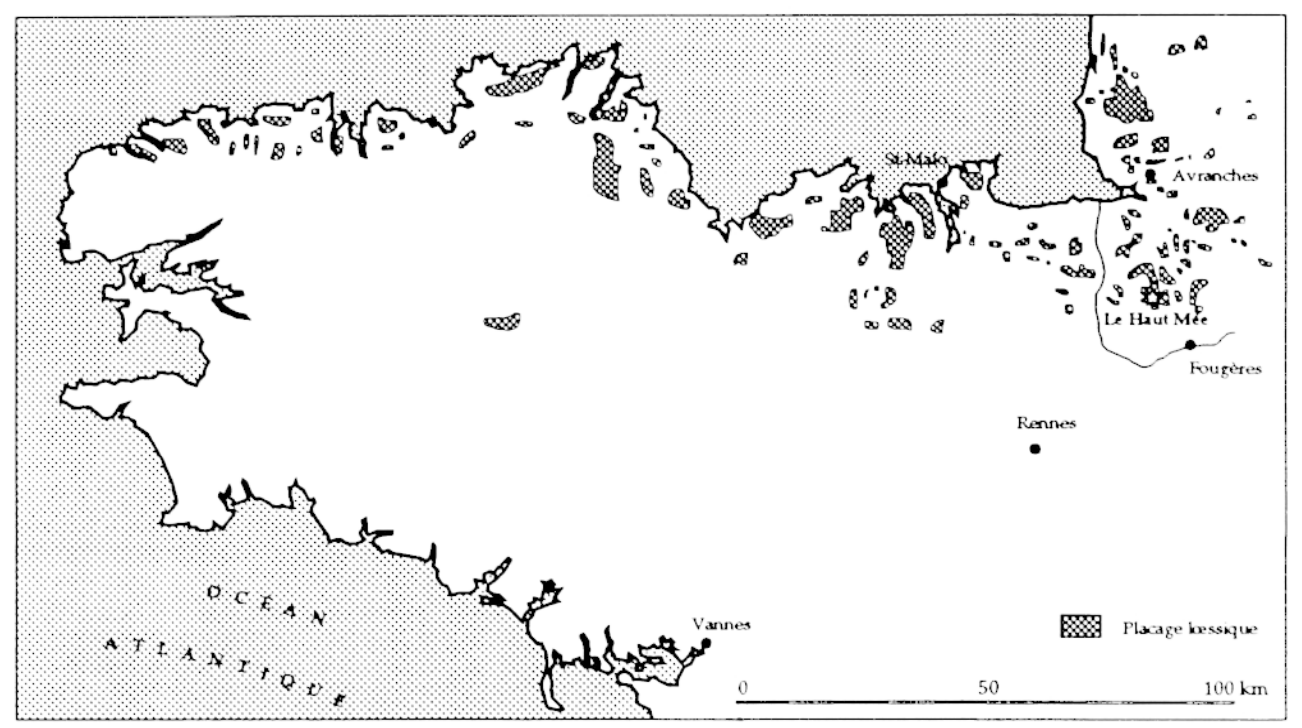

Fig. 2 - 1)istrihution des lessien Armorigue (D.A.(). (. Boujot diapres Joly. I9so).

sinon il est celui d'un limon brun à taches grises plus ou moins nettes et à fines concrétions noires ferro-manganiques. Ils sont présents sur tout le territoire, excepté au Nord-Ouest (faciès sableux); on les observe sur les interfluves et replats à faible pente, et parfois au pied des versants. Leur épaisseur, maximum au niveau d'une ligne Virev-Saint-James-Coglès (2 à $4,50 \mathrm{~m}$ ), décroît nettement vers le Sud-Est en même temps que leur extension qui devient très sporadique. Néanmoins. on retrouve partout ce matériel limoneux, même en dehors des zones cartographiées en loss, mélangé avec le substrat altéré (arène) ou formant une mince pellicule.

En résumé, l'habitat néolithique ancien du Haut-Mée est implanté sur un placage lossique, ce qui ne surprend personne connaissant lattrait exercé par ces terres fertiles sur les populations contemporaines du Bassin parisien, elles-mêmes issues de la sphère rhénodanubienne: la présence sporadique des loess en Bretagne. plutôt disposés au nord de la péninsule (lig. 2), reste un parametre liable à intégrer à tout essai de modélisation et de recherche prospective d'habitats semblables. Dans le cas présent, le site est également proche de la variété des roches caractéristiques des phénomènes de métamorphisme de contact - cornéennes, schistes tachetés, etc. - toutes susceptibles de fournir un matériau de choix dans la fabrication de certains objets.

\section{L'ENVIRONNEMENT NATUREL IMMÉDIAT}

Le champ de fouilles, déterminé par l'emprise foncière, s"inscrit sur une légère pente entre une sorte de petit plateau au Nord, large de 300 à $500 \mathrm{~m}$ sur $1000 \mathrm{~m}$ de long, aux terres réputées fertiles, et une zone basse tourbeuse, de constitution familière pour les habitués

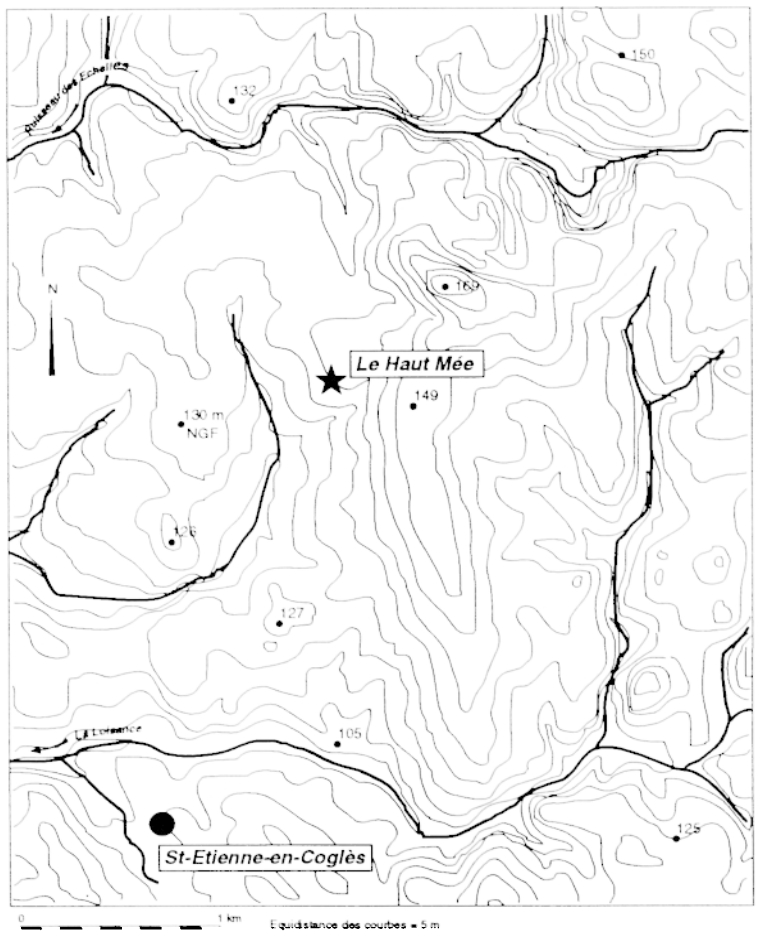

Fig. 3 - Topographic de la region du Haut-Mke (I).A.(). (. Boujot diupres 1).1).1:. lougeres).

de la région. Demblée, celte dernière zone nous semblait devoir retenir une attention toute particuliere, notamment a loccasion des terrassements " de purge " décidés par la D.D.E. en prévision de la construction d’un ouvrage d'art. et cela en raison. d'une part, du fait probable qu'elle devait constituer le point deau le plus proche des habitations dés lépoque néolithique, et. d’autre part, pour toutes les potentialités qu'elle suggérait dans le cadre d'une étude paléoenvironnementale 
sur le site du Haut-Mée. Il nous a paru indispensable d'établir, durant les travaux de purge et de remblaiement, une coupe stratigraphique des unités lithologiques aperçues, en eflectuant dans le même temps les prélèvements qui s'imposalient au niveau de la couche tourbeuse (à paraitre).

Le premier contact avec le Coglais montre, outre la valriété des vallées qui surprennent partois par leur aspect encaissé des lors qu'un sous-sol tenace est traversé (lig. 3), une constante présence des alfleurements rocheux, pour l'essentiel des granites. La pente du Haut-Mée ne fait pals exception et une dalle visible sur la partic nord de la parcelle mérite à es titre un bref commentaire: striéc sur plusicurs metres carrés, selon une direction Nord-Sud, par le raclage successit de soes de charrues pour lesquels elle était à une époque invisible, cette dalle est lillustration éclatante des phénomènes érosifs ayant aflecté ces terrains depuis plusieurs siecles, pour ne pas dire davantage. 11 apparait en conséquence légitime de devoir ajouter 20 a $30 \mathrm{~cm}$ au moins au-dessus de la couverture sídimentaire recouvrant les actuelles structures archéologiques en creux si lon reut raisonnablement spéculer sur leurs dimensions originalles en rapport avec le niveau du sol ancien.

\section{LA PRÉHISTOIRE RÉCENTE DU SECTELR}

Le bilan documentaire opéré dés notre arrivéc savéra asse\% pauvre pour la période néolithicue. Une liche descriptive fut ncianmoins établie par D). Leroy, dans lo cadre d'une prospection-inventaire (1988), a lactif du gisement de surface de Bonteville a Montours sur lequel nous reviendrons. Plusieurs menhirs sont datalleurs connus sur cotle dernière communc, en particulier un spectaculaire spécinen brise en deux. long d’une dizane de mitres, au lieu-dit La Pedrinais. Encore plus a l’Est du département. les sépultures mégalithicuess siolués de la forêt de Fougères attestent par ailleurs d'un Néolithique récent/final bien implanté sur les marches de Bretagne: plusicurs tertres bas et lalignement impressionnant de menhirs en quarty dans ce même massif forestier - connu par ailleurs pour alvoir livré plusieurs anncaux-disques (Philippe, 1926) - pose davantage de problemes yuant à leur datation. Il est en les tous cas ecrtain que le Néolithique ke plus ancien de la region se résumatit jusqu à ce jour alux lessons décorés de boutons au repoussé décourerts lors de la fouille du châtcau de loougères (Bigot. Le Carduner. 1987).

\section{Méthodologie : techniques de fouilles. relevés, enregistrement}

Les structures archéologiques mises en évidence par les sondages préliminaires apparaissant sous 30 a $40 \mathrm{~cm}$ de terre végétale, on procéda au décapage extensit de lat zone concerné, soit une superficie denviron $8000 \mathrm{~m}$ '. au moyen d'un engin chenillé muni d'un godet lisse. Cette opération sest déroulée par bandes équivalent a deux largeurs de godet (environ $+\mathrm{m}$ ). Le mobilier archéologique récolté au cours du travail a fait l'objet d'un enregistrement suivant chaque tranchée, à intervalles réguliers.

A lissue des terrassements, la richesse en mobilier de certaines zones (fig. 4) peut ainsi être mise en parallèle avec la densité des structures sous-jacentes. Outre une répartition spatiale, ce premier enregistrement a parfois facilite des remontages ou des associations entre des objets hors contexte et des objets en place. Une petite berme a été laisséc vers la centre de la surface fouilléc: cette "banquette témoin" permet de conserver une stratigraphie densemble at servit de rélérence topographique pour les relevés altimétriques réalisés au théodolite. Chaque structure a fait lobjet d'au moins deux relevis, correspondant a la surface de décapage et son fond, la différence entre les deux mesures exprimant la profondeur conservée de lexcavation.

Afin de laciliter le relevé du plan général, un carroỵge lixe fut implanté avec une trame de carrés de dix mitres de côté. Ce découpage orthométrique de la surface a partois pu compléter lenregistrement de mobilier hors contexte, notamment dans la partic orientale du décatpage. Toutes les structures néolithiques ont été fouillées soit par moitié (fosses, trous de poteaux), soit completement (en particulier certaines fosses riches en mobilicr). Les stratigraphies n’ont été relevées que lorsque les comblements présentaient de réclles singularités. ce qui reste exceptionnel sur le site compte tenu de l'arasement important des lestiges. Dans certaines fosses où l’industrie lithicue semblait particulièrement abondante, le tamisage particl des terres s'est imposé alin de récuperer les esquilles de débitage non repérables a la fouille.

Des photographies (diapositive et négatil couleur) ont complété les relevés de lerrain. Un enregistrement vidéo $8 \mathrm{~mm}$ a couvert lensemble des travaux de fouilles et des prises de vues numériques ont permis de gagner un temps appréciable en évitant les relevés graphicues des structures empierrés, directement dessinées à laide des logiciels appropries (Aérophoto, Illustrator, Photoshop). Entin, la période des labours et des hersages coincidant avec notre intervention, quelques prospections au sol furent effectuées dans les parcelles aroisinantes. Du mobilier lithicue fut ainsi ramassé à proximite. indicuant une extension probable de l'habitat au-delat de lemprise routiere et un possible gisement du Néolithique linal $100 \mathrm{~m}$ au Nord de la parcelle concernée, ec que confirment quelques silex tailles recucillis en limite nord du décapage (un fragment de "scie à coches" en silex d"aspect pressignien).

\section{DESCRIPTION DES STRUCTLRES ARCHÉOLOGIQUES}

\section{La période gallo-romaine et l'âge du Fer}

Un vaste enclos probablement quadrangulaire ceinture l'extrémité du promontoire du Hatut-Méc. C'est en loul cals ce que semble indiguer les fossis perpendiculaires retrouvés a l'Ouest el a l'lest du décalpage. correspondant peut-ître aux quatre côtés d’un même 


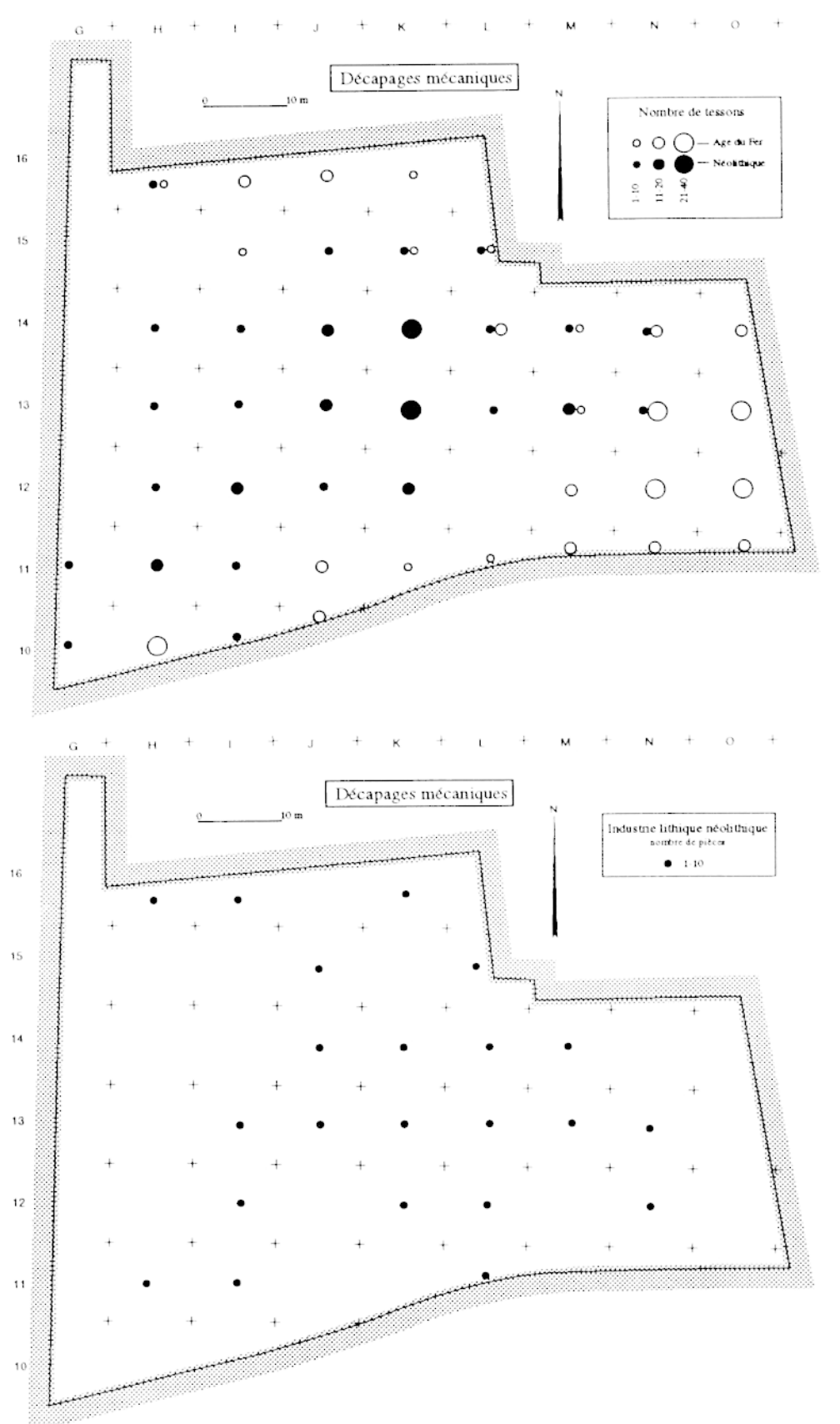

Fig. 4 - Repartition du mobilicr archéologiçue recucilli at cours du decapage mécanicpue.

ensemble. Le mobilier récolté dans les différents sondages est très pauvre mais la présence d'un lot de céramique, dans le fossé 145. permet d'attribuer cet enclos à la période gallo-romaine voire peut-être à l’Âge du Fer. Dans la partic orientale du décapage, et plutôt en périphérie de celui-ci, un petit ensemble de structures protohistoriques fut mis atu jour. Il s'agit avant tout d'un Épandage de mobilier el de blocs de pierres rougis par laction du feu, dont le rejet couvre une légère dépression aux contours imprécis. Les céramiques associées à ce rejet ne semblent cependant pas avoir subi l'effet de la chaleur. L'ensemble mobilier - à publier dans une note séparée - paraît bien homogène at permet de proposer une fourchette chronologicue allant de la tin de La Tène moyenne au début de La Tène finale.

\section{Le Néolithique}

Trois grands types de structures en creux sont at ripporter au Nćolithique: les "trous de poteaux". les fosses simples, allongées ou circulaires, enfin les "fosses doubles", toutes ces dernieres de morphologies et de remplissages répétés à l'identique. 


\section{Les trous de poteaux}

Alors que les deux autres types de structures apparaissaient immédiatement au cours du décapage mécanique, les trous de poteaux furent beaucoup plus difficiles à mettre en évidence : sur plus d'une cinquantaine de fosses de maintien des superstructures en bois que compte le plan du bâtiment néolithique, seuls six d’entre elles purent être identifiées après le passage du godet lisse... Il aura fallu deux nettoyages a la binette plus un décapage manuel soigné à l'aide de la truclle pour que l'ensemble ressortît de manière indiscutable. Le problème n'est pas nouveau dès lors que l'encaissant présente les mêmes couleurs et les mêmes textures que lencaissé ; il implique néanmoins un constat mitigé, celui de ne pas pouvoir affirmer l'inexistence d’autres séries de trous de poteaux au sein même de la maison ainsi que sur toute l'étendue du décapage. Mais un tel travail de nettoyage fin reste exclu sur une telle surface et dans le cadre d'une fouille préventive aux échéances clairement affichées. Du coup, dans un environnement semblable, on reste songeur sur nos capacités à repérer de tels trous de poteaux à l'occasion d'une simple évaluation...

Quoi qu’il en soit, le décapage mécanique fut bien maîtrisé dans les secteurs les plus sensibles, en particulier à la hauteur de la zone "potentielle" néolithique, soit $40 \mathrm{~cm}$ sous le niveau superficiel de la prairie : 15 a $20 \mathrm{~cm}$ plus bas les trous de poteaux disparaissaient, $15 \mathrm{~cm}$ plus haut ils nous restaient invisibles, noyés dans l'horizon sombre humifère. Si lon comptabilise maintenant les
$30 \mathrm{~cm}$ de sédiments qui ont pour le moins disparu avec le temps, entrainés par l'érosion, on totalise une profondeur minimum de $80-100 \mathrm{~cm}$ pour les trous de poteaux néolithiques. Leur diamètre moyen à cette hauteur de décapage est de $50 \mathrm{~cm}$ mais les parois évasées dégagées à la fouille suggèrent, bien entendu, des ouvertures originelles en surface bien supérieures. Le remplissage limono-lossique apparemment indifférenciable des trous de poteaux tranchait néanmoins sur un point (sans doute pas remarqué de façon systématique mais si souvent répété qu'il devint au fur et à mesure un lil conducteur), celui de la présence de petits charbons de bois aléatoirement dispersés, possibles et ultimes témoignages du sol d'occupation de l'époque. De même, plusieurs structures présentèrent un mélange fortement arénacé curieusement discernable vers leur milieu du comblement décapé, du haut jusqu’à la base, là où l'on pouvait légitimement s'attendre à trouver le "fantôme" du poteau en bois ; il est difficile de mieux expliquer cette substitution par le pourrissement du bois que par l'enlevement des poteaux... Peu de matériel est issu de ces trous : ceux de la maison ont néanmoins livré quelques tessons néolithiques ainsi que des éclats de silex; seule la structure n"16, en façade, contenait plusieurs éclats du tranchant d'une lame de hache polic en quartz. polycristallin (lig. 5). Quant à l'organisation qui peut être lue par le biais des relevés généraux, elle se résume à deux ensembles cohérents. l'un renvoyant à un bâtiment trapézoödal. l'autre à un second édifice disposé "en avant" de celuilà mais présentant une moindre envergure.

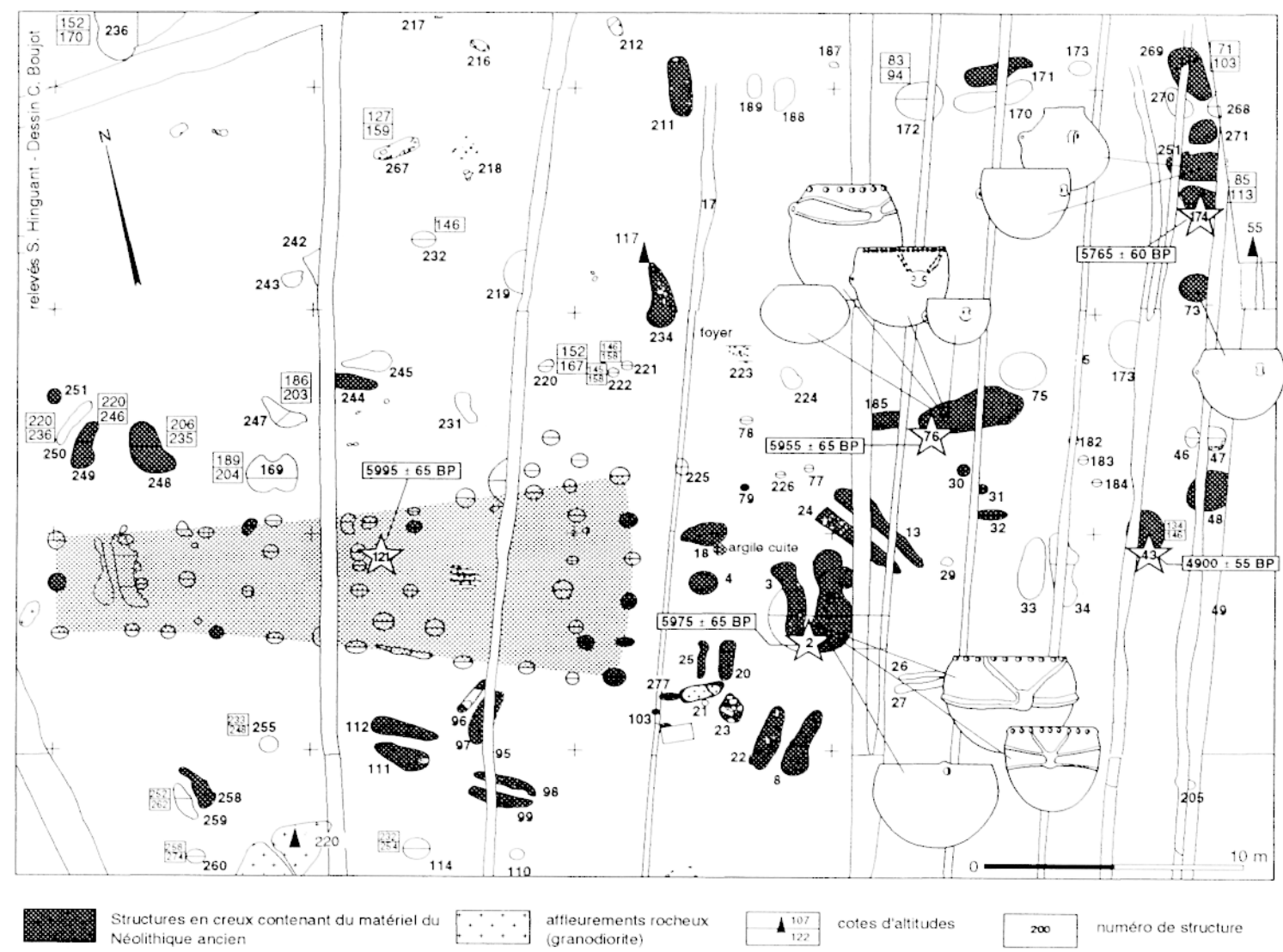

Fig. 5 - Plan des structures miolithicues (1).A.(). (. Boujot). 


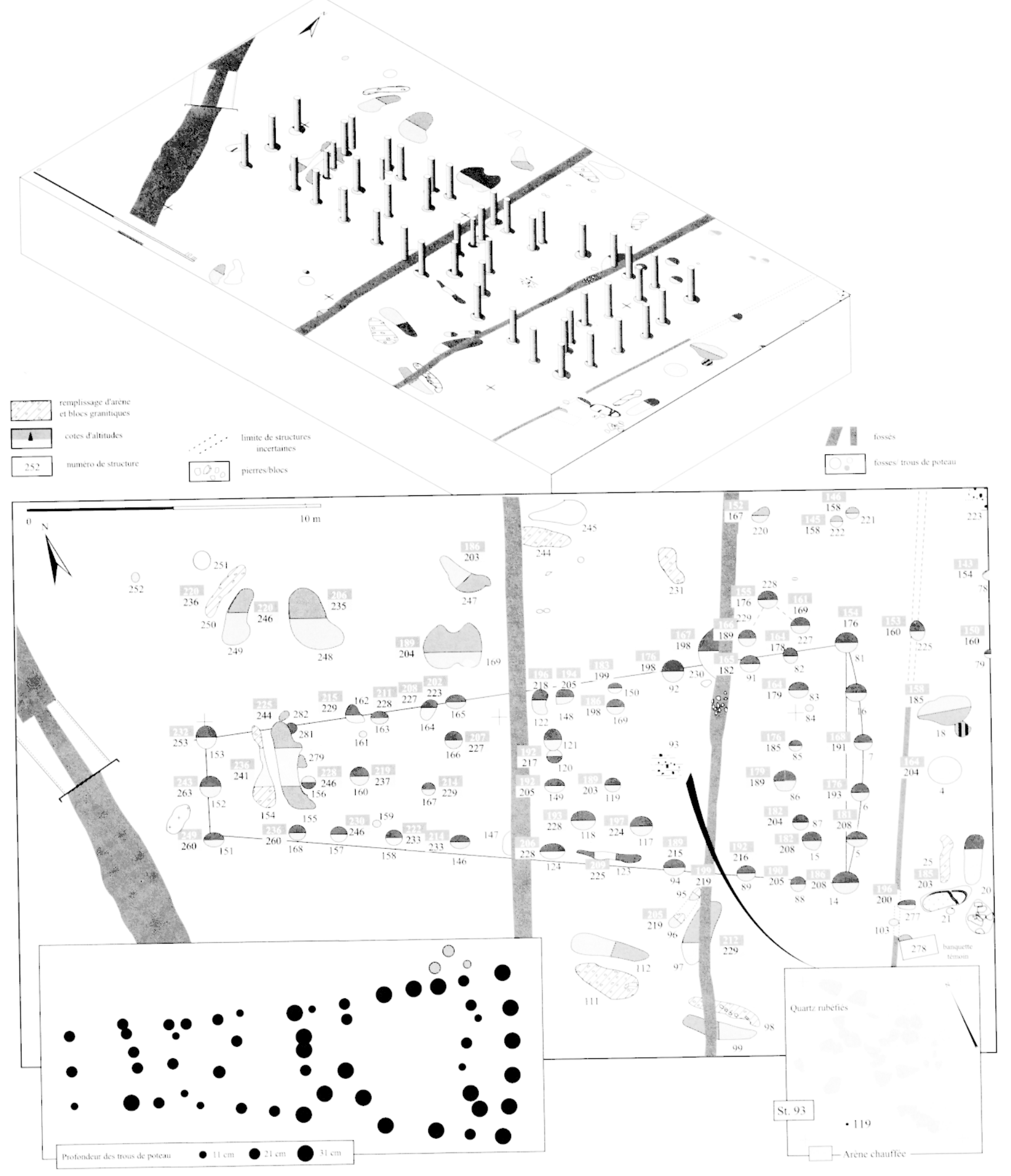

ERRATUM pour la figure 6 de laarticle de Serge CASSEN. Claude AUDREN, Stéphane HINGUANT. Gä̈lle LANNUZIEL et Grégor MARCHAND). "L'habitat Villeneuve-Saint-Germain du Haut-Méc (Saint-Etienne-enCogless. Ille-et-Vilaine)", Bulletin de la Sociéte Préhistorique Française, tome 95, n" 1, janvier-mars 1998, $1.41-75$.

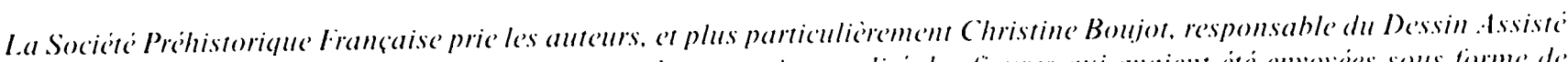

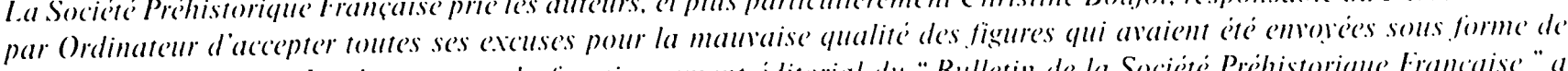
fichiers informatiques. Le changement du fonctionnement éditorial du " Bulletin de la Societe Prehistorique Françaisce " a

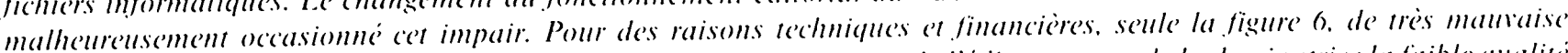

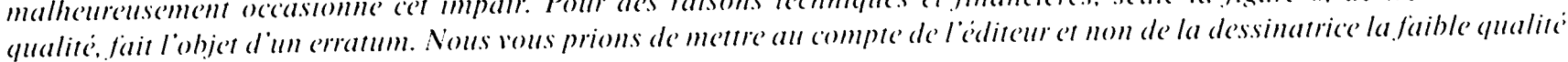
des autres figures de l'article. 


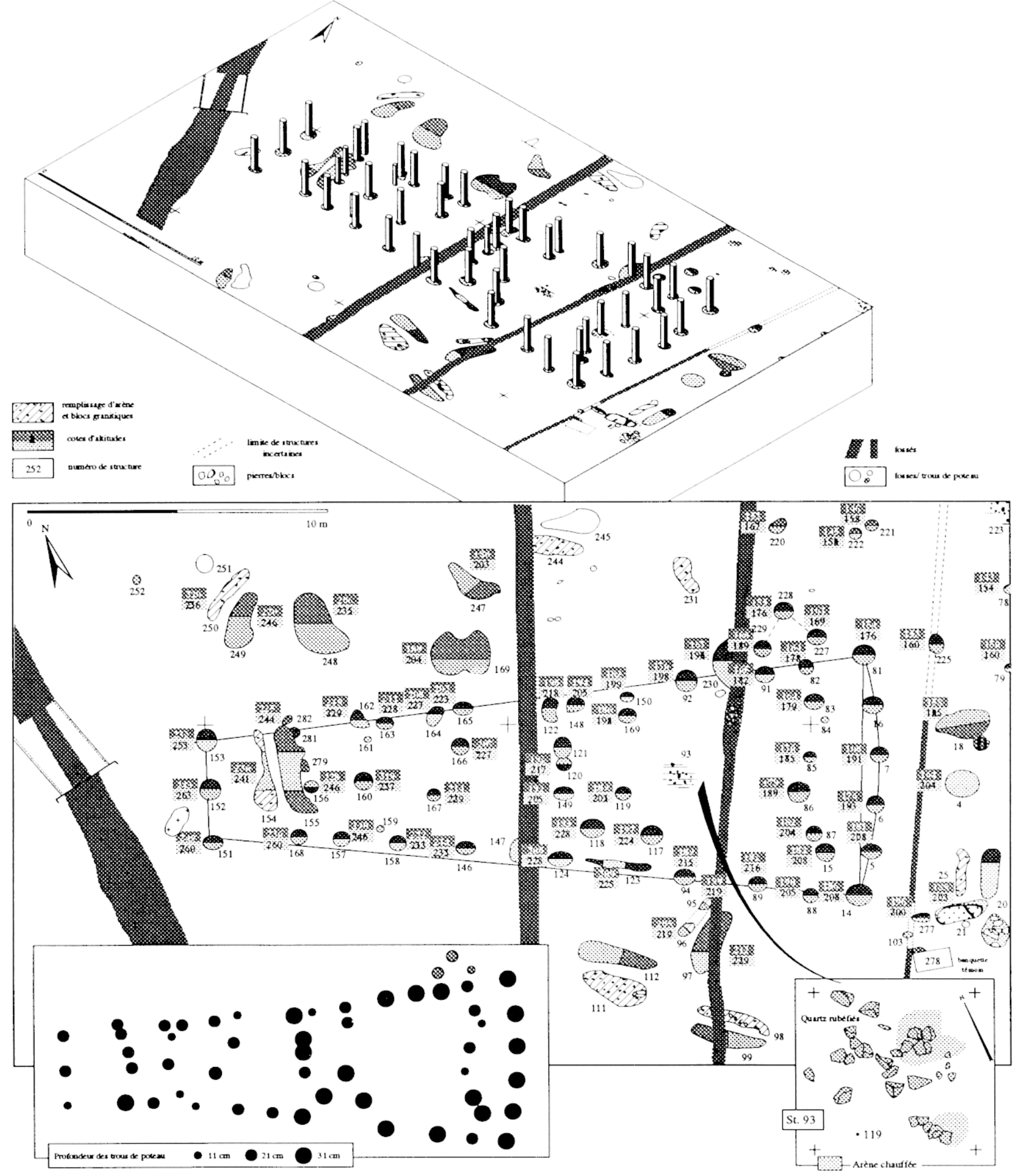

Fïg. 6- Analyse graphiçue du bâtiment néolithique (1).A.(). (. Boujot).

La plus grande densité de trous de poteaux est développée dans les secteurs H-I-J 13 el dessine demblée un plan trapézoüdal prononcé, la petite base disposée à l'Ouest et la façade (ou zone frontale) à l'Est selon une disposition cardinale assez rigoureuse. Les deux rangées longitudinales présentent un rythme peu régulier des trous de potcaux espacés tous les 1.50 a $2 \mathrm{~m}$; en revanche. ceux de la façade occidentale el ceux de la base arrière sont séparés d’une distance exacte (à ce niveau de fouille...) de $2 \mathrm{~m}$. Les profondeurs paraissent à première vue variables et peut-être trop dépendantes de la puissance du décapage mécanique pour que leur interprétation ne soit pas sujette a caution, en particulier dans la partic orientale où l'on est en droit de s'attendre 
at une plus grande ampleur des fosses; elles sont ici sans doute diminuées par la contrainte représentéc par le rocher sous-jacent et systématiquement atteint dans ce secteur. Cela dit, on ne peut nier les proportions supéricures des "poteaux" en façade ainsi qu’au niveau de ce que nous serions tenté de dénommer "entría". De fait, sur le côté Sud de la maison, a la hauteur du plus grand espace de dégagement intéricur. trois fosses profondes $(117,118,119)$ sont disposées en rapport direct avec une tranchéc (123) creusée dans laalignement des fosses longitudinales: curieusement remplic d’un mélange fortement arénacé alors que le substrat est lossicjue à est endroit. cette structure pourrait être interprétéc comme une sabliere basse. IEn sorte yue la formation " en Y" qui la surmonte s'identitic sans exalgération aucune aux "portes" reconnues dans les architectures domesticues du monde Rubané. Aucune tieree véritable nest eependant à relever et nous écarte du modile " danubien " encore conservi sur le balssin occidental de la Seine. Notons l'amats de quarty rubeliés (93). dans laxe du battiment, placé au centre de lespace largement ouvert évoqué cyelques lignes plus hatut. Compte-tenu des enlivements superficiels consécutifs au décapage mécanicue ces restiges résiduels témoignent salns altcun doute de lexistence d'une structure de combustion dont on observe ici que le "lond". de surcrô̂t sàns alceumulation significative de charrbons, et dont loorganisation densemble apparât bien diflicile à reconstituer. Cette découverte est néanmoins d'importance, es lype de foyer domestique restant tris fugace et rarement observé dans les conditions des decalpages industricls.

Un peu de chronologic relative nous est tout de même acessible graice a des recoupements a lintéricur de lédilice où une " fosse double" (154. 155) fut creusce alt détriment des trous de poteaux 281 et 279 : etant donné que es type dexcavation double est en laçade lui-même recoupé par des fosses V.S.G. (3 et 28 par 2), on aura compris la compression de temps. lhomogénéité et la cohérence de loceupation néolithique suggerés par ces relations stratigraphiques.

De même que les tieress veritables sont absentes du plan de la maison du Hatut-Mé, de même les fosses latérales dextraction des matériaux manquent a l'appel si l'on se reporte encore aux rélérents habituels. Peut-être deux structures en creux non datées dans la partic Nord (248 a 169) pourraient-elles jouer ce rôle... Une explication est à proposer : certains creusements néolithiques visibles en avant de la maison el dans le secteur plus oriental K.L. 14, très apparentés par leur forme à ces fosses dextraction décrites par exemple en Bassin parisien, ne sont a l'heure actuelle protonds d’a peine 15 a $20 \mathrm{~cm}$ : autrement dit, des losses laterales qui s'en iraient chercher le loess "géologique " et stopperaient sur les niveaux arénacés nous seraicnt proprement indiscernables à la suite du décapage, el ceci en raison d'une profondeur excaréc moindre que celle des trous de poteaux... Quoi qu’il en soit et pour résumer. il semble bien que plusicurs détails architecturaux nous écartent du schéma auquel on était en droit de sattendre: il s"agit bien d'une véritable déstructuration du plan traditionnel sur laquelle nous reviendrons en conclusion.
Le second cortege de trous de poteaux digne de commentaires est celui rencontré dans les secteurs K.L. 14. Deux alignements parallèles de trois trous de poteaux $(30,31,32$ et $182,183,184)$ s`inscrivent entre un cortìge de fosses néolithiques (185, 76, 175 d’un côté: 33, 34, 43, 48 de l'autre côté). A l'ouest, un alignement perpendiculaire formé de trois autres trous de poteaux $(79,226,77)$ semblerait appartenir a cette organisation densemble. La structuration que nous appelions de nos veeux dans les paragraphes précédents semble ici s’établir, en particulier dans l’agencement de réritables tieres normales aux fosses latérales dextraction. Lennui, c'est que le diametre de ces trous nexcede pas $25 \mathrm{~cm}$. ce qui est tout à fait insuffisant dans l'hypothese de poteaux porteurs ; de plus leur profondeur est notablement supérieure à celle des spécimens relevés dans la maison précédente; de sorte qu'en de telles conditions, il serait curieux que les autres rangées aient disparu. En conséquence, on peut šinterroger sur la réalité d'une seconde maison V.S.G.; ne serait-ce pas plutôt un batiment annexe à vocation tout autre que celle de lhabitation?

\section{Les fosses simples}

Déja éroqués lors de la description des plans donnés à lobservateur par le biais des trous de poteaux. les fosses neolithiques attestés sur la surlace de fouille présentent une profondeur movenne de $20 \mathrm{~cm}$ sous les 30 a 5() $\mathrm{cm}$ du décapage. Saluf exception du chapelet des structures 269 a 174 riches de matériels, elles sont regroupées à proximité des bâtiments entrevus ce qui, at révidence. nexclut pas d'autres excavations de cette époque en dautres endroits du chantier.

Dans la catégorie des losses simples, la structure 21 (lig. 9) avait bien entendu retenu notre attention pour la simple raison qu'elle était constituée d'une dalle de granite $(850 \mathrm{~kg})$ en position secondaire, de surcrô̂t brisic en deux et reflétant un aflaissement d'une partic qui confirmait la nature artiticielle de son positionnement. Décelée dés les débuts de notre intervention. dans lemprise de la vignette 1995, cette dalle fut dès lors "tlanquéc" d’une banquette-témoin. Le décapage soigné à son contact permit de circonscrire une fosse sous-jacente plus étendue que la surface du bloc. C'est durant la fouille de l'extrémité orientale de cette fosse qu'une première lame de hache polie intacte (fig. 11 , $n^{\prime \prime 25) ~ f u t ~ m i s e ~ a u ~ j o u r, ~ p o s e ́ e ~ a ̀ ~ p l a t ~ s u r ~ l e ~ f o n d ~ a r e ́ n a c e ́ ~ c t ~}$ englobée d'une line pellicule d'ocre rouge (un fragment d’ocre usé par frottement provient d'ailleurs de la fosse 28): un second spécimen, pris dans la même roche (fibrolite), fut découvert sous la dalle de couverture.

Cette dalle en granite local révéla tout son intérêt dès l'instant où son extrémité occidentale, longtemps protégée sous la banquette-témoin, put être dégagéc et netloyée, puis renverséc sur le côté afin de poursuivre la fouille de la structure en creux. Il ne fait pas de toute que cette extrémité est entièrement travaillée, précisément piquetée, la rendant ainsi légèrement arrondie à partir d’une sorte d’étranglement obtenu lors de la taille du bloc originel; des enlèvements caractéristiques de cette mise en forme sont observables sur les 
arêtes latérales. La " base". brute de forme. est plutôt mince et pointue. La fouille de la structure 23, menic antérieurement, aliat dejaj attiré notre atlention sur le seul cals d’unc fosse de taille réduite (diamitre: $1 \mathrm{~m}$ ) manifestement remplie de blocs de granite laisant immancuablement penser à un " calage"; dans la mesure où atucun trou de poteaux ne présentait ce type de maintien, on pouvait en conclure qu il pouvait sagir si l'hypothese de la simple fosse dépotoir était un temps rejelic - du callage doune structure inconnue, un peu : linstar de ex yue nous inspiraient dejai les "losses doubles" du gisement. Dès lors, léventualité yue cette losse 23 ait pu servir à un moment donné de fosse d'implantation diune pierre leves, en loocurrence cette dalle traraillece trourica a plat sur la fosse contiguë 21. apparait aujourd hui comme une autre hỵpothese en tout point recevable.

Pour conclure sur es secteur de fouilles dégagé dans les derniers jours de lopération de terrain. on insistera sur la presence de trois "trous de potcaux". visibles au contact de la tosse 21. el yui donnent l’impression appuyéc d’appartenir alu systeme yue pouvatit constituer la pierre dresséc - pour ne pas dire la stele - avant qu clle ne soit rabattue sur la possible sépulture souterraine. On ajouterat entin yu un amas de plusieurs dizaines de tessons tres érodés. semblant appartenir a all moins deux individus dillicilement reconstituables, sétalait a proximité immédiate de la pointe occidentale de 21 . Leur présence a cel endroit ne peut quajouter alu caractire exceptionnel de l'ensemble.

\section{Les "fosse's doubles"}

Des le netloyage pousse de la vignette 95. un type de structure apparut netlement sans pour autant pouvoir être explicue par comparaison arec des taits semblables decrits par ailleurs. Au bout du compte, es sont seizo couples de losses identiques qui, a ce jour, nous laissent perplexes yuant a leur destination. On est frappé demblec par la partaite similitude de ces fosses apparaissant comme dexalctes reproductions d'un modice pourant stre décrit comme suit : deux fosses allongés et paralliles, variant au nivealu du déapage entro 2 et $6 \mathrm{~m}$ dans la longucur el de 0.30 a $1 \mathrm{~m}$ dans la largeur : l'unc est constituse d'un limon gris-noirâtre organicye sans éléments lithiques, lautre est combles d’unc arine granitique, partois pure, partois milangec de lass. englobant bien souvent un amoncellement de blocs de granite dont ertains sont manifestement superposés diun côté de lexcalvation (lige. \$).

On doit reconnaitre que laspect anthropique du phónomine ne sest pas imposé des le dépant el un doute persistait dans notre esprit, même si les comparaisons provocuces par lamalyse préliminaire de la ceramic|ue nous portaient dejia vers des sites contemporains du batssin de l'Yonne où des structures "cousines" plus

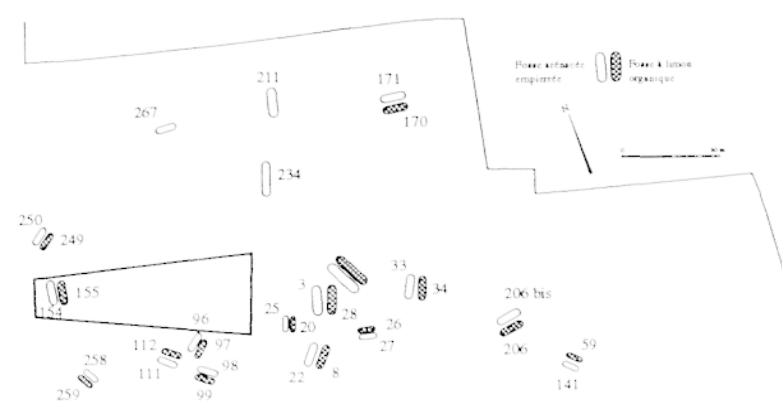

Fig. 7 - Repantiton der foms doubles par rapport atu plan du hitiment.
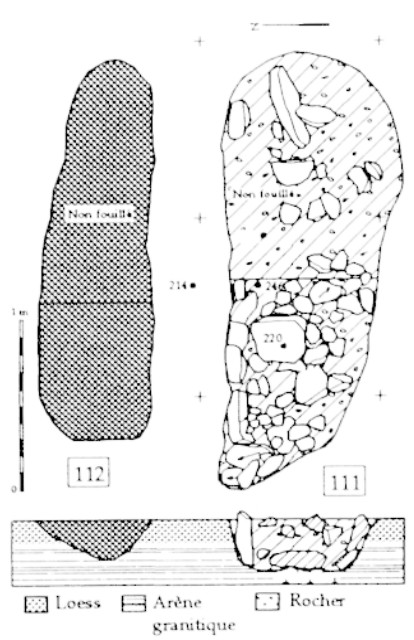

Repere des releves photographiques

3 Numéro de structure
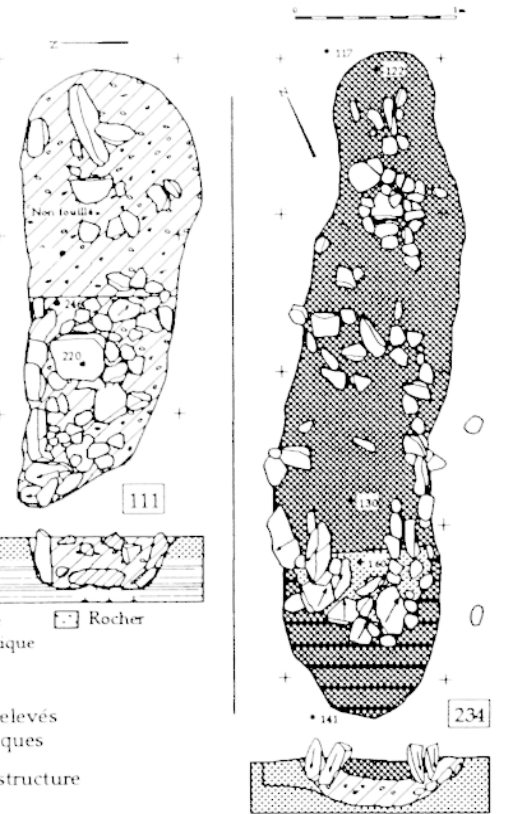
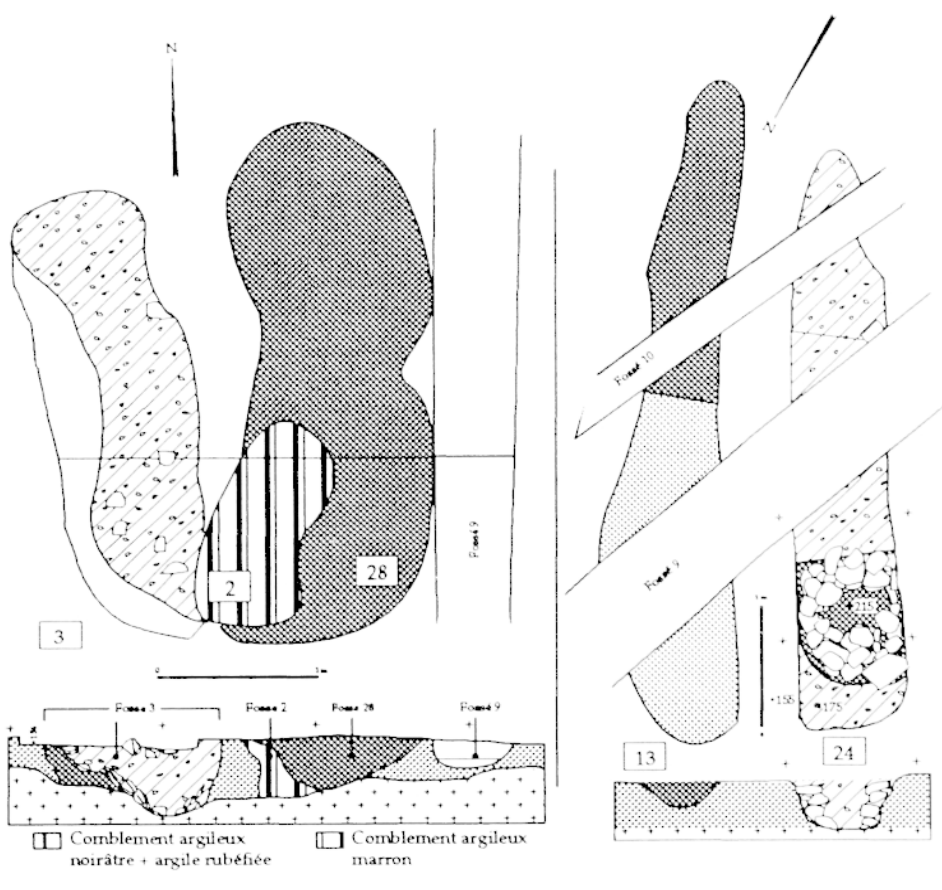

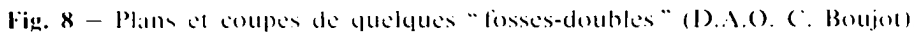




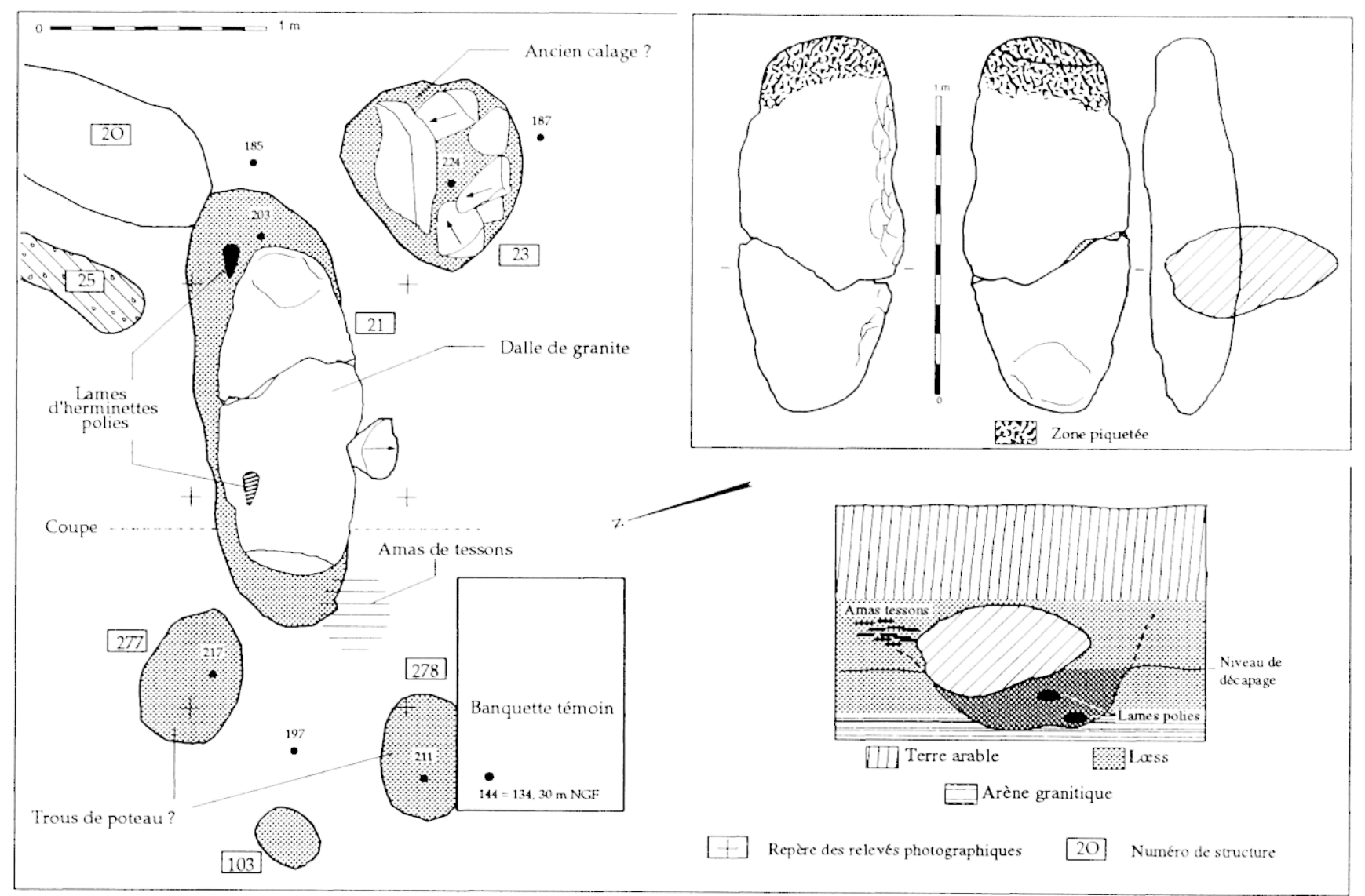

Fig. 9 - Analyso graphicue du secteur de la losise 21 (1).A.0. Boujou/(assen).

que semblables (fosses empierrées) avaient pu être décrites dans les années cinquante (Carré et al., 1958). L'éventualité même que nous puissions être en présence de chablis s'est posée à plusieurs reprises: A. Gebhart, géomorphologue qui a bien voulu passer nous donner son avis sur le terrain, a cependant infirmé ce point de vue.

Passons sur la morphologic et sur laaspect des orientations qui ne donne guère l’image d’un phénomène naturel. La seule observation des coupes pratiquées marque bien l'exécution de fosses individualisées et non pas celui d'un comblement naturel interstratilié après laarachage d'un arbre; le tri systématique des matériaux - arène et limon organique - ne plaide pas non plus en faveur d'un remplissage progressif: de surcrô̂t, le positionnement des pierres écarte délinitivement leur caractère aléatoire et la fosse 24 montre une véritable organisation de type "calage". Car c'est une des explications les plus vraisemblables que nous ayons pu trouver : l'absence de matériel signilicatif (récipients entiers, parure, etc.) dans les structures voisines à comblement sombre et lin ne pousse pas le chercheur même imaginatif à les interpréter en tant que sépultures. Mais s’il est vrai que le sable mêlé à la pierre est un matériau de calage idéal pour une structure dressée ne s’appuyant pas sur des élévations voisines, comme ce fut le cas pour la maison (et ceci par comparaison avec le loss qui aurait pu servir de matrice), quat-t-on bien pu ériger sur le site du Haut-Mée? L'organisation d'ensemble ne se prête guère à des régularités de disposition, même en centrant l'analỳse sur le bâtiment néolithique (tig. 7).

Quoi qu'il en soit, les comparaisons manquent a notre propos, et les seules analogies avec les fosses circulaires doubles de l'habitat de Sandun à Guérande (Letterlé (t al., 1991) ne tiennent pas longtemps, ces dernières sappliquant davantage à des trous de poteaux qu’à des fosses dextraction.

La chronologie relative nous est plutôt favorable. En effet, les fosses 154-155. presque résiduelles après le décapage mécanique, recoupent deux trous de poteaux de la maison alors que les fósses 3 et 28 , en façade. sont elles-mêmes surcreusées par une fosse simple V.S.(j. On le voit, il semble bien que l'on puisse attester de la contemporanéité des fosses doubles avec l'habitat néolithique: d`ailleurs, quand du matéricl est identilié dans leur remplissage, il sagit dans tous les cas de tessons ou de vestiges lithiques néolithiques.

Quant à la question des " objets" qui auraient pu être dressés dans ces emplacements, sauf à considérer que des menhirs aient été détruits et évacués du site. exception faite de la dalle en 21, resterait l'hỵpothese de stìles en bois.. 


\section{ANALYSE DU .IOBILIER}

\section{La production céramique}

I. corpus étudié correspond à l'ensemble des valses trouves en structures et en décapage. 57 individus (N.M.l.) lurent reconnus dans 59 structures. Les lots les plus importants sont ceux des tosses : $2,3,4,21,28,43$, 73. 76, 174 et 251. 46 individus sont issus de ees dix structures, soit $78^{\circ} 0$ des vases reconnus. 258 tessons proviennent du décilpage du site. 12 individus sont recomnus de façon certaine. De létude morphologique et technologicue, il ressort lide d'une grande homogéneite du materiel dans les formes, matériaux et décors. Une siriation sur lopposition céramique lins/céramicue grossicre, distinction par ailleurs trop vague, na pas lieu dêtre retenue ici. Dune part, toutes les céramiques ont reçu un traitement de surface soigné: d’autre part, largile utilisée comprend, saul' quelques exceptions, un dégraissant de granulométrie moyenne (<ou égal a $2 \mathrm{~mm}$ ) ou line (< $<1 \mathrm{~mm}$ ). La présentation du maléricl céramique se fera suivant ses caractères technologiques généraux, puis par groupes de valses.

\section{Technologie}

Le dégraissant utilisé est quasiment le même pour tous les vases. Lobservation des pâtes est effectuéc a la loupe binoculaire couplée a un moniteur vidéo afin d'avoir une vue globale de l'échantillon. Toutes ces céramiques compremnent une forte proportion de muscovite en pailletles (mica blanc). Le lissage des vases contribue a orienter es particules parallèlement aux surfaces, leur conférant un aspect brillant. Largile contient également des feldspaths en mêmes proportions que les micaschistes. Ces grains nexcedent pas $1 \mathrm{~mm}$ dans leur plus long segment. Le troisieme mineral essenticl est le quart\%. Sa proportion dans la pate est supericure aux autres composants. Les grains de quart/ anguleux résultent sans doute d'un concissiage anthropique plus ou moins poussé. $\dot{A}$ la différence des autres minéraux, on note une hétérométrie suivant les individus puisque quelques céramiques présentent des grains allant jusqu’a 6 at $7 \mathrm{~mm}$ de long. Dans ces cals. l'aspect extérieur de la céramique est irrégulier en raison de l'alfleurement de ces particules. Pour la grande majorité des vases, ces grains ne vont guère au-dela do $2 \mathrm{~mm}$ de long.

Cette homogénéité du dégraissant reflete tout a fait les ressources argileuses du site. En eflet à environ $150 \mathrm{~m}$ au Sud du site, dans la zone basse tourbeuse, les engins ont mis au jour un gisement argileux. La terre employéc peut provenir de cette argile très chargée en muscovite et en petits galets de quarty qui auraient servis atu concassilge. Toutefois, un essai de montage de vase avec estle "terre" a montré qu'utilisée telle quelle, sat trop grande plasticité entraînait laffaissement de la céramique pendant le séchage. Dans l’hỵpothèse d'une utilisation de cette source, le concalssage du quarty comme dégraissant ajouté paraît nécessaire. Un examen sur lames minces contirme lanalyse à la binoculaire. Largile contient des fragments de granite et de microgranite. Les grandes phỵlites ont conservé leur lexture (état de muscovite) ee qui semble indiquer une utilisation darene granitique frâtche, non altéréc. Les céramiques n" I et 3 (lig. 10) ont rigoureusement la même composition. Elles font partic d’unc même production es yui confirme la contemporaneite de es deux décors. Aucun fragment d’os calciné et pilé nest remarqué dans la pâte.

Sur de nombreux vases, on observe des cassures en bisealu sur joints de colombins à soudure délectueuse. Sur certains vases a cassures émoussécs. lorientation de eses dernieres, systématiquement horizontale par rapport au valse, les divise en plusicurs bandes qui correspondent à autant de colombins. Sur quelques exemplaires. on note des cassures en gouttiere. Dans ce cas la jonction de deux colombins se fat par un travail de la pate du bas vers de haut. fiaces interne et externe.

Les surfaces extéricures des vases sont bien régularisíes. Les éventuelles traces de doigts, de colombins. sont clfacées, sans doute par le procéde dégalisattion de lype "main-mouillée”. De cette action il résulte une surface unic el mate. Les surfaces internes présentent plus rarement un tal soin. On note, sur de nombreas exemplatires, des traces dégalisation de la surface a laide d’unc spatule à extrémité ćtroite (ens. $2 \mathrm{~mm}$ ) en materiau ligneux comme en attestent les fines stries parallikes. Les surfaces des vases ne sont jamais polies. La seule brillance des parois est due aux pailletes de muscovite. Il ny a donc qu’un seul traitement de surlice. mais tres soigné clfoctus avant cuisson sur pate encore humide. Sur plusicurs exemplaires, on note un encrouttement cendreux fitec interne. Cette pellicule atteint parfois $1 \mathrm{~mm}$ dópaisseur. toujours locialiséc vers k fond du vase. Dautres éramiques provenant des mêmes structures ne portent pas de telles traces. Ces dernieres peuvent donc être consecutives à une utilisaltion spécilicue de ces vases. Il ne s'agit pas deun catramel alimentaire car, en ce cas, il y aurait des traces de leu sur les faces externes. Ces marques résultent peutêtre d'un stockatge de matières cendreuses.

Les couleurs des parois extérieures sont variés. Elles ront du beige au brun clair en passant par la gamme des bruns/rouges, puis gris/noirs. D`une maniere générale. la teinte la plus frécuente est le brun clair tirant sur te rouge. Les parois interieures ont quelquetois les mêmes coulcurs que l'autre face, mais le plus souvent elles sont plus foncés, voire noires. Le coeur des tessons est souvent gris/noir ou noir, assez rarement rouge. L'essentiel des vases a donc subi une cuisson réductrice plus ou moins intense, puis une oxydation de surface. Loxydation se remarque sur les tranches des tessons, et parfois sur une épaisseur assez large.

\section{Groupes de vases}

\section{- Les grands rases de stockage à cordons appliqués}

Les anses de ces vases sont souvent cassés, mais le remontage prouve que leur symétrie est toujours ternaire. Quatre exemplaires de ce type furent recueillis fosse 2, une structure 76 et 4 , deux structures 3 . L'exemplaire n" + (fig. 10) a une épaisseur de $7 \mathrm{~mm}$ : 


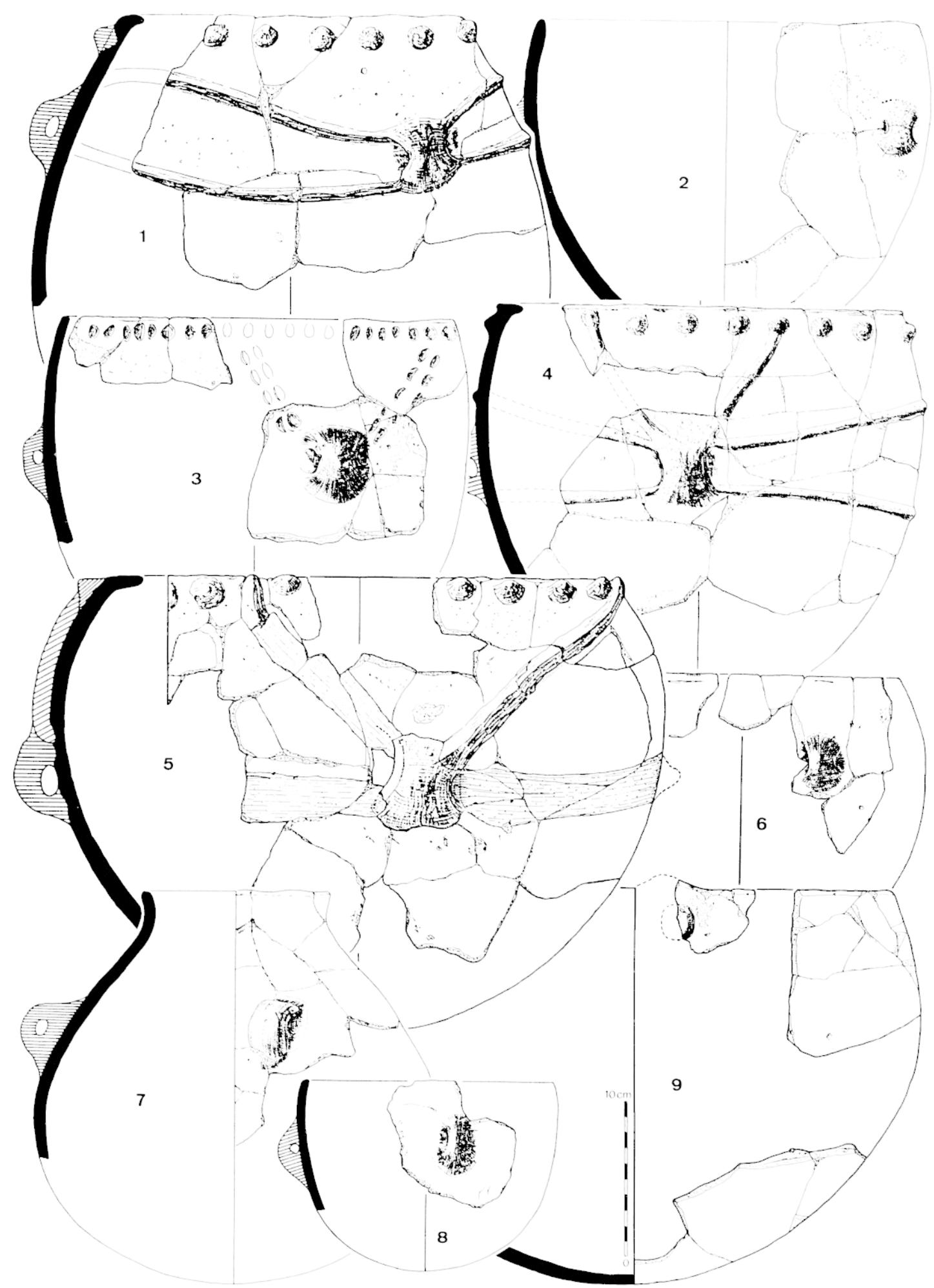

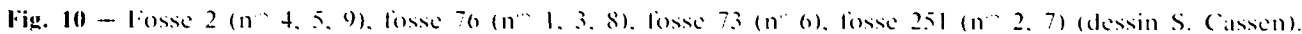

11 tessons se rattachent a cette poteric. Ses dimensions sont les suivantes : diametre a louverture bord externe (Doc) : $26,6 \mathrm{~cm}$ et bord interne (Doi) $22,8 \mathrm{~cm}$; diametre maximum (Dmax) : $29 \mathrm{~cm}$ : hauteur supposéc (I1): $26,3 \mathrm{~cm}$; volume supposé ( Vol): 45 litres.

Les cassures se situent aux jonctions de colombins. Deux anses en ruban ne recollent pas à la panse. Du second exemplaire il ne reste que la partic centrale. La technicue de montage, visible ici, consiste à modeler un ruban de pâte assez large, puis de le replier sur lui-même atin d’oblenir une épaisseur plus importante. La livre est plane et rentrante. Ellle est formí par étirement de la pâte du bord du valse vers lintéricur. 
Ce vase présente un décor modelé typique de la phase récente du Villeneure-Saint-Germain. Des cordons lins et peu proéminents sont appliqués sur la surface du vase (une vue sur calssure montre qu’il s’agit de pâte rapportes). (es cordons ont une distribution ternaire a partir des quatre points daatlache des anses. Deux dentre eux sont légèrement incurvés et se rejoignent d'anse at anse, en haut et en bas. Les autres se rattachent Éalement en haut de lanse mais partent en $V$ vers lo rebord et se terminent par une patstille. Ces dernieres sont également appliqués. Le décollement de lune d'entre elles montre qu'un coup d’ongle a précédé son apposition. sans doute pour augmenter l'adhérence. Le vase I..H.M. I 2-47 a une épaisseur de 7 à $10 \mathrm{~mm}$ : 9 tessons se rattachent à cette céramique. Ses dimensions sont : $\mathrm{I}$ Oc $=32 \mathrm{~cm} ; \mathrm{Doi}=27,4 \mathrm{~cm} ;$ Dmax $=39$ $\mathrm{cm}: \mathrm{II}=29.6 \mathrm{~cm}: \mathrm{Vol}=431$.

Cette céramique est très érodé: les traitements de surfaces sont bien soutent invisibles. Les fractures sont émoussies, mais leur disposition montre que les colombins devaient être étirés sur une hauteur de $t$ a $7 \mathrm{~cm}$. ce qui suppose un boudin de pâte initial asse gros. Le rebord rentrant sur $2 \mathrm{~cm}$ environ résulte, a la diflérence du vase précédent, d’un ajout d’argile. De petites plaquettes, de 3 a 6 cm de long. sont collées au bord intericur du vase. Les cassures, fréquentes en cette zone fragilisie. montrent que la pate fut ensuite ramené sur les parois externe et interne du valse.

Deux ansess en ruban sont conservés. Deux tris grands lessons présentent des trous de pertoration eflectués avant cuisson : il ne salagt done pass de trous de réparation. Iapres la courbure des deux tessons, es perforations se situcraient dans une partic basse du vase, voire vers le fond, ea qui pose le probleme de leur fonction. Peut-être s’agit-il de trous d’écoulement de liquide contenu dans une matiere (bouillie. herbes...) ? Les cordons appliquis sorganisont suivant deux directions. Ceux qui rejoignent les anses par leurs points d’attache intërieurs ont disparu, mais la pâte porte les traces de leur décollement. Les cordons partiant du haut des anses forment un decoren V très élargi et se terminent par une pastille sous le bord. Les pastilles larges (1.5 cm) et próminentes sont également appliquées. L.II.M. 12-56 mesure 7 à $9 \mathrm{~mm}$ d'épaisseur (20 tessons en tout). Ses dimensions sont : Doe $=23 \mathrm{~cm}: \mathrm{D}$ max $=37 \mathrm{~cm}$.

Latmosphère de cuisson de cet exemplaire est à tendance oxydante durant toute sal duréc. Les caractéristiques de montage et de pâte sont les mêmes que pour les atutres vatses. Toutefois cet exemplaire est bien mieux conservé yue les précédents, et le lissage semble encore plus soigné. Des traces noires en surface font penser à un enfumage partiel. Un tesson atteste de la presence danse en ruban plus petite que pour les autres círamicyes de ee lype. La levre de ce vase est arrondie. Les décors sont modelis. Il s’agit de pastilles appliquées sous le bord. In coup d’ongle précede lapplication. Le bord participe également du thime décoratif puisquail est quelquelois prolongé dans le sens des parois alin de former de petites protubérances, faisant du bord une ligne ondulante. Ces protubérances sont modelées a partir du bord du vase: il n’y a pas d'ajout d'argile.
Une douzaine de tessons appartiennent à un autre vase de stockang a cordons appliqués (L.H.M. F2-80). Il mesure 9 a $10 \mathrm{~mm}$ dépaisseur. La surface porte des traces denfumage. Des micro-stries de grattage de la pate apparaissent sous laction du lissage de type "mainmouillée". Ces stries se remarquent autour de laanse et le long du cordon. Face interne, on note de larges traces dégalisation de la surface $(5 \mathrm{~mm})$ et des plus lines (2 mm) consécutives a lemploi deune spatule en matiere ligneuse. Les cassures sont droites ou légerement biseautées. Le décor se compose de cordons en $\mathrm{V}$ d'l cm d'épaisseur qui rejoignent le bord. Aucun fragment de bord de ce vase ne nous permet de connaîtro l'organisation générale du décor.

La structure 76 a livé 58 tessons qui appartiennent à un grand vase de stockage a cordons (fig. 10, n" 1). Son épaisseur est de $9 \mathrm{~mm}$ et ses mesures sont: $\mathrm{D}$ )o $=$ $22 \mathrm{~cm}: 1) 0 i=19 \mathrm{~cm}: D \max =39 \mathrm{~cm} ; 11=34 \mathrm{~cm}: 1 \mathrm{ol}$ $=58 .+1$.

Beaucoup de lessons de cette céramique sont érodes. Quelques-uns montrent des traces de grattage a la spattule, de $2 \mathrm{~mm}$ de large sous le rebord interne, ainsi yu iutour et sur les pastilles. Les cassures se situent a la jonction des colombins. Ceux-ci devaient être tres importants car ils sont stires sur 7 a $11 \mathrm{~cm}$. Le rebord légerement rentrant est étiré a partir du bord. Les cordons partent des quatre points d'attache des anses. Les cordons supéricurs sont incurvés vers le haut du valse, mais se rattachent sur les anses. Ce vase ne porte pas de décor en V. Il saggit plutôt d'une organisation en "guirlande" des cordons supérieurs et inférieurs, interrompue par les anses.

Lat structure 4 contenait 35 tessons dont 32 appirtenaient a un grand rase de slockage a cordons appliqués (L.H.M. 12-32). Les cilssures observés montrent cyue c valse possédait un rebord rentrant. Une cassure i un point de jonction de colombins met en évidence une technicyue particuliere de montage. Celle-ci consiste a inciser oblicuement un colombin afin den appliguer un autre, es qui augmente ladhérence de la pâte.

Lat structure 3 a également livré 2 individus portant des cordons appliqués.

Les deux exemplaires L.H.M. Dec-212 a n”13 (tig. 11) proviennent du même vase. Le décollement de leurs cordons laisse apparaitre la préparation de pincements doubles de la pate avant application du décor modelé. Le site du llaut-Méc a donc lourni un minimum de 16 vases de stockage à décor modelé de cordons en 1 . ou en "guirlande". Leur fonction de vase à provision ne lait aucun doute si lon considere les volumes.

\section{- Le grompe de rases a col ou en boutcille'}

Lexemplaire te plus complet est eelui decouvert dans la structure 251 (lig. 10, n"7). Il s"igit d"une boutcille a panse globuleuse et a col éversé. Lépalisseur varie entre fet $9 \mathrm{~mm}$. Ses mesures sont : Doe $=12.5 \mathrm{~cm}$; I max $=27 \mathrm{~cm}: H: 26 \mathrm{~cm}: \mathrm{Vol}=231$.

La cuisson de ce vase fut réductrice, a phase finale oxydante (surfaces brun clair). Un encroûtement de mattières cendreuses est visible sur les tessons proches du fond. Le lissage est soigne. Les calssures sont en biscalt 


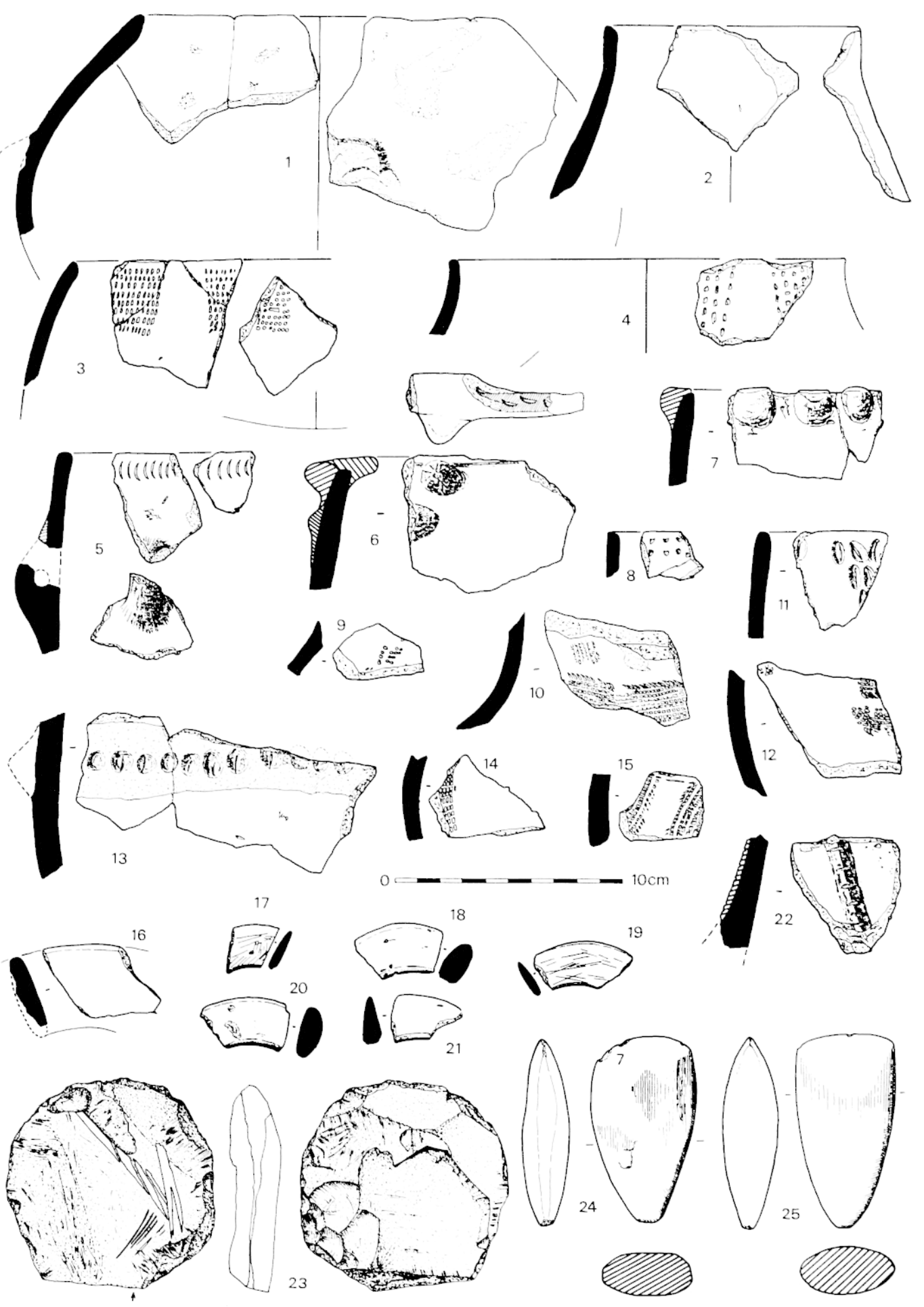

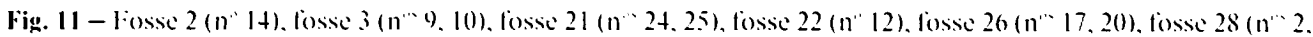

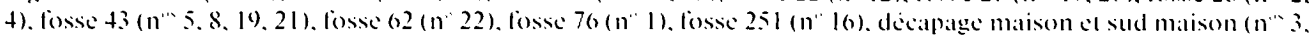

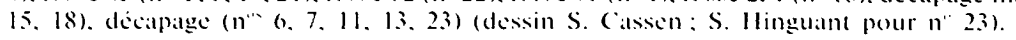

et en gouttière. Les anses sont faites d'un ruban de pâte replić sur lui-même avant application. La panse a reçu des pincements préalables avant de recevoir les moyens de préhension.

Les autres fragments proviennent de bouteilles à col haut. Il ne reste malheureusement trop souvent que le col. Dans la structure 21 , deux fragments appartiennent à la même céramique (L.H.M. 21-34 et 35). Le col est droit et le départ de la panse prouve bien qu elle est très globuleuse. Ce vase a subi une cuisson oxydante homogène car la pâte est très rouge dans le cocur des tessons et en surface. 
La structure 3 a livé un fragment de col (L.H.M. 1:3-17). La cuisson est oxydante. On note de très légères traces d'égalisation de surface.

Le dernier élément de cet ensemble provient de losse 174 (I..1I.M. 174-6). Quatre tessons proviennent de ce valse. Lópaisseur est de $7 \mathrm{~mm}$. La cuisson est oxydante et le lissige soigné. Le dégraissant diffère des autres valses. Ici les grains de quartz sont émoussés, roulés. Il ne s’agit donc pas d’un conciassage. Peut-être est-ce un sable de riviere?

\section{- I.e sroupe des rases en demi-sphere}

La céramique lig. 10, n" 3 est un vase d'une épaisseur de $7 \mathrm{~mm}$. Le coeur des tessons est noir et les surfaces oranges. La cuisson est réductrice, a phase finale oxydante. La face interne de certains lessons portent des traces dencroûtement cendreux. Les surlates des tessons sont bien souvent érodées, mais il semble que cette céramique a reçu un traitement de surtace soigné. Des pincements digités doubles (pouce et index) ecinturent le bord. Deux lignes en $V$ partent également des anses en ruban vers k bord.

1)ix-sept tessons proviennent d'un vase en demi-sphere dicouvert également structure 76 (L.11.M. 76-91). Les tessons mesurent $5 \mathrm{~cm}$ dépatsseur. Le coeur est noir et les tranches externes plus claires. La surface extérieure est brun/rouge avec des traces plus noires dues a des "coups de feu". Le lissage est très soigné el la lève amincie. cette céramique possede des anses en bouton de petite taille a perforation horizontale. Trois tessons (L..H.M. I2-136 a 138) proviennent d'un petit bol à cuisson oxydante. Les surfaces ont probablement subi un enfumage particl. Deux petites anses en ruban se rattatchent à cette céramique. Un petit bol très lin $(2 \mathrm{~mm}$ d'épaisseur) vient également de cette fosse (L.H.M. F2-100). Sa surface brune est bien lissée. La levere est aplanie et une anse line se rattache a la panse a $1 \mathrm{~cm}$ du bord. Une derniere céramique adopte cette forme. II s'agit d'un exemplaire trouvé structure 21. pres de la dalle couchéc. Douze tessons (L.H.M. 21-54 à 65) caractérisent un bol avec de petites anses en bouton. La cuisson fut oxydante, homogène. Le coeur et les surfaces sont rouges. De nombreuses traces de grattage à l'intérieur sont effectuées a l'aide d’une spatule de $2 \mathrm{~mm}$ de largeur. Le dégraissant est de petit calibre.

\section{- Le groupe de vases e'n trois-quarts de sphere}

On dénombre de façon certaine 6 individus adoptant cette forme.

Le n"1 (fig. 11). losse 76, a une épaisseur de $6 \mathrm{~mm}$. La cuisson fut réductrice a phase terminale oxydante. Les surfaces rouges portent des traces de "coups de feu". Cet exemplaire est bien lissé. La forme de ce vase est ferméc, mais pas franchement en $3 / 4$ de sphère en raison d'une rupture de pente située a $8 \mathrm{~cm}$ du bord. Cincuante-quatre tessons proviennent de la céramique n" o (lig. 10). Lépaisseur est de $7 \mathrm{~mm}$. La cuisson est réductrice a phase linale oxydante. Le lissage est soigné : des traces de grattage sont visibles autour des anses. Le dégraissant est très lin et la proportion de muscovite est fable. Les fractures sont souvent émoussics. On note toutefois quelques cassures en biscau.

La céramique n" + (lig. 11) comprend 53 tessons. Fill mesure $5 \mathrm{~mm}$ dépaisseur. La cuisson fut à tendance réductrice. Les surfaces sont brun/noir et bien lissís. Celle céramique comporte un décor d’impressions faites a laide d'une baguetle tine appliquée de laçon oblicue par rapport à la paroi du vase. L'outil utilisé etait appointe. Les impressions sont plutôt profondes. Elles sont disposées en panneaux à partir du bord. Des rangeses rerticales paralleles sont interrompues par des zones vierges. La disposition génerale de e theme décoratil est peut-être en triangles, pointes en bass, à partir du bord.

La structure $17+$ a livé 3 tessons appartenant a un bol a ouverture fermec. La cuisson fut oxydante. I.al surfice extéricure est brun/rouge arec des traces de " coups de leu". Des nombreuses traces de grattage eflectuces a laade d'une spatule de $2 \mathrm{~mm}$ de large sont visibles a rintéricur. Des anses en bouton pertorés sont associćs à cet exemplaire.

Deux tessons trouvés en décapage au sud de la maison appartiennent a un valse en forme de sphere (lig. 11. n" 3). Celte céramique de $7 \mathrm{~mm}$ dépalisisur a subi unc euisson tres réductrice. Les surfaces sont noires, bien lissés et la kive est arrondic. Cette éramique porte un decor dont la disposition rappelle celle de lexemplaire L.H.M. 28-20. lei Également il sagit d’impressions allongess a laide d’uno baguette, entoncic de liąon oblique. Sur un tesson, loutil fut enfoncé perpendicularement a la paroi, ce qui donne des impressions rondes.

\section{- loss alutres formess}

La structure 251 a liver un vase en forme de "sate" (lig. 10, n"2). Lépaisseur varie entre 7 et $10 \mathrm{~mm}$. Ses dimensions sont : DOe $=24 \mathrm{~cm}: H=21,5 \mathrm{~cm}: \mathrm{Vol}=$ 29,21.

Le cocur des tessons est noir et les surfaces brun/rouge. La cuisson fut donc réductrice a phase terminale oxydante. Des traces de "coups de leu" sont également visibles. Le lissage est soigné. De lines stries sont peutetre consécutives à une égalisation de surface a l'aide d'herbes. La forme de ce vase est ouverte, la livere est arrondie. Trois anses en bouton sont appliqués a $4.5 \mathrm{~cm}$ du bord. La pâte fut appliquée, puis perforéc. Une dentre elles est en cours de perforation. Ces anses seraient done plus un moyen de préhension que de suspension.

Un grand tesson appartient a la fosse 76 (L.H.M. 76-62). Il est épais de 1 a $1,5 \mathrm{~cm}$. Le coeur est noir. mais la céramique a subi une lin de cuisson oxydante. Des traces de grattage de la paroi sont bien visibles sous le bord. La cassure de ee tesson est franchement biseautée. Lal levre est large et plate, parfois débordante par rapport à la paroi. Cet élément appartient sans doute à un énorme vase de stockage si l'on considère la très faible courbure du bord. 


\section{Les décors}

\section{- Les décors modeles}

Ils sont réalisés par ajout de pâte, pincements de la pâte et impressions digitées. Tous les vases de stockage à cordons et pastilles font partie de cette technique décorative. Le tesson L.H.M. 42-2 présente également un cordon appliqué dont la partie sommitale est ornéc d'impressions résultant sans doute de coups d'ongle. Le décor de L.H.M. Dec-270 est réalisé par pincements d'un cordon appliqué. Les pincements sont effectués par impression de la tranche du pouce. Des décors de pincements en $V$ et autour du bord ornent lexemplaire n"3 (lig. 10). Une organisation similaire se retrouve sur le n" 11 (fig. 11). Les pincements sont doubles (pouce et index) sous le bord. (nn note également le départ d'une ligne en $\mathrm{V}$. Un autre exemple de ce décor apparaît sur laanse L.II.M. Dec-328. Ce tesson provient sans doute d'un grand vase de stockage a décor en $V$.

\section{- Les decors impressionnes}

Ils sont variés. Les instruments utilisés sont le poinçon (baguette, tige creuse), loongle et le peigne à dents séparées. Les décors au poinçon ont déjà été relevés pour les exemplaires n"3 3 at 4 (fig. 11). Le tesson n" 8 (lig. 11) provient d'un bord de vase de $7 \mathrm{~mm}$ d’épaisseur. Le coeur de la céramique est noir ainsi que les surfaces. Les impressions sorganisent en deux lignes irrégulières sous le rebord, distantes de $4 \mathrm{~mm}$. L'outil utilisć est probablement une tige creuse enfoncée de fiçon oblicue si l'on en juge les traces en demi-lunes.

Deux tessons proviennent d’une même céramiçus. mais de structures diflërentes ( $n^{\prime \prime} 5$, fig. 11). Ils sont décores d’impressions d'ongle sous le bord. Ces deus fragments appartiennent à une céramicle de forme ouverte en demi-sphere ou en "sac". Ine anse en rubany est associec. Les impressions sont eflectués par longle du pouce.

Les autres décors impressionnés sont réalisés a laide de peigne à dents dégagés. Le tesson n" $1+$ (lig. 11 ) provient d’une céramique ayant subi une cuisson réductrice. Le lissage est soigné. La calssure biscautéc témoigne d’une soudure de colombins détectueuse. Le décor est constitui de quatre rangés d’impressions au peigne. Le nombre de dents ne doit pals dépasser t. Il sagit d’impressions traincós sur la surface. Une fois le peigne applicjué sur le vase, il lut traîné dans le sens de sal longueur. Cotte techniçue laisse apparaître de très fines stries à l’intérieur de chacue impression, qui font penser a un objet en matciatu ligneux.

La structure 3 a livé deux fragments décorés au peigne, appartenant à la même céramique (n"' 9 at 10, ligg. 11). L'outil utilisé comprend 9 dents de section plus ou moins rectangulaire. Il est applicué de fiçon verticale par rapport à la céramique. Le tesson étant incurvé, les dents du milieu se sont moins enfoncés. Limpression de la derniere dent est en virgule et sert de pivot. L'organisation générale du décor doit être en bandes horizontales disposées sur le col et la panse, avec des zones vierges. Le décor de L.HI.M. F3-34, trìs eflacé. reprend cette organisation. Le tesson n" 9 reprend la même technique de dent pivotante. L'organisation du décor est très irrégulière. Il est impossible de dénombrer k nombre de dents de looutil. Le n" 15 (lig. 11) reprend de nouveau la technique de la derniere dent pivotante. Cette céramiçue brun/rouge possède un décor régulier organisé en deux bandes paralleles. Le peigne utilisé possède 3 ou + dents.

Lanse en ruban L.H.M. Dec-373 porte la trace d'une graine en son milieu. Cette derniere nest sans doute pas restéc dans la pâte lors de la cuisson du vase car alucunc trace de carbonisation nest visible autour, ni au fond de lempreinte. L’importance de cette impression, et sal position centrale, font penser à une action volontaire de la part du potier. et pourrait constituer un décor pour le moins original, mais déjà connu sur les récipients Ertcbolle. ou encore sur les manches d'outils conservés dans les laces alpins suisses où des empreintes de cériales " dicorent" le goudron de lixation.

\section{Synthèse des caractères principaux de la céramique}

Cette céramicue est tress homogène d'un point de va technologique. Une seule source argileuse est vraisemblablement utilise pour toute la production céramique. Les scules diflérences notables sur le dégraissant se font sur la granulométrie des grains de quarty. (de moins d’l $\mathrm{mm}$ a $8 \mathrm{~mm}$ ). Le lissage est en géneral tres soigne. Sur plusicurs exemplaires, de provenances dillérentes, on note des traces d'égalisation de surlace a lalide d’une spatule de $2 \mathrm{~mm}$ de largeur. Il existe cependant un point laible dans la chatine operatoire. La proportion de cassures en gouttiere ou en biseau sur joints de colombins delectucux est grande. La phase de montage semble revêtir moins dinterêt au profit des dernieres etapes : lissage, dícors. Sur de nombreux exemplatires. notamment les vatses de stockage, une préparation de la pâte en vece d'unc application de pâte (anses. pastilles. cordons) est remarquéc. Il s'agit de pincements doubles ou de coups d'ongles.

Tous ces caracteres communs plaident en liveur d'une production très homogène. I'n même savoir-faire s'observe sur lensemble des córamiques du site (les pincements préparatoires, par exemple, ont la même taille: il šagit sans doute d'un même individu potier). Il est probable qu'une ou deux personnes ont produit ce materiel sur une période assez courte (duréo maximum: période active d’un individu). L'importante proportion des vases de stockilge est tout at fait compréhensible sur un site d'habitat. Le rolume de ces valses implicue qu’ils nétaient pals déplacés. mais tenalient lieu de réserve-silos.

Les caractères décoratifs principaux de eetle céramicjue sont les suivants :

- les cordons appliqués en l'ou ceinturant la círamicus:

- Les pastilles appliquies sous le bord:

- Les rebords rentrants formés d’un cordon applicué:

- les décors au poinçon:

- les décors al peigne. 
Ces caracteres se retrouvent dans lestape récente du Villeneuve-Saint-Germain. Les céramiques a cordons en $V$ et rebord interne. alvec quelquefois prolongement du bord en appendiess proéminents appuient cette attribution, anciennement Augy-Sainte-Pallaye (Constantin, 1985: Constantin a al. 1987). Les exemples comparables géographiquement les plus proches pour la céramique du Haut-Méc. el mis a part le gisement roisin de l'Oisillere, se trouvent en Basse-Normandie. Sur le site d'habitat du Haut-Saint-Martin à Mondeville, des fragments de cordons en V'el de rebord rentrant furent decouverts (Chancerel d't (1l.. 1993). Le site de la Grande Piece a Valframbert (Orne) ainsi que le paléosol de la Commune Sèche a Colombiers-surSeulles (Cahados) ont également livé des décors modeles de ex type (Chancerel at al. 1993, 1995). Le V'S.G. normand est par ailleurs inventorie a Reville ( Manche), Ver-sur-Mer ou encore Jord dans le Calvados. Sur le cours inférieur de la Scine de nouvealux sites ront bientôt. a neon pas douter. sajouter aux repires pointes ces dernieres annés, comme a Bardouville.

\section{L'industrie lithique}

\section{lames de haches polies et bracelets}

Deux lames de haches polies entieres ont été recucillies, on la vu. sous la dalle de granite ouvragéc recouvrant la fosse 21. alu point que kur présence isolede el leur stat de conservation nous ont poussé a interpréter colle structure en creux datiantage comme une probable sépulture quine losse détritique. (On remaryue alec intérêt que leur section respective fig. 11, n”2 24 at $25)$ different. loune stant ovalaire. lat seconde oftrant des bords fitedles rendant ed aspect épuarri. Mais le materiatu est strictement le même. cest-i-dire une librolite a reinures brun-rouge dont C.T. Le Roux a bien voulu contirmer le diagnostic al l'oeil nu. Ce type de roche sorait present dans la région de Saint-Malo, $50 \mathrm{~km}$ all Nord-ouest.

l.e remplissige inferrieur du trou de potcalu 16 situé en façade de la maison a livé plusieurs petits fragments du tranchant doune lame de hache polie yui a manilistement rencontré un obstacle réticent lors de son utilisation... Il sigit de quart/ polycristallin blanchatte contenant un mincial vert-pale translucide qui est du beryl (allumino-silicate de beryllium). Lassociation cluarl/ + beryl est caracteristique des lilons de quarte tardits qui recoupent les massifs granitiques. el des filons do pegmatte à quarte + Reldspath + tourmaline + minerallisatlons diverses. La région du llatut-Mós prisente un grand nombre de filons de quartz. recoupant le massil granitique de lougeres: a ces lilons sont cependant steriles. lassociation quart + beryl est en revanche bien connue dans les anciennes mines de la Villeder au Sud de Josselin (Morbihan) et les carrieres de granite do Meney Goaillou (Coray, Finistiere sud). Ces fragments proviennent donc dialleurements extéricurs.

Plusieurs spécimens de bracelets ont bien entendu rentorcé la panoplic des objets directeurs de la culture V.S.(j. Fragmentés, ils sont en pierre (lig. 11. n"16. 17 et 19) ou bien en argile cuite (lig. 11, n"' 18, 20 et 21), d'une nature identique aux pates identities sur les récipients córamiques. Les roches employés se partagent entre schistes divers, fréquents dans cette partic du Massil armoricalin. et corncennes: un spicimen large est en serpentine. Dans ce dernier cas, lanalyse par lame mince a permis de lire la structure maillec typique qui so développe aux dépens de roches basiques ou ultra-basiques: on reconnatt des résidus dolivine. diamphibole et de phylittes. La serpentine est inconnue dans la région : il faut aller la chercher du côte de BolleHe-en-Terre (Côtes-d Armor), la balie d'Audierme (l:inistore. lîle de (joix (Morbihan). entin Champtoceau an region nantaiso (Loire-Atlantique). Notons dis a présent. el a la différence du reste de la Bretagne, qu une majorité de bracelets en Morbihan sont en serpentine (Le Roux, Lecert. 1971) : ce tait. cumble au gît de matior premiere at a latslior de fabricition econnus a (ipoix, contirme dans lî̀le par les dicourertes recentes d'un spécimen d'anneia-disque achere prospections Soc. Archéo. Lorient), platide doreset dejia en laveur de lorigine sud-armoricaine deune part des bracelets extraits de celle roche verte.

lone aute lame mince sur un discute taille a revele une corncionne argileuse yuart/o-feldspathique a litage sedimentaire conserve. dont la composition mincialogique est la suivante : plages amibö̈les sousent coalesentes de cordicrite pinitiséc : biotile brun alcijou fortcment pliochö̈yus soulignant k litage ou seciante sur colui-ci : muscovita rare: plagioclase (oligoclatse) associé a du quarle dans certains lits : cristaus de tourmatline dissomines: minéraux opatyues : yuart/en cristaus polvidrigues: grands porphyroblastes dandalousitc a bordure biotitique: yuelyues cristan squeleniques de staurotide. Une elle composition mincralogigue est typique de roches riches en alumine moditiós al contact du granite de Fougeres: la notice de lat calte géologigue ne signale pars la presence de staturotide et mentionne lexistence possible dandalousite. I. Echantillon en question (et sans doute la plupant des bracelets en cornionne du site) provient vaisemblablement de la bordure immidiate métamorphisic du gramite locial (tige. 1). I n fragment de bracelet a egalement benclicio d'une analese petrographique: il signt doune cornesnne yuartzo-feldspathiyue riche en ler. arec biolite: k fer se résout en amals de micrograins dissémines danns la roche. partois de liçon jointive donnant unc couleur tres sombre: le kldspath est diflicilement identitiable, même atu fort grossissement. Cetle rocke peut être associé a lechantillon précident dans laaturóste de métamorphisme de contact du granite de lougires.

Si ks exemplaires de bracelets an kerre cuite a section plate sont sans alucun doule " linis ". ceux en pierre prisentent encore les traces des stapes de leur labrication : les arîtes extericures sont en cours de polissages. Des plaques tratailless en schiste a chiastolite, découtertes en décilpalge (lig. 11, n"23), prourent une chaine opirattoire presque complete sur les licux même de Thabitat. Lanncalu-disque en serpentinc conserve une seuk face bien polic : sal largeur singuliere justitic yu on ait utilise crocable (n"16). 


\section{Répartition spatiale du reste de l'industrie lithique}

L’industrie lithique est peu abondante. Avec 250 pieces, soit $58.5 \%$ du corpus V.S.G. qualilié d’homogène. les fosses $2-28,48,76$ et 251 sont parmi les plus riches. Le mode de collecte du matériel a privilégié les grandes pièces. L’absence de tamisage systématique des sédiments explicue partiellement la rareté des éclatts et des esquilles. Ainsi pour le silex côtier, même lorsque l'on possède les nucléus. le volume des produits obtenus est très faible. Ces limites évidentes ne permettent pas de formuler toutes les conclusions qui vont suivre de manière absolue, mais on peut supposer quand même que les occupants du Néolithique ancien sont responsables en partic de cette hétérogénéité et du "classement" des produits de débitage. Pour lanalyse ci-après, le corpus a été divisé en cinc parties:

- Ies fosses homogènes du Villeneure-Saint-Germain $(n=21)$;

- les fosses sans élément diagnostique particulier ( $n=14)$ :

- le décapage de la zone d'habitation:

- le décapage sur les aires connexes, quelques struetures a l'Est du site $(n=5)$ et les vestiges issus des déblais:

- la partic Nord du site (tranchéc 30 et fosse 236), à outils du Néolithique récent/linal.

Une premiire estimation de ces ensembles montre que les trois premiers comportent des vestiges fort comparables, sans intrusions manifestes; lanalyse de l’industrie lithique Villeneuve-Saint-Germain a été elfectuée sur cette partic du site. Mais il va de soi que les conclusions de cette étude se balsent dabord sur les structures les plus importantes en nombre de pieces (structures 2, 48. 76 e 251). Le décapage sur les aires adjacentes, à l'Est du site, a également fourni du matériel, pour lessenticl attribuable au V.S.G., mais il convient daborder ces zones avec circonspection, puisque des vestiges céramiques de périodes plus récentes y furent découverts.

\section{Roches coupantes et matières premières}

Le classement des matières premières à l'oeil nu ne pose pas de problemes notables, puisque dune part le silex n'est absolument pas patiné. d’autre part parce qu'il existe de nettes solutions de continuité entre les matieres. L’identification de l'origine des matériaux a été effectuéc après classement par A. Chancerel (S.R.A. de Basse-Normandie) et G. Fily (Laboratoire de Géologie, Université de Caen), avec lappoint de lames minces. Nous remercions ici ces deux chercheurs pour leur disponibilité et leur collaboration. Toutes les indications de provenance reprennent leurs indications. Les silex à cortex non-roulés, nécessairement importés. sont classables en plusicurs types, toujours d'une excellente qualité. Le silex 1 est un silex de la base du Bathonien moyen (Jurassicjue), dont les aflleurements sont situés sur la bordure du Massil Armoricain, entre Bretteville/Laize (sud-est de Caen) et Ecouché (Ouest d'Argentan). 11 y est connu sous le terme "silex du Cinglais" (Chancerel et al. 1995). Lo 2 A et le 2 B sont plus ubicuistes sur toute la bordure du Massil Armoricain. et si le premier est plutôt issu de niveaux du Crétacé, lorigine du second n'a pu être précisée. Il existe en outre parmi ces silex a cortex vit, diverses matieres représentés par seulement une à trois pièces. La présence de l'opale résinite est particulièrement importante à signaler, puisquon aurait la les traces les plus anciennes de sal diffusion en Bretagne. La circulation de cette roche dans l'Ouest de la France a fait l'objet de plusiaurs synthèses essenticllement descriptives (Cassen, 1987: Fouéré, 1994), qui ne permettent pas encore de prendre lexacte mesure des techniques et des méthodes employés, ni de comprendre encore les enjeux de ce commerce si particulier. Des trois fragments identiliés ici. un seul provient d'une structure V.S.G. (ensemble 2-28), un autre, brûlé, a été trouvé en décapage à proximité de cette structure, le dernier était dans une tranchée de décalpage sur l'habitation principale. La contemporanéité avece loccupation du Néolithique ancien est donc fort probable.

Les matières glanées sur la Massif Armoricain couvrent un large spectre géologique, mais elles restent minoritaires dans laassemblage. Un silex côtier (cortex roulé) est observé, avec une certaine diversité de faciès. Il y a du grès lustré, roche tertiaire qui se présente en placages locaux, parfois de laibles dimensions, dont lidentification est diflicile. Les quartz, de médiocre qualité clastique, sont présentes sous différentes formes. Il y a

\begin{tabular}{|l|r|c|c|c|c|c|}
\hline \multicolumn{1}{|c|}{ Matiere } & $\begin{array}{c}\text { Fosses } \\
\text { V.S.G. }\end{array}$ & $\begin{array}{c}\text { Fosses } \\
\text { diverses }\end{array}$ & $\begin{array}{c}\text { Decapage } \\
\text { habitation }\end{array}$ & $\begin{array}{c}\text { Zones } \\
\text { connexes }\end{array}$ & $\begin{array}{c}\text { Zone nord } \\
\text { (Néoréc.) }\end{array}$ & Total \\
\hline 1 & 146 & 7 & 35 & 16 & 1 & 206 \\
\hline $2 \mathrm{~A}$ & 15 & 0 & 2 & 1 & 0 & 18 \\
\hline Galet & 52 & 3 & 4 & 1 & 0 & 60 \\
\hline Divers silex & 17 & 1 & 17 & 5 & 0 & 40 \\
\hline Silex brûlé & 37 & 2 & 5 & 8 & 1 & 39 \\
\hline Grès lustré & 1 & 0 & 2 & 3 & 0 & 53 \\
\hline Grès grossier & 0 & 0 & 2 & 0 & 0 & 2 \\
\hline Quartz & 43 & 4 & 4 & 3 & 0 & 54 \\
\hline Cornéenne & 0 & 3 & 1 & 0 & 0 & 4 \\
\hline Opale résinite & 1 & 0 & 2 & 0 & 0 & 3 \\
\hline Total & 322 & 23 & 82 & 49 & 8 & 484 \\
\hline
\end{tabular}

Tabl. 1 - Répartition des matieres premieres taillés en fonction des grandes unites de fouilles. 
un quartz lilonien, à gros grains, avec des taches de rouille. Les galets de quarty blanes roulés ont servi de percuteur: la matiere est plus tine et homogene. On remarque également un éclat issu d'un galet roulé de cristal de roche (structure 76). Parce que ces roches sont d’une lecture difficile, nous les écarterons de létude entreprise ci-après, même si l'existence de quelyues piées esquillés en quart\% est indubitable. Une silicification probablement d'origine tertiaire a fait lobjet d'une tentative de débitage. Enfin, les cornéennes granitisées ne sont pas issues du substrat immédiat (granite), mais de l'auréole de métamorphisme proche; elles ont été partois utilisées comme pieces intermédiaires dans une percussion sur enclume. II existe deux varictés. unc très micacéce et une autre verte sans mica, suivant probablement l'origine des maticies initiales métamorphisés.

I.es silex atu cortex natif (1.2 A. 2 B) ont parcouru au minimum une eontaine de kilometres depuis la Normandic, avant darriver sur ce site. Les côtes les plus proches pour le silex cotier se rencontrent dans la baic du Mont-Saint-Michel, à environ $25 \mathrm{~km}$. Quant à lopale résinite. clle a franchi plus de $125 \mathrm{~km}$ si son origine est bien la région d'Angers/Situmur.

\section{Le débitage}

Le fractionnement des chaines operatoires dans lespace. et corrélativement dans le temps, est une des caractéristiques principales du débitage sur le site du llaut-Méc. Aussi. s`il n’est jamais possible d’étudier l’intégralití des operations de production. plusieurs lenêtres sourrent sur dilérentes séquences. Löndustrie lithique est domincic par lopposition entre les débitages laminaires et les débitages déclats, qui recouve presque exactement une distinction entre matières de bassin sédimentaire al matieres ramalssés sur le Massil Armoricain.

\section{- Ises serentences laminaires}

Ces séquences sont incompletes, puisquilles no comportent pour lessentiel que les lames de plein débitage, régulieres. longues et larges, a trois pans, lémoignant d'un excellent nivealu technicue. Lorigine de ces

\begin{tabular}{|c|c|c|c|c|c|c|c|c|c|}
\hline $\begin{array}{c}\text { Categorie } \\
\text { /matiere }\end{array}$ & 1 & $2 \mathrm{~A}$ & $2 \mathrm{~B}$ & Galet & $\begin{array}{l}\text { Silex } \\
\text { divers }\end{array}$ & $\begin{array}{l}\text { Silex } \\
\text { brûle }\end{array}$ & $\begin{array}{l}\text { Gres } \\
\text { lustré }\end{array}$ & $\begin{array}{l}\text { Opale } \\
\text { résinite }\end{array}$ & Total \\
\hline Nucleus & 0 & 0 & 0 & 5 & 2 & 0 & 0 & 0 & 7 \\
\hline Eclat & 21 & 1 & 14 & 11 & 5 & 4 & 2 & 1 & 59 \\
\hline Eclat perc. sur enclume & 5 & 0 & 5 & 2 & 0 & 1 & 0 & 1 & 14 \\
\hline fragment proximal & 6 & 1 & 9 & 4 & 2 & 1 & 0 & 1 & 24 \\
\hline autre fragment & 27 & 3 & 7 & 6 & 6 & 13 & 0 & 0 & 62 \\
\hline Eclat cortical & 2 & 0 & 0 & 3 & 0 & 0 & 0 & 0 & 5 \\
\hline fragment autre & 1 & 0 & 0 & 0 & 0 & 0 & 0 & 0 & 1 \\
\hline Lame & 9 & 2 & 0 & 1 & 2 & 1 & 0 & 0 & 15 \\
\hline fragment proximal & 22 & 1 & 2 & 0 & 0 & 4 & 0 & 0 & 29 \\
\hline autre fragment & 39 & 4 & 2 & 0 & 1 & 11 & 1 & 0 & 58 \\
\hline Lamelle & 3 & 1 & 1 & 0 & 1 & 0 & 0 & 0 & 6 \\
\hline fragment proximal & 1 & 0 & 1 & 0 & 0 & 0 & 0 & 0 & 2 \\
\hline autre fragment & 6 & 0 & 0 & 0 & 0 & 0 & 0 & 0 & 6 \\
\hline Tablette & 1 & 0 & 0 & 0 & 0 & 0 & 0 & 0 & 1 \\
\hline fragment & 0 & 0 & 1 & 0 & 0 & 0 & 0 & 0 & 1 \\
\hline Crête et néo-crête & 0 & 0 & 0 & 0 & 0 & 0 & 0 & 0 & 0 \\
\hline fragment & 2 & 1 & 0 & 1 & 0 & 1 & 0 & 0 & 5 \\
\hline Enlevement de corniche & 0 & 0 & 0 & 1 & 0 & 0 & 0 & 0 & 1 \\
\hline fragment & 1 & 0 & 1 & 0 & 0 & 0 & 0 & 0 & 2 \\
\hline Chute de burin & 11 & 0 & 0 & 0 & 1 & 0 & 0 & 0 & 12 \\
\hline Bâtonnet & 4 & 0 & 0 & $\theta$ & 0 & 0 & 0 & 0 & 4 \\
\hline Microburin & 1 & 2 & 0 & 0 & 0 & 0 & 0 & 0 & 3 \\
\hline Debris & 0 & 0 & 0 & 0 & 0 & 1 & 0 & 0 & 1 \\
\hline Esquilles & 26 & 1 & 16 & 1 & 1 & 7 & 0 & 0 & 52 \\
\hline Total & 188 & 17 & 59 & 35 & 21 & 44 & 3 & 3 & 370 \\
\hline en $\%_{0}$ & 50.8 & 4,6 & 15,9 & 9.5 & 5.7 & 11.9 & 0.8 & 0.8 & 100 \\
\hline
\end{tabular}

Tabl. 2 - (irandes callegories du debitage suivant les principales matieres taillés (pieces brutes et relouchess ou utilisés).

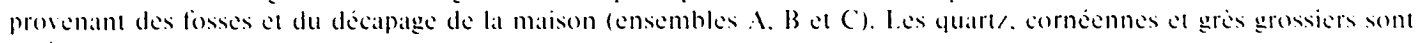
colus.

\begin{tabular}{|c|c|c|c|c|c|c|}
\hline Taux $(\mathrm{en} \%)$ & 1 & $2 \mathrm{~B}$ & Galet & $\begin{array}{l}\text { Silex } \\
\text { divers }\end{array}$ & $\begin{array}{l}\text { Silex } \\
\text { brûlé }\end{array}$ & Totalité \\
\hline Taux general de lames (lames/totalite des pieces lithiques) & 43.1 & 10.2 & 2.9 & 19.1 & 36,4 & 31,6 \\
\hline Taux restreint de lames (lames/totalite des produits debites, lames et eclats) & 56.6 & 14,6 & 3.7 & 23.5 & 45,7 & 41.5 \\
\hline Taux d'utilisation (outils/totalite des pieces lithiques) & 30.3 & 32.3 & 11.4 & 38.1 & 13,6 & 23,0 \\
\hline
\end{tabular}

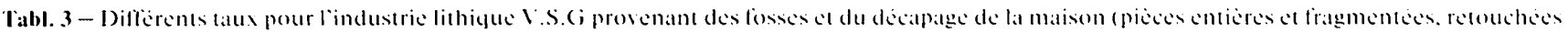
(1) 11011$)$. 
produits est un problème délicat à aborder : sous quelle forme la matiere a-t-elle circule? Les silex taillés a cortex non roulé, d’importation lointaine, représentent $87.5 \%$ de la matière taillec (hors quarty). Les lames régulières ne sont réalisées que sur ces silex, parmi lesqualles le type l est la variété largement dominante (tabl. 1 et 2). Il existe également de telles méthodes de débitage sur le type 2 A. peut-être sur le 2 B (mais mal représenté sur le site), ainsi que sur un silex marronclair à inclusions blanches. Comme l'outillage est d'abord sur les lames, et que les lames sont d'abord en silex importé, le taux d’utilisation de ess matieres est tris important, autour d’un tiers des pieces (tabl. 3). Leur représentation au sein de l'outillage est également hypertrophice. Le silex de type l par exemple représente la moitio des pieces lithiques mats les deux tiers des outils. Ces taux sont très élevés pour des industries du V.S.(j. I) ordinaire sur les sites du Bassin parisien. le poureentage de lames, rapporté a l'ensemble des piées lithiques, ne dépasse guere les 10 "0 (Bostyn. 1994).

\section{- Quelles ke'hniques :}

Lobservation des talons des lames de plein débitage permet de poser l'hypothése de l'intervention de deux techniques: la percussion indirecte el la percussion tendre. Cette distinction se fonde toujours sur les travaux expérimentaux de J. Pelegrin, mis en application pour la période qui nous concerne ici par $A$. Augerealu (1993) ou F. Bostyn (1994). Dans la mesure où léchantillon analysé est en dessous des criteres statistiques de liabilité (37 talons, dont 12 attribués à la percussion indirecte at 9 a la pereussion tendre. ke reste étant indéteminé), une telle assertion doit ŝtre prise arec prudence. lin suivant cette partition. une distinction apparait également dans les donnés dimensionnelles et morphologicues: les lames débités, par hypothese, a la percussion tendre sont plus larges, avec des écarts-types plus étendus, et un prolil régulierement arquí.

\section{- Lames et lamelles}

Quelle que soit la technique employée, la régularité des lames est un des traits caractéristiques. La multimodalité de lhistogramme des largeurs montre qu’il n’y a pass de standard (tabl. t) el cette disparité confirme que le débitage ne s'est pas fait sur place. Il n’y a pas d’indices suftisants d’un débitage de lamelles. Les pièces classées dans cette catégorie sont soit des produits très irriguliers, soit des lamelles qui s"intercalent dans le débitage laminaire pour rectitier un cintre.

\section{- Aperçu des méthode's}

La mise en forme par des crêtes latérales à la préparation réguliere est indubitable. comme en témoignent certaines lames. Cette opération peut intervenir alors que le plein débitage suit son cours : il s'agit alors d'une opération de correction, exécutéc avec soin (nervures transtersales régulieres sur des lames). L’intervention de crêtes antéricures est également manifeste avec les lames sous-crêtes. Dans quelques cas seulement. des négatifis de directions opposécs sont décelables sur les lames. Le débitage se fait donc à partir d’un plan de frappe unique, probablement relayé par un second opposi lorsque la rectification de la carene lexige.

In nucléus permet de vérilier toutes ces opérations en volume, mais il convient d'être prudent puisqu'il est implante sur une matiere locale, une silicification terthaire qui a imposé ses contraintes. Ainsi, des cassures resilicitiés au scin de la roche ont entrainé des fractures imprévues lors du débitage; le plan de frappe est établi sur l'une delle. Ce bloc a subi une mise en lorme très sophistiquéc, qui reprend les modalités techniques

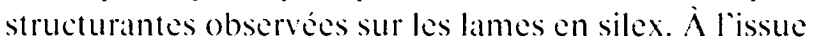
d'une phase de décorticage ou de préparation impossible a restituer, on observe plusieurs aménagements: - une crête antéricure à deux pans a pour effet de preparer la table et les llanes:

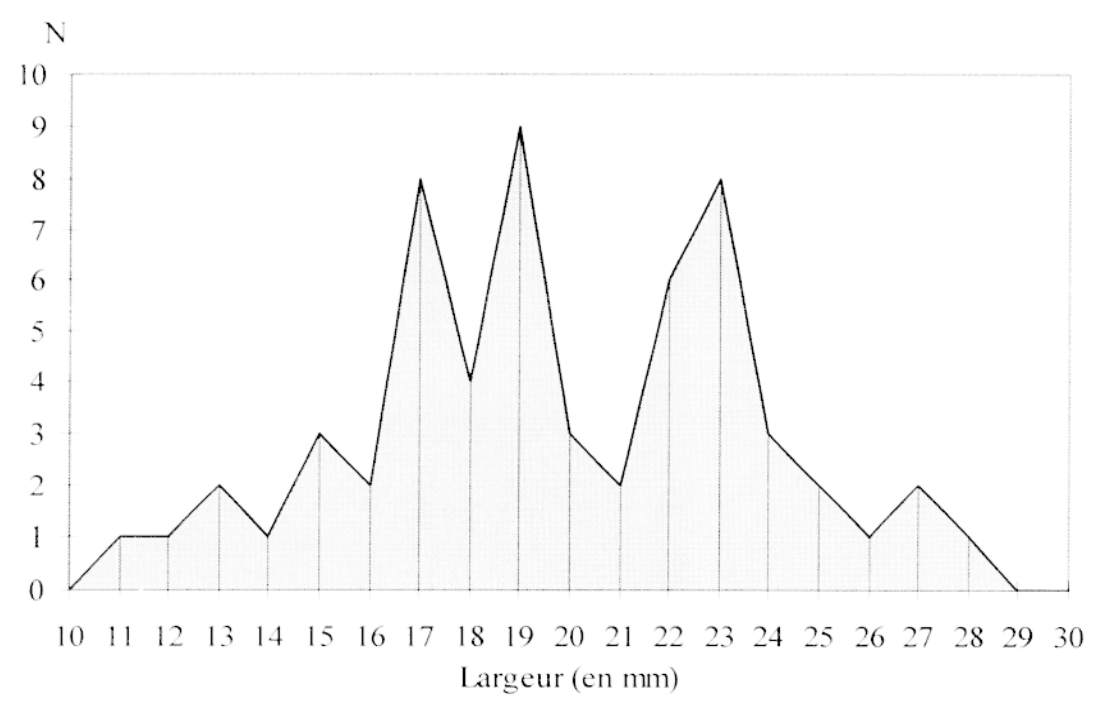

Tabl. f - llistogramme des largeurs des lames et lamolles (5t elements). 


\begin{tabular}{|l|l|c|}
\hline \multicolumn{1}{|c|}{ Support } & Categorie & Vombre \\
\hline \multirow{4}{*}{ Lame } & Grattoir & 5 \\
\cline { 2 - 3 } & Burin & 12 \\
\cline { 2 - 3 } & Perçoir & 2 \\
\cline { 2 - 3 } & Troncature & 6 \\
\cline { 2 - 3 } & Armature & 1 \\
\cline { 2 - 3 } & Coche & 1 \\
\hline \multirow{3}{*}{ Eclat } & Grattoir & 6 \\
\cline { 2 - 3 } & Coche & 1 \\
\hline Eclat ou lame & Armature & 1 \\
\hline Total & & 35 \\
\hline
\end{tabular}

Tabl. 5 - Tableau upologigus simplitic do

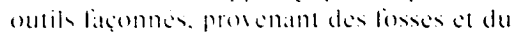

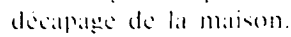

- unc crête postero-latérale à deux pans est situća à galuche du nuckéus, pour le tailleur. Blle na que peu d’incidence sur les thanes ou le dos: clle a probablement une fonction de secours:

- un troisieme angle de ce volume est également en position postéro-latérale. el opposé au précédent autour de late de symétric du nucléus qui passe par le centre de la table. Cel angle na pas été préparé par une crête. mais par des enlevements daxe, essentiellement a partir d’un plan de frappe opposé au principal el aujourd hui disparu. Cet angle, ou pseudo-crête (car il al ce rôk) a ete emporte par une fracture accidentelle k long diunc diaclasi.

Au dibut de la sépuence de plein débitage. la crite antericure a rebroussio au milieu de sa longueur : la poursuite des operations malgré tout naa abouti yu a accentuer les rebroussés. entrainant labandon du nucléus. La crêle postero-latérale gatuche el la pseudo-crêk pos-

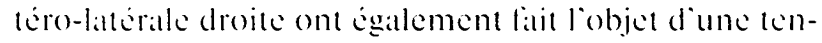
lative de débitages. également arortic pour les mémes raisons. l.e rythme escompté semblait être semi-tournant. et lobjectif devait être la production de lames. Labsence déclats en cetle mattiere dans le reste de l’industric lithicue montre encore la dispersion du materiel, que ne suftit pals a explicyuer labsence de tamisalge.

\section{- Dos cidats de misce c'n formo}

lin plus des lames, des éclats ont étidentities parmi les silex importes (1 et 2 A notamment). Lal majorité dente eux est de petite dimension (10 a $20 \mathrm{~mm}$ ), et leur morphologic incite a les clasiser parmi les dechets de mise en lorme, ou plutot de recidratge minime des volumes dibités (néo-crête, enlisements de corniche.

\begin{tabular}{|c|c|c|c|c|c|c|c|c|}
\hline $\begin{array}{l}\text { Categories } \\
\text { /matieres }\end{array}$ & 11 & $2 \mathrm{~A}$ & $2 \mathrm{~B}$ & Galet & $\begin{array}{l}\text { Silex } \\
\text { divers }\end{array}$ & $\begin{array}{l}\text { Silex } \\
\text { bruile }\end{array}$ & $\begin{array}{l}\text { Gres } \\
\text { lustre }\end{array}$ & Total \\
\hline Grattoir sur lame & 2 & 0 & 0 & 0 & 0 & 0 & 0 & 2 \\
\hline fragment & 2 & 0 & 0 & 0 & 0 & 1 & 0 & 3 \\
\hline Grattoir sur éclat & 2 & 0 & 0 & 2 & 0 & 0 & 0 & 4 \\
\hline fragment & 0 & 0 & 0 & 0 & 1 & 1 & 0 & 2 \\
\hline Burin diedre sur lame & 2 & 0 & 0 & 0 & 0 & 0 & 0 & 2 \\
\hline fragment & 1 & 0 & 0 & 0 & 0 & 0 & 0 & 1 \\
\hline Burin sur troncature sur lame & 2 & 1 & 0 & 0 & 0 & 0 & 0 & 3 \\
\hline fragment & 1 & 0 & 0 & 0 & 0 & 0 & 0 & 1 \\
\hline Burin sur cassure sur lame & 3 & 1 & 0 & 0 & 0 & 0 & 0 & 4 \\
\hline fragment & 1 & 0 & 0 & 0 & 0 & 0 & 0 & 1 \\
\hline Perçoir sur lame & 1 & 1 & 0 & 0 & 0 & 0 & 0 & 2 \\
\hline Troncature sur lame & 2 & 0 & 0 & 0 & 0 & 1 & 0 & 3 \\
\hline fragment & 1 & 0 & 0 & 0 & 0 & 1 & 0 & 2 \\
\hline Troncature sur lamelle & 0 & 0 & 0 & 0 & 0 & 0 & 0 & 0 \\
\hline fragment & 1 & 0 & 0 & 0 & 0 & 0 & 0 & 1 \\
\hline Eclat a coche & 1 & 0 & 0 & 0 & 0 & 0 & 0 & 1 \\
\hline Lamelle a coche & 1 & 0 & 0 & 0 & 0 & 0 & 0 & 1 \\
\hline Lame utilisee ou retouchee & 0 & 1 & 0 & 0 & 1 & 0 & 0 & 2 \\
\hline fragment & 13 & 1 & 1 & 0 & 0 & 1 & 0 & 16 \\
\hline Lamelle utilisee ou retouchee & 0 & 0 & 0 & 0 & 0 & 0 & 0 & 0 \\
\hline fragment & 1 & 0 & 0 & 0 & 0 & 0 & 0 & 1 \\
\hline Eclat utilise ou retouche & 5 & 0 & 2 & 0 & 0 & 0 & 0 & 7 \\
\hline fragment & 8 & 0 & 0 & 2 & 4 & 0 & 1 & 15 \\
\hline Lame esquillee & 2 & 0 & 0 & 0 & 0 & 1 & 0 & 3 \\
\hline Eclat esquille & 1 & 0 & 0 & 0 & 0 & 0 & 0 & 1 \\
\hline Autre piece esquillee & 3 & 0 & 0 & 0 & 0 & 0 & 0 & 3 \\
\hline "Armature" & 0 & 0 & 0 & 0 & 1 & 0 & 0 & 1 \\
\hline Dos abattu étroit & 0 & 0 & 0 & 0 & 1 & 0 & 0 & 1 \\
\hline Microburin + outil & 1 & 1 & 0 & 0 & 0 & 0 & 0 & 2 \\
\hline Total & 57 & 6 & 3 & 4 & 8 & 6 & 1 & 85 \\
\hline en $\%$ & 67.0 & 7.1 & 3.5 & 4.7 & 9.4 & 7.1 & 1.2 & 100 \\
\hline
\end{tabular}

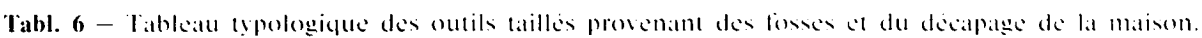


mise en forme de plan de happe). Cependant, leur nombre est trop réduit pour que l'on puisse soutenir l'hypothise d'un débitage a d'une mise en forme sur place pour toutes les lames. Les quelques grands iclats. souvent retouchés ou à simple fil ébréché posent également probleme quant à leur place dans la chaîne opératoire. On distingue des plages de cortex, assez limités, mais il n'y a pas d’activités de décorticage. Rien n’indique un débitage autonome d’éclats pour ces matières.

\section{- lorisine des lames}

Il est nécessaire de supposer de multiples modalités de déplacement des silex importés, et notamment la circulation de nucléus ecrtainement mis en forme, sientuellement à un stade avancé du plein débitage... puis leur départ vers dautres parties du site non exploitées. ou d'autres sites. Par ailleurs, on peut penser que d’autres lames sont parvenues déja débités sur le site. Cetle diversité s’accommode assez bien avec la dualité supposée ici des techniques de taille, et la dispersion des largeurs de lames.

\section{- L.c déhitage d'éclats}

Les matieres siliceuses que lon peut glaner sur le manssif armoricain (silex côtier, gris lustrí. quarty) ont lait uniquement l'objet d’un débitage d'éclats. Ces roches nont pas toutes une origine strictement locale, il en est ainsi du silex côtier. Les rares exceptions à cette régle sont potenticllement porteuses d’intormations, mais le faible nombre d’éléments empêche dexplorer tris avant ess tenêtres ouvertes sur de nouveaux comportements. Comme on l’a vu. un nucléus en silicification crtiaire d'origine locale a fait lobjet d'une mise en forme trés complexe, en vue d'un débitage laminaire. que la médiocrité de la matière n’a pas permis de mener à bien. Par ailleurs, le silex 2 b n'a supporté qu'un débitage d'éclats, de même que l’opale résinite (éclats tirés à la percussion directe dure. et dans un cas sur enclume). Or toutes deux sont des matières d'importation, dont on pouvait penser quelles auraient supporté un investissement technique plus complexe. Les séquences a éclats se sont déroulées sur le site, même si là encore une dispersion des produits s'est faite après le débitage. qui ne permet pas de saisir toutes ces opérations.

Le silex côtier a lait l'objet d’un débitage d'éclats qui ne doit rien à la production de lames. L'objectil du débitage est la production déclats minces, corticaux ou non. La présence de cinq nucléus permet d’en évoquer les méthodes. Quatre nucléus sont unipolaires, mais les changements d'orientation semblent rapides, puisque l'on observe des vestiges de tables d'orientations différentes. Lexploitation semi-tournante abandonne un dos cortical. L'un des nucléus porte un bulbe volumineux qui a ete pris perpendiculairement, il sagit done du débitage d'un gros iclat cortical. Un nucléus montre une ultime tentative avortée d'ouverture d'un plan de frappe opposé. Entin, il ý a un nucléus multipolaire, où trois plans de frappe permettent dexploiter une même table, opposéc a un dos cortical. Les corniches sont soigneusement abrasécs. La technique de percussion employéc est la percussion directe dure. Toutes ess pièces mesurent entre 32 et $46 \mathrm{~mm}$ de longueur maximale, les tables de 32 a $37 \mathrm{~mm}$. les derniers enlevements utiles sont des éclats de 18 a $25 \mathrm{~mm}$ de long. Cette faible dispersion conlirme leur unité. L'un des nucléus a été réutilisć en percuteur.

\section{L'outillage}

Contrairement au débitage. les opérations de fabrication des outils sont bien représentées sur le site, par les chutes de burins, quelques éclats de retouche parmi les rares esquilles et quelques outils cassés au débitage. Loutillage représente en moyenne $23 \%$ des pieces, avec des variations suivant les matieres.

\section{- La gestion des supports}

Les lames dominent nettement loutillage, avec 60 "o de la totalité des supports at presque les $9 / 10$ des supports transformés. Le taux de transtormation des lames, obtenus uniquement sur le silex de type 1 (le seul pour lequel on dispose de suflisamment de pieces pour une exploitation statistique), est de $25.9 \%$ o. Le taux d'utilisation $\left(45.7^{\circ}(1)\right.$ est largement sous-estimé, puisquil ne prend pas en compte tous les fragments mésiaux probalblement cassés lors d'une percussion bipolaire sur enclume, et parce quaucune étude tracéologique n’a été réaliscé. En réalité. il est fort probable que toutes les lames ont été utilisées!

La répartition de ces produits dans l'outillage façonne ne peut litire lobjet que d’hypotheses bascés sur un corpus limiti.

- Les burins sont aménagés sur les supports les plus robustes, avec une grande dispersion dans les largeurs (entre 12 e $27 \mathrm{~mm}$ ), mais une épaisseur jamais inférieure a $6 \mathrm{~mm}$. De plus, ces lames sont en général peu arqués. - Les troncitures et les grattoirs sont fabriqués aux dépens de lames dont la largeur est assez standard (17 mm. plus rarement 23 ou $24 \mathrm{~mm}$ ) et une épaisscur de + i $5 \mathrm{~mm}$.

Les éclats tiennent une place marginale dans l'outillage, avec 35,30 o des supports d'outils. Pour le silex de type 1, le taux de transformation des eclats, n'est que de $4.8 \%$. Il est probablement plus important pour les matieres locales ou sub-locales (silex côtiers), mais le faible nombre de pièce n'autorise pas de tels calculs. Les grattoirs requièrent des éclats épais, qui seront issus des premieres phases du débitage, taillés done dans le silex côtier qui seul parvient sur le site sans être totalement décortiqué. En revanche, toutes les catégories déclats seront utilisées pour leur tranchant brut.

\section{- Les ontils}

Lapprovisionnement a longue distance a pour corollaire une utilisation maximale des supports laminaires ; beaucoup d'outils ont ainsi une histoire complexe.

l.es hurins. - Ils représentent $34,3 \%$ de l'outillage aménagé, et $14,1^{\circ}$ alu sens large (comprenant tous les outils). Les modalités de fabrication sont des plus 
diverses: il est possible de les grouper en trois types. yui sont en nombre à peu près identique:

- L coup de burin a été donné sur une troncature oblicue. qui dans deux cas consiste en une large coche (fig. 12, n"1). I. 'autre est un burin double, opposi a un burin sur cassure:

- Les burins sur cassure sont dans ce contexte difliciles a apprecier. En eflet. la percussion bipolaire sur enclume très liréquente des lames a pu produire des stigmaltes quasi-identiques, même si les fractures latérales "en battonnet" se différencient en général des chutes de burin par leur protil torse. Il nest cependant pas impossible que les artisans néolithiques aient pu mette a protit une telle fracture accidentelle:

- Les burins diedres se distinguent des deux précédents dans leur utilisation éventuelle. Ce sont des burins d’axes, dont l'angle est fermé, alors que les autres sont des burins latéraux, a angles presque droits (lig. 12, n" 2).

Les nombreuses chutes de burins montrent toujours que le tranchant de la lame-support a éte retouché préalablement, observation qui se conlirme sur la plupart des burins. Ces modilications sont soit des aménagements du bord pour contrôler au mieux la chute, soit des traces d'utilisation préalable de la lame.

\section{- Line hipothese fonctionnelle: la fabrication de burin par percussion bipolaire sur enclume'}

Les stigmales de la percussion bipolaire sur enclume ont été observés sur tous les supports et toutes les matières. Ils sont suffisamment systématiques pour que l'on puisse en faire une des caractéristiques majeures de ce site. Pour le silex, elle est la cause du fractionnement de la plupart des lames, sans que l'on puisse proposer de chillire absolu. puisque les expérimentations restent à mener sur les différents stigmates des cassures. Les signes les plus évidents sont des pseudo-coups de burin yui partent de la cassure et investissent les deux faces du support et ses tranchants. des cassures en flexion arec bourrelets, des batonnets (enlevements torses latéraux), ou encore des surfaces de détachements vibrées (négatifs et laces inférieures). Il existe des éclats tres typiques de la percussion sur enclume, dont certains portent des nervures régulières sur la face supérieure, preures supplémentaires de la reprise de grandes lames. L'aspect remarquable de celle action sur ce site est quelle ne détruit pas sỵstematicuement les pièes, puisqu il existe de longues lames esquillés, des fragments mésiaux de lames a peine marqués, et finalement peu de pièces esquillées. Quelle est la finalité de celte action? I In élément de réponse a éte apporté récemment par l'analyse tracécologique de burins V.S.G. a Neauphle-k-Vicux (Yvelines) par $S$. Philibert (1996). La partic utilisée nest pats le burin en soit, mais le tranchant compris entre le pan et la fice inférieure, dans une action transversale. L'hypothese est celle d'un travail des plantes (fibres textiles?) Dés lors, il est possible d'envisager au I laut-Mée une volonté délibéréc de ríaliser des fractures en bâtonnets. identiques au pan de burin. Cette hypothése expliquerait d'une part la percussion ligere el peu destructrice de la majorité des lames, d'autre part lesquillement de la partic opposic a l'angle du burin sur les outils identiliés comme tel (deux burins diedres, un sur troncature). Enlin. cette hypothese permet de ker l'ambiguïti sur certains produits, dont la morphologie évocuc à nen pals douter les burins sur cassure, landis yue lia technique montre une percussion sur enclume arec tracture en bâtonnet. Le burin, outil déja dominant au 1laut-.Mé, serait donc impliqué dans une activité majoritaire (les burins diedres d’axe ont peut-être eux des lonctions difiórentes).

Cependant. lanicité du phénomène est peut-être lacelice, si loon considere le caractere ubiquiste d'une telle lechnicue, dans sa manifestation archéologicue. Il peut y aroir dautres motivations. La fabrication d'un tranchant grâce aux esquillements semble être trop alciatoire, alors qu une simple retouche y suftirait. Par ailleurs. lemmanchement des lames na pas pu produire de tels stigmates. Il faut done penser que toute piece allongéc a pu être percutéc. Les traces diacharnements sont rares.

\section{- l.es srattoirs}

Les grattoirs sur lames sont courts (moins de $40 \mathrm{~mm}$ ). II en val de même pour les grattoirs sur éclats. toujours trapus, mais sans aucune standardisation (lig. 12, n" 4).

\section{- Les tromcantures}

Une grande lame porte une troncature distale, tres légerement oblique (fig. 12, n" 8). Dans la mesure où cet aménagement ne moditic pas beatucoup la silhouette de la piece. elle se distingue des autres piócs. Pour cellesci, la tronciature est nettement oblique, latcialiséc a droite et convexe (lig. 12, n" 5-6). In vestige de piquant-triedre, non régularisé a son extrémité apiciale. sur deux troncatures indique yue ee procéde de labrication etatit employé. Lune delle est associéc à un microburin sur lextrémité opposé. peut-être de maniere alcidentelle. Une autre des troncatures a éte probablement remanice plusicurs fois: les retouches inverses semiabruptes qui précident les retouches directes dans létal terminal de la pièce ont peut-être pris appui sur une premiere scric de retouches directes (ou sur unc cassure) aujourd hui disparues, el ce pour des raisons techniques (angulation). Il est de coutume pour le Néolithique de qualifier ess outils de lames de latucille lorsquelles portent un lustrí. ce qui nest gueres sident ici.

\section{- Les perceirs}

Lln perçoir sur lame est réalisé par deux lignes de retouches alternes, une tronciature rectiligne et un bord abattu concile, es yui dígage une pointe kégerement désaléc (tig. 12, n'7). Il s'agit d’un outil court et robuste $(32 \times 17 \times 5 \mathrm{~mm})$. Lautre perçoir a une histoire technicuue plus complexe, puisqu il est implanté sur le mésial d’unc lame sous-crête perculéc sur enclume. el en conséguence très abîméc (multiples bâtonnetsi). Il 

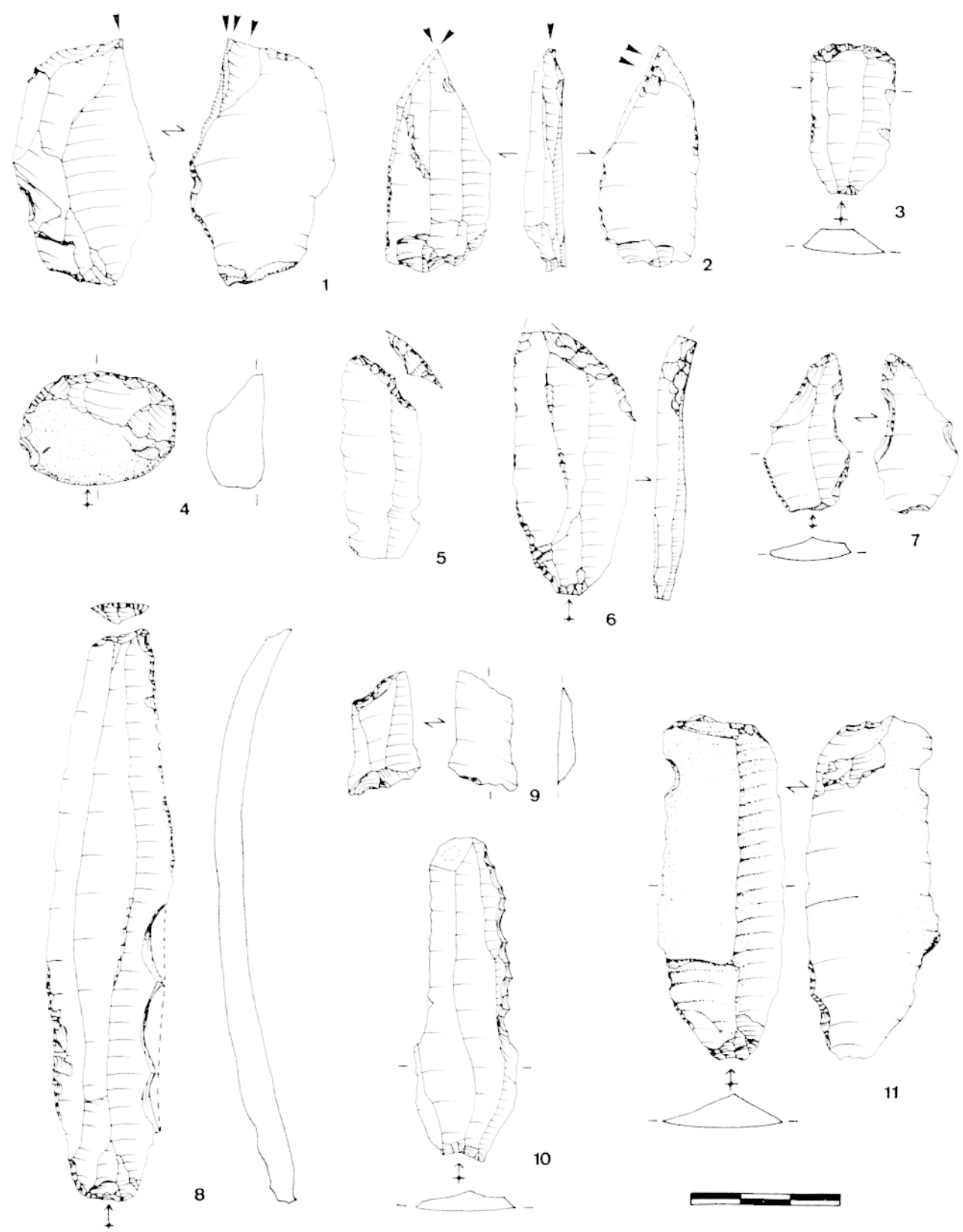

Fig. 12 - n 1: burin sur coche (troncalture): n 2 : hurin disdre sur lame a squilles provimales: n 3 :

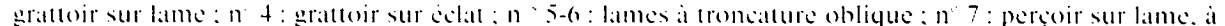

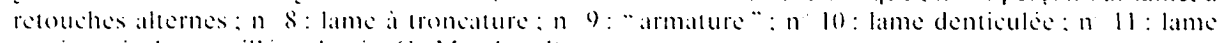
somi-corticiale esquilloc (dessin (i. Marchand).

ny a cuin seul bord abattu. particl. rectiligne, et at retouches directes semi-abruptes. Lune des extromites d’une piece esculllic sur lame est usce el a pu servir comme perçoir, mais clle n’a pas été chassíc typologiquement avec ces pieces.

\section{- les armatures}

In fragment de lame réguliere est réalisé dans la zone sub-corticale d'un silex (tig. 12, n"9). Elle est soctionnéc par une troncature directe, oblique et rectiligne el par une calssure oblique de même direction, particllement reprise par retouches directes et inverses. Lal forme générale est done un rhombe. Celte piece nest pas plus une hèche dissymétrique danubienne (lleche perçante), qu une lieche tranchante. Erentuellement. la tronciture entiere, calsséce en pointe. a pu être la partic active de l'outil.

Un fragment de piece a dos, lamelle ou éclat mince est Également à signaler, dans une matière indéterminio car trop patince. 11 mesure $6 \mathrm{~mm}$ de large pour $2 \mathrm{~mm}$ dépaisseur. Son appartenance alu systeme technique décrit ici est difficile à apprécier. 


\section{- less outils sur masse' c'mtrale'}

Les 2 outils entiers en quarty ont des caractieres et des stigmates suflisamment différents pour que loon puisse supposer des utilisations différentes. Il y a un " chopper" (structure 76), plat et de grandes dimensions $(88 x$ $84 x+8 \mathrm{~mm}: 331 \mathrm{~g}$ ). La percussion a enlevé bon nombre d'éclats rebroussés, yui forment une arête vive a l'une des extrémités. les deux pans ont ensuite été abrasés. Il ny a pas les étoilures indiguant une utilisation comme percuteur pour le silex. Le percuteur n"1 (structure 28) est grossierement quadrangulaire el asse lourd (95 $x .59$ $x 50 \mathrm{~mm}:+20 \mathrm{~g})$. Les angles sont écrasés et ont vraisemblablement servi à la percussion du silex.

\begin{tabular}{|l|l|l|c|}
\hline \multicolumn{1}{|c|}{ Matiere } & \multicolumn{1}{|c|}{ Action } & \multicolumn{1}{c|}{ Type } & Vombre \\
\hline \multirow{3}{*}{ Quartz } & Percussion & Percuteur & 1 \\
\cline { 2 - 4 } & & fragment & 6 \\
\cline { 2 - 4 } & Abrasion? & "Chopper " & 1 \\
\hline \multirow{2}{*}{ Gres grossier } & Percussion & Percuteur & 0 \\
\cline { 2 - 4 } & & Pragment & 1 \\
\cline { 2 - 4 } & Piece intermediaire & Piece esquille & 1 \\
\hline \multirow{2}{*}{ Corneenne } & Piece intermediaire & Piece esquillee & 4 \\
\hline & & Total & 14 \\
\hline
\end{tabular}

Tabl. 7 - ()utils sur masse antrale des losses.

Les pieces esquillées sur matériaux métamorphisés indiquent peut-être une certaine carence en materiaux, dautant yue certaines de ces roches de substitution sont vraiment tress fragiles. On remarque un galet de cornéenne verte, qui a d'abord été poli par l'utilisation sur une face seulement, puis bouchardé sur une arête. pour entin être écrasé sur enclume dans le sens de la longueur.

\section{Les orientations des chaînes opératoires}

La typologie de l'outillage et les modalités du débitage laminaire désignent à n'en pas douter un ensemble Villeneuve-Saint-(iermain. Il convient plutôt de s’altarder sur la grande originalité de eet assemblage, notamment en ec qui concerne l'économic des matières premières et la gestion du debitage.

\section{- Lne gestion complexe des matiores de des produits}

Une logique lechnicue apparaît clairement à lissue do colte étude: il sagit pour les occupants du llaut-Méc d’aflirmer leur appartenance au monde V.S.Ci., malgré les contraintes majeures de lenvironnement, en loccurrence la pénurie de matériaux lins et de grands volumes. Tous les caracteres de l'industric en découlent. Lacquisition préférentielle des matériaux à longue distance et le fractionnement des chaînes opératoires de production dans lespace distinguent immédiatement ee systeme de tous ceux présentés dans ec travail. Fin corollaire, on observe l'importance des supports laminaires dans loutillage et le fort taux laminaire général pour le débitage, puisque l’importation de lame est la plus rentable suivant le rapport longueur de tranchant/poids de matière. Parallèlement, la pénurie de matériatux à proximité a pu compromettre le développement d’un débitige d'éclats.

Lal gestion differenticlle des matieres en fonction des produits escomptés est particulièrement nette, arec lexistence de plusicurs chatnes opératoires de débitage: production laminaire aree des mises en forme soignées et production déclats plus sommaires. La modicité de l'onsemble étudié ne permet pas de développer certains aspects a peine entrevus, comme le débitage d'iclats sur une matiere importéc. Cette deonomie particuliere nest pas une nouvealue pour le V.S.(j., mais clle sempare d'autres matériaux. Ainsi, l: Bostyn a signalé lopposition entre un débitilge laminaire très soigné réalisé au punch sur un silex tertiaire, plus rarement secondaire, et un débitage laminaire de moindre qualite eflectue au percuteur tendre sur un silex secondatire (Bostyn. 1994). Il est étonnant de constater que eette dualite technique se retrouve al HautMé, mais lì sur une même matière. klle rellite une dillérence de niveatu technique. et une éventuelle spécialisation des activités, yui signe tout autant que loutillage, une industric du V.S.(i.

Leidatement des chatines opératoires dans lespace est dû lui plus particulierement à limplantation du sitc foin des gites de silex indispensables a la reproduction de loutillage. L’importation de lames est clairement observes mais encore une fois d'autres comportements sont suspectés. comme limportation de nuclíus preformes. L'utilisation maximale des produits it haut investissement technique ne peut surprendre dans un kl contexte: ce qui étonne cependant, c’est que cette utilisation natille pas juscu à la réduction des supports. L. abandon de grandes lames en silex importé est apparemment paradoxal, car dispendieux suivant une eertaine logigue économique. ll témoigne done d’un stress tout rebatit sur he silex et de contacts frécuents aree les régions sédimentaires. Il révèle également limportance accordic a la longueur des outils, peut-être tant d'un point de vac fonctionnel, que d'un point de vue social (prestige) ou culturd (conception que l'on a de l'outil).

\section{SINTHÈSE ET PROLONGEMENTS}

Il sera fait le choix, dans cette ultime partic, d'un certain nombre de domaines de recherche et de rapports analogiques quil nous parait opportun de commenter a la lumiere des résultats enregistrés dans le Coglais.

\section{L'architecture du bâtiment}

Il s’agit du premier plan de maison de lestape la plus ancienne du Néolithique régional. Ce type d’architecture de bois et de terre, aux parois rectilignes, propre aux sociétés domestiques du VI' at V' millénaires constitués en Furope eentrale et repérés jusque dans k bassin de Paris. était encore récemment reconnu à l'Ouest, a Poses (site de Sur-la-Mare. Billard at al., 1996). sur le cours inféricur de la Seine, et jusquion Normandic, aux portes de Caen (Le Haut-Saint-Martin à Mondeville - Renalult, 1994). Cela dit, a la diffërence 
de cette dernière maison, lorganisation des "tierees" ne suit plus le modèle danubien, plutôt bien conservé sur les $1000 \mathrm{~km}$ de son développement européen. Non seulement les tierces véritables ont disparu, mais le fort indice de trapézoödalité et la courbure légère mais indéniable de la façade constituent l'originalité de l'ensemble. On peut dès lors évoquer une véritable désorganisation ou déstructuration du modèle ancestral. pourtant encore très reconnaissable dans les plans des maisons V.S.G. ou Bliquy relevés en Bassin parisien et en Hainaut. Si nous voulons maintenant rechercher des analogies formelles à la maison du llaut-Mée, nous dovons nous tourner vers l'Yonne où le bâtiment 13 de Sainte-Pallaỹe, fouillé par H. Carré (id., 1958, 1959), offre les points de convergence les plus nombreux : il en est ainsi de la trapézö̈dalité prononcéc, du dessin particulier de la façade qui abandonne la rectilinéarité, de la mauvaise reproduction des tierces et de labsence des fosses latérales. Toutes ces déviances cumulées font système dautant micux que les traditions céramiques, nous le verrons, sont en tous points convergentes entre l'Yonne et l'llle-et-Vilaine. Restent les habitations du Marteau à Pontavert (Aisne) dans lesquelles C. Constantin a bien remarqué l’absence de fosses latérales, la trapézoüdalité des plans. l'obliquité inhabituelle des tierces et l'irrégularité des parois (id., 1985); quand on sait que la céramique très probablement associéc à ces unités architecturales est de type Limbourg. on comprend tout l'intérêt porté à lévocation de ce rapprochement.

Si la trapézoïdalité prononcée du bâtiment du llautMée peut être comprise comme l'exagération d'un caractère évolutif propre au Rubané du Sud-Ouest, le dispositif " en $Y$ " est quant à lui, au contraire, un trait architectural reconnu sur une aire géographique précise, allant des secteurs Rhin/Meuse jusqu'à l'Alsace, recoupant par là même d’autres entités spatiales séparées par l'analyse, celle en particulier mence à l'échelle des pratiques funéraires (Jeunesse, 1995). La seule explication proposée à ce dessin particulier du plan fait appel à la composante mésolithique, à vrai dire sans davantage l'expliciter, l'hỵpothèse retenue étant que le dispositif en question constituerait une référence symbolique aux architectures circulaires des chasseurscueilleurs (Modderman, 1985). Ici, dans le Coglais, en contexte V.S.G. mais sur un terrain pionnier, la proposition peut alors prendre une dimension supplémentaire quil faudra bien envisager et tester dans cette période cruciale de transition. Notons pour le moment que la forme en $Y$ détermine au sol un vaste espace de dégagement, exactement comme sur les plans des bâtiments (Alte Linearbandkeramik) du Niederlanden (id., 1985), et que, d'autre part, de tels volumes sont obtenus dans les maisons trapézoïdales V.S.G. de Poses (et d'autres sites V.S.G. ou bliquyen) grâce à des poteaux centraux se substituant aux traditionnelles tieres.

\section{Du rapport analogique entre le plan des maisons et celui des tertres funéraires}

La similarité formelle observée entre le trapèze allongé des maisons du Néolithique "ancien" d’Europe centrale et nord-occidentale et celui des tertres funéraires essentiellement repérés en Scandinavie, Allemagne du nord et Pologne est une déjà longue histoire, surtout débattue et médiatisée par les auteurs anglais après que G. Childe (1949) eût attiré leur attention sur le sujet en citant les travaux antéricurs de Sprockoll (1938) et de Glob (1949). La publication en 1966 des fouilles du "Fussel Lodge long barrow" en Angleterre est l'occasion pour $P$. Ashbee de revenir sur la question en soulignant les analogies flagrantes relevées entre la tranchéc périphérique au tertre qu'il vient de fouiller, où sont encore marqués les poteaux en bois, et les maisons polonaises de l'étape récente du L.B.K., bâtiments évoluant vers la trapézoödalité et régulièrement repérés par une tranchéc de fondation où s’alignent en se touchant presque les différents poteaux de maintien en bois. Les comparaisons établies précédemment entre la maison du Haut-Mée et celle de Champs Guyot à SaintePallaye nous remettent d'ailleurs en mémoire le rapprochement établi par le même Ashbec (1970) entre le plan de ee dernier bâtiment et ceux du groupe culturel polonais de Bryesc Kujawski, cela dans le but d'alimenter l'enquête sur l'origine des tertres dans les îles britanniques. $\dot{A}$ propos des maisons polonaises, il nous faut souligner en aparté lexacte identité du rapport des bases $(2,25)$ du plan trapézoïdal d'une maison Lengyel comme celle de Krusza Zamkowa avec celui du HautMée (Czerniak, 1980), et, d'autre part, la tendance manifeste a la courbure de la façade dans l'étape récente du Lengyel comme celle de la maison 55 du site n" 4 de Brzesc Kujawski (Bogucki, Grygiel, 1993). Mais, pour en revenir à la relation dont il est question dans ce chapitre, chaque fois que le sujet est abordé, le manque de preuves et de liens directs suffit à faire douter ceux que les seules conjectures ne satisfont pas (Corcoran, 1969). Les derniers écrits originaux sur le sujet (Hodder, 1984) illustrent d`ailleurs bien les difficultés à surmonter pour que la pratique appuie la prévision théorique du modèle; nous en voulons pour preuve les curicux courts-circuits liant les maisons d'Europe centrale et le plan quadrangulaire allongé des allées sépulcrales du Bassin parisien ou encore lorientation des mêmes bâtiments superposée à celle des entrées des tombes a couloir bretonnes. On voit dailleurs à travers la synthèse de M. Midgley (1985) que nos collègues britanniques ressassent le sujet en proportion inverse du manque de maisons néolithiques trapézoïdales répertoriées sur leur territoire, el que les préhistoriens de l'Europe nord-continentale n'envisagent pas du tout ce lien de filiation arguant de l'influence "mégalithique" occidentale sur leurs plans de monuments... Quoi qu'il en soit, notons que ce dernier auteur souligne quelques risques de confusion possible entre les bâtiments post L.B.K. et certains monuments de terre à compartimentation interne en bois.

Les récentes observations faites en Bassin parisien concluant à une exacte superposition entre danciennes maisons rubanées et des tertres allongés globalement datés du Cerny sont bien sûr l'occasion de relancer le débat à partir d'arguments que l'on peut juger plus solides (Chambon, Mordant, 1996). Ainsi peut-on constater à Balloy que quatre des onze monuments funćraires se surimposent sans doute aucun à quatre 
bâtiments du Rubané récent/linal sur un site qui en compte cinc. Cette troublante continuité d'occupation peut laisser supposer une consécration de lespace domestique où se joucrait la mémoire des ancêtres. Un autre exemple de "superposition" est donné par le "bâtiment" trapécoüdal du V.S.G./Aug̣ linal à Molinons dans l'Yonne (Prestreau. Thevenot. 1996) qui présente, en fait. bien des caractères d’un tertre arasé identifiable par ses lossés de délimitation. $A$ ce stade des rapprochements, on ne manquera pas non plus de souligner un des aspects nouveaux reconnus sur les tertres d'Armoricyue sud. et précisément sur celui de Lannecer (jadouer en Erdeven (Morbihan - Boujot et al. 1994) qui oflere la particularité d’âtre ceint d’un fossé périphérique, de plan trapézö̈dal, aux angulations fort marquées et à la laçade courbe dans la manière de la maison du llaut-Méc - détail architectural que ne reproduisent pas aussi bien les étroits et longs monuments découverts dans la plaine de Caen (Desloges, 1989) mais yue lon retrouve, en revanche, sur un mode tres proche, dans un tertre aussi fameux que celui de Dölatuer Heide (Saale, Allemagne) bien qu'il soit daté du Silzmünde (Berhens, Schröter, 1980). Chronologiquement parlant, le monument d'Erdeven est recoupé par des structures plus récentes datées du Castellic a coupe-i-socles, signes céramiques que l'on retrouve dans les premieres tombes a couloir à chambre circulaire de la rigion camacoise, ou encore par la biais des echanges de récipients dans les tombes a couloir de type identique en Normandic (Cassen, 1993: Chancerel, Billard. 1991). La céramique recueillie dans le lossé du tertre el a la périphérie du caveau, caractériscó par une décoration de cannelures et de lignes de boutons au repoussé. est par contre eclle attribuća a l'étape ancienne du Castellic. Entin, proche d'Erdeven, le tertre trapésoüdal du Manio 2 a Carnac se démarque par de possibles calages de poteaux internes, plantés sur le corps du monument. suggérant alors une superstructure périssable dont le lien chronologique n'est pas facile a établir avec les deux coffres funéraires sousjacents decouterts en 1922, mais qui pourraient bien sûr rappeler l'architecture domestique originelle en bois.

En résumé, les comparaisons théoriques établies en leur temps entre plans de maisons et plans d'architectures funéraires semblent pouvoir être enlin validés pour la lrance septentrionale : la ligure trapézoüdale allongée ne sera d'ailleurs pas une donnée exclusive aux tertres a "coffres" puisque les grands cairns de Bretagne nord et du Poitou, regroupant les premieres tombes à couloir, reproduiront le dessin d'origine (Barneney. Le Planti), marquant par là même une continuité de traditions allant dans le sens d'une véritable dynamique ivolutive (Boujot, 1993, 1996).

Aprés que les sociélés du Rubané occidental alient regroupé leurs morts à lextéricur du village - peut-être dans la continuité du patron des nécropoles mésolithiques - et que les sépultures V.S.G. aient été clairement rapprochées des espaces d'habitations, il ne serait en délinitive pas trés surprenant que les inhumations individuelles de l'étape chronologique postérieure gagnent le corps de ces tertres édifiés à l'image des anciennes et traditionnelles maisons familiales. En leur sein, le plan circulaire ou quadrangulaire des sépultures a contour fermé peut alors relancer en Bretagne le débat - nous lallons vu ici amoré a propos du dispositit en $Y-$ sur la part créative des traditions indigenes du Mésolithique des zones côtieres et des bassins versants.

\section{La question des pierres dressées ou stèles et ce qui les relie aux espaces funéraires}

Lívocation des longs tertres arasés normands ou ceux de Bretagne sud, ces derniers en général plus démonstratils en raison délévations encore préservés, nous permet dassurer une opportune transition alve la pierre ourragéc du llaut-Méc. Celle-ci, taillée et mise en forme, piquetes a une extrémité alors que l'autre est restec brute et efliles, n'est bien entendu pals sans rappeler l'aspect d'une stile alors que son utilisation en couverture d'une losse allongée nous éloignerait plutôt de celte premiere et hypothétique destination. On connaît, en elfet, en Morbihan et en Finistere, au moins deux exemples incontestables de steles "gravés", conservess en position verticale, en liaison direck alec un monument luncraire: le tertre (1) 2 du Manio (Carnale, Morbihan - Le Rouzic et al., 1923) at le terte de Kermorvan (Le Conquet, Finistire - Le Pontois. 1929). Des éléments allant dans ce sens peuvent être aussi retirés de la fouille récente du complexe mégalithicue du Petit Mont en Arzon (Lecornec. 1994): une fosse bordic d'un systeme pierreux de calage, implantéc a lextrémité du terte primaire (vers 4500 ans ar. J.-C.), piégé sous le cairn le plus ancien, est a connecter tres probablement avec la plus grande des stèles débités et réutilisées dans la construction des différentes tombes à couloir édiliés par la suite sur le site. Par un raisonnement équivalent, on rapprochera arec profit les steles gravées et réutilisés dans la tombe a couloir de Mane Rutual a Locmariaguer du tertre imposant et contiguë, a la constitution argileuse typique, qui fut un temps considéré comme un prolongement du tumulus de la tombe a couloir mais qui, alu contraire, lui est antérieur (Le Rouzic, 1965: Mériméc. $1835)$. En sorte que tous ees indices cumules rendent vraisemblable lidée que la dalle en question sur ke site du Coglais ait pu être dresséc dans la fosso adjacente, où fut reconnu ce qui s'apparente k plus à un calage de pierres, et que la fosse allongéc - contenant deux lames de haches intactes dont une enrobé d'ocre, matière si bien en usage dans le Mésolithique de loouest - suggère une tombe de la famille des "sépultures sousdalle". sépultures souterraines a contour fermé dont on sait limportance dans la genese des architectures monumentales édifiées au-dessus du sol (Boujot, 1993, $1996)$.

Par ailleurs, la similitude de traits entre la pierre du Haut-Mé - munic d’étranglements de part et d'autro de lextrémité piquetée el arrondie - et certaines des pierres dressés a l'intérieur de plusieurs tombes à couloir à chambre circulaire (Guennoc. Finistere), ajoute encore une autre correspondance a lensemble de ces liaisons qu'il s’agira à nen pas douter d'exploiter : lo caractere anthropomorphe et l'interprétation parfois 
apposée ("Déesse-mère", "Idole néolithique", "Gardienne des morts") peuvent d'ailleurs se concevoir autrement et nous préférons, quant à nous et en accord avec P. Gouletquer (id., 1991) y deviner un des principes masculins qui animent l'ensemble des signes fondamentaux de lart parietal armoricain (Bailloud et al.. 1995) dont un grand nombre sont en fait signifiants dans un tout autre contexte que celui des tombes à couloir (L'Helgouac'h, 1983 : Maisonneuve, 1983).

L`idée d'une stèle retenue pour interpréter la dalle de la losse 21 - que l'on rapprochera avec prudence des observations faites à Saint-Just (Morbihan - Briard ' al.. 1996) autour d’un menhir gisant, sans liens stratigraphiques, près de la tombe à couloir nord de la Croix-SaintPierre et pour lequel la fosse de calage voisine donnerait une date ${ }^{1+4} \mathrm{C}$ à $6070 \pm 80$ B.P. (Gil $8840:-5240$, -4740 av. J.-C.) - se renouvelle également à propos des intrigantes losses doubles dont on a vu que plusieurs d'entre elles présentaient les signes caractéristiques d'un calage de blocs enserrant une matiere disparue, en l'occurrence une massive pièce de bois plantée à la verticale. Après avoir évoqué sans conviction Sandun, et bien que la relation puisse paraitte cette fois par trop exotique, la morphologie et la disposition de ces structures allongées font immanquablement penser aux tout aussi bizarres Stendingegrave (Stcinpackungssräber. Stone-packing graves) du Néolithique moyen danois, contemporaines pour les plus anciennes des premières tombes à couloir du Jutland (Jorgensen. 1977. 1993). Longtemps considérées comme des sépultures, ces fosses doubles allongées et empierrées qui jouxtent une fosse quadrangulaire (la Maison des Morts), elle-même divisée en deux tranchées parallèles - au point qu'un décapage mécanique protond ne laisserait que cette impression d'un couple de fosses allongées - sont en fait d'une interprétation difficile puisquaucun cadavre ny fut à ce jour découvert (malgré des concentrations fortes en phosphates) et que seules des traces de possibles sacrifices de boculs accompagneraient quelques lames de haches polies et autres ciseaux en silex. La mention ainsi faite du caractère proprement non domestique de ces structures, ici comme la-bas, est simplement de nature à nous faire davantage réfléchir sur les possibles finalités de leur implantation... Enfin, géographiquement et chronologiquement moins éloignées, et sans doute fonctionnellement plus proches des faits rapportés en Bretagne. plusieurs fosses découvertes dans la nécropole Cerny. de Balloy ont elles aussi été reconnues comme de possibles témoignages d’implantations de pierres ou mégaxyles dressés (Chambon. Mordant, 1996). La validation de telles hypotheses est ardue mais les descriptions du llaut-MÉ pourraient néanmoins consolider le scénario en formation.

\section{La chronologie céramique}

Bien que la production céramique nous semble atteindre un nombre de formes et de décors tout a litit significatif pour pouvoir être commentéc de façon profitable. il n'est pas sûr que des quantilications supplémentaires puissent dans notre cas déboucher sur des résultats vraiment décisifs: les comparaisons chiflices qui pourraient être menées avec les ensembles de la zone eponyme du V.S.G. nous confronteraient à des corpus largement supérieurs.

Cela dit, les correspondances établies entre l'Ille-etVilaine et l'Yonne, à l'échelle des architectures domestiques, qui peuvent surprendre par l'éloignement des sites concernés, sont pourtant à nouvealu pertinentes dès l'instant où l'on tente d'établir d'autres rapprochements dans le registre des formes et des décors céramiques. Car un des traits remarquables du Haut-Mée tient a ces bords plats rentrants (cordons horizontaux internes) et à ces boutons et cordons placés sous l'ouverture des récipients : voilà des caractères qui, réunis sur un même individu, renvoient davantage au groupe d`Augy délini par G. Bailloud (1964) à partir des éléments fournis par ce dernier département. On ne discutera pas ici de l’intérêt à réactiver cette entité après qu'elle ait été confondue soit avec le V.S.G., soit avec le Cerny-sud (Constantin, Manolakakis, 1991). L’habitat éponyme d'Augy demeure, quoi quil en soit, une référence obligéc a laquelle rattacher la production bretonne, d’autant plus que la ligne sous le bord opérée par impressions verticales d'ongle est aussi un autre el indéniable point commun : parmi les publications réeontes, on relevera également les séries régionales comparables de Passy-Lal sablonnière 5,6 et 7 (Carré. 1996). En remontant vers le nord-ouest, bords rentrants aplatis, cordons a boutons sous le bord, parfois associés à des impressions pivotantes au peigne sont signalés à Judris (Souppes-sur-Loing, Seine-et-Marne) et Les Hautes Bruyères (Villejuit, Val-de-Marne - Lanchon, 1984). Chenou, Guercheville (Seine-et-Marne Simonin, 1996), Villerable ou encore Lery en bords de Seine (Eure - Verron, 1976). Passons sur le groupe dẹja éroqué des sites de la région basse-normande pour deseendre sur le bassin de la Loire où de nouveaux vestiges très proches prouvent l'extension de ec concert de traditions loin vers le sud, comme a la Tuille (Nohant-enGraçạy, Cher - Hamon, 1995). Bien entendu, tous ces habitats sajoutent aux autres témoignages du même secteur géographique qui attestent depuis plus longtemps l'implantation du V.S.G./Augy bien à louest de la zone de définition premiere : ainsi dans l'Essonne et le Loiret (Simonin, 1988: Manolakakis, 1991), l'Indre, l'Indre-etLoire et le Loir-et-Cher (Bailloud 't al., 1987: Villes. 1984), voire dans la Vienne comme à Dangé. SaintLeomer et Bellefonds (Constantin, 1985: Patte, 1971: Joussaume, 1986). La publication prochaine des vestiges récemment mis au jour à La Pierre du Lane à SaintNicolas-de-Bourgueil (Indre-ct-Loire - Couvin at al.. 1996), ou ceux de découverte plus ancienne comme à lîle Ponneau (Saumur. Maine-cl-Loire - prospections R. Cadot), Ancenis et le pay's de Retz (La Jarry, Pointe Saint-Gildas, Port-aux-Ânes, Tharon-Plage, Le PontNeufen Loire-Atlantique - prospections B. Poissonnier. Y. Viau. M. Tessier) montreront aussi combien le cours de la Loire fut bien l'un des vecteurs essentiels dans la transmission des traditions V.S.G. vers l'Atlantique. Notons cependant que ni les anses ensellés, ni les boutons au repoussé, ni les boutons à dépression centrale ne sont présents dans le corpus du Haut-Mée. 
autrement dit aucun des éléments diagnostiques permettant d’assurer une étape encore plus récente du V.S.(j./Augy pourtant repérée sur les marges immédiates du Massif armoricain (Les Pichelots et La Bajouliere en Maine-et-Loire-Gruet. 1986, 1991) ou de l'horizon Cerny de l'Ouest de la France identilié sur Fougìres, non loin du llaut-Mée (Bigot, Le Caeduner, 1987). Ce dernier terme dattente, que nous avons à plusieurs reprises proposé et explicité en tant qu’instrument temporaire de classement (Boujot, Cassen, 1992 ; Cassen, Müller, 1992: Cassen, 1993), devra à nen pas douter être précisé dans les réflexions à venir : ainsi, certains des éléments de cet horizon - créé sous l'inlluence du Cerny-sud dont l'usage a aussi retardé la distinction des signes céramiques en Normandie (Chancerel ('t al., 1995) - semblent d’ores et déjà pouvoir être rangés dans le V.S.G. plutôt que dans une étape chronologique contemporaine du Cerny "oriental" (Boujot. Cassen. 1997). Cela dit, il est patent que les décors poinçonnés identifiés sur ce site du Coglais, pour peu que leur découverte ait été isoléc du contexte en question, auraient tout autant pu être rattachés à du Cerny, comme nous serions par exemple tenté de le faire avec un tesson découvert dans les anciennes fouilles des alignements de Kermario (Carnac, Morbihan) marqué d'une thématique décorative identique à celle du vase n" 3, fig. 11 (Miln. 1881): preuve, semble-t-il, dans le cas de la séric eoglisienne, d'une transition sensible vers cette culture a lacies variés, en sorte quil est a prévoir que la décomposition des règles d’appartenance aux différentes étapes culturelles dans cette moitié du $\mathrm{V}$ millénaire s'en verra compliquée à mesure de l'avancéc vers les rivages atlantiques...

\section{Économie et traceurs de l'industrie lithique. Une industrie de pionniers?}

Au llaut-Mée, lapparent paradoxe qu'il y a à baser un systeme technique lithique sur des lames de grandes dimensions alors que les ressouress en matieres premières taillables sont quasi nulles conduit à s”interroger sur les motivations des occupants V.S.G. Remarquons en préalable que l'importation de silex pour l'outillage domestique se distingue clairement de l'acquisition des haches dapparat carnacéennes; elle est différente tout autant de la circulation des haches utilitaires à partir des grands ateliers (Plussulien en Côte-d'Armor, ou Ecoyeux-Taillebourg, en Charente-Maritime) durant tout le Néolithique. Le taux de renouvellement des outils non polis est beaucoup plus rapide. La recherche de tranchant eflicale ne peut se satisfaire de réavivages, elle est done corrélée à une certaine abondance de la matière. Le maintien des normes culturelles V.S.G. alors même que les contraintes environnementales les rendent trís coûteuses "économiquement" répond à une logique particulière. Il est évident en effet que ce choix exceptionnel dans la Préhistoire récente armoricaline trouve ses racines dans une volonté forte daflirmation de la continuité culturelle et de lidentité du groupe, et d'une rigidité intellectuelle certaine des halbitants du llaut-Méc. Elle s'accommode bien de l'hypothese d'un front de colonisation actil, dont le moteur est la conquête de nouveaux territoires par des groupes humains, et non une simple acculturation.

La fragilité d'un tel choix technique apparaît clairement a moyen terme : le fort investissement technique dans le débitage laninaire de grands modules implique un long apprentissage de la configuration du volume a débiter, avec une succession déchecs et de gâchis, difficile a mettre en ceuve sur le massif armoricain, à moins de recourir a une importation massive de matière brute. Fn dautres termes, la descendance des pionniers a rapidement dû perdre le bagage technique traditionnel. simplement faute dentrainement. $\dot{A}$ notre échelle de compréhension, la rupture est probablement brutale. Le débitage déclats à faible prédétermination. réalisé au percuteur dur. qui va lui succéder au début du Néolithique moỹen régional répond done à une logique technique endogène. Le fait est qu une telle évolution se déroulera également sur les terrains sédimentaires, sur une grande partic du territoire français. Il ny a done pas de simple déterminisme géologique dans cette evolution. mais sûrement un effet daccélération sur le massil armoricain et en tout cas une solution " de moindre elfort" pour les populations néolithiques du massif armoricain, soulagées des lourdes contraintes culturelles qui devalent peser sur leurs réseaux d'échanges.

Les bracelets sont linalement des traceurs bien pratiques pour pointer les sites attestés ou potentiellement lavorables du Néolithique le plus ancien dans louest de la France. On insistera en particulier sur les ateliers de fabrication distribués sur la limite du Massif armoricain (fig. 13), où plusicurs centaines de fragments, sourent recoltés à la surface des champs, illustrant toutes les étapes de la taille et de la mise en forme, mêlés à un débitage laminaire du silex, supposent des habitats V.S.(j. tout à fait constitués : si l'on connaît de longue datte ceux de La Butte à Marolette (Sarthe) ou de La llavardiere a Sablé (Sarthe - Bailloud, Cordier, 1987), les gisements exceptionnels de Champ-Dijon a Rollesse-Fontaine, La Grande Piece et Lal Plaine des Creichets a Louvigny, toujours en Sarthe (Nevoux, 1993, 1995: Birée, 1995), lémoignent d'une occupation dense sur plusieurs hectares de terrains. Plus au sud en Maine-et-Loire, dans le secteur des communes de Morannes, Fontaine-Guérin. Pontigné, les nombreux fragments de bracelets finis ou en cours de labrication rícoltés en surfice, le long de petites vallés se jetant dans les vastes zones marécageuses du lit de la Loire. laissent présager une remaryuable densité de sites V.S.G./Cerny comme le confirme tout près de li. a Brion, la juxtaposition doune de eses parures avee un vase a pastilles au repoussé (Barbier 't al., 1995). Par ailleurs, laassociation tertre/bracelet, plus précisément : sépulture à contour fermé/bracelet, est l'une des raisons qui avaient poussé l'un d’entre nous, en conséquence du modèle élaboré par C. Boujot sur les structures funciaires et en collaboration avece chercheur, at replacer le groupe des tertres et tumulus carnacéens dans une étape chronologique antérieure au développement des tombes a couloir. Dans le Morbihan. les bratcelets recucillis dans le modeste terte a coflre unicue de Bréhan-Loudéac, les "sépultures sous-dille" de 


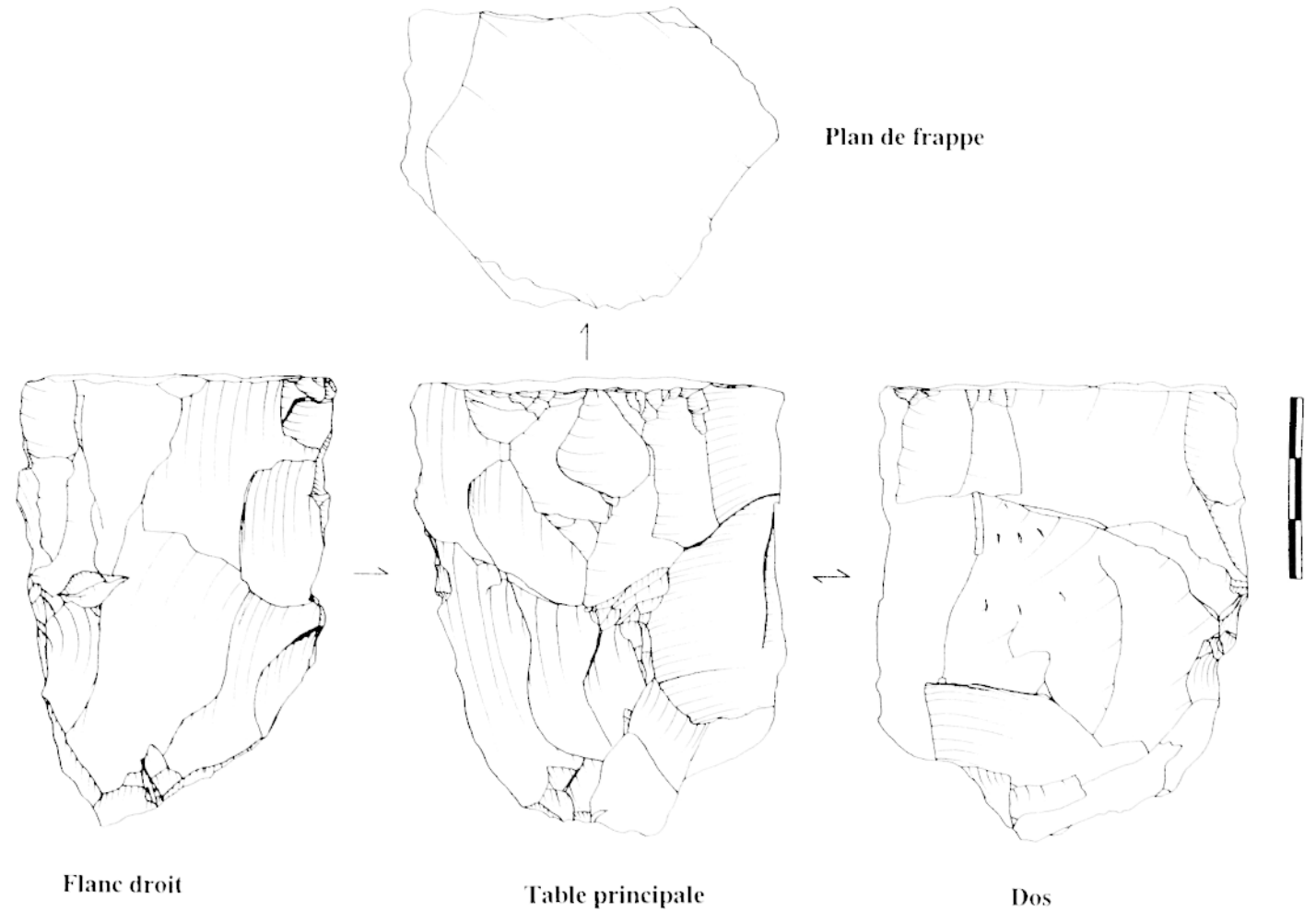

Fig. 13 - Nucléus a crêtes multiples en silicilication tertiaire (les lones sans ombrage sont des éclatements le long des diaclases. Dessin (i. Marchand).

Bernon en presquî̀le de Rhuys ou de Saint-Julien en presqu'île de Quiberon (Boujot, Cassen, 1992) en sont des exemples démonstratifs malgré un aspect architectural éminemment moins spectaculaire que la crypte du Mané er Hroëck en Locmariaquer, si fameuse avec son bracelet en jadéite associé à plus d'une centaine de lames de haches polies non fonctionnelles dont une majorité en fibrolite... Des bracelets furent aussi découverts à la base de la pierre dressée de Ty Lechir à Locoal Mendon (Le Rouzic, 1899); un élément supplémentaire à raccrocher au cadre chrono-culturel ici défendu et aux liaisons organiques tertres/stèles.

Les lames de haches polies en fibrolite du Haut-Mée. les bracelets en cornéenne et en schiste, nous rappellent que ces roches régionales, et les coquilles marines de la mer toute proche, firent l'objet d'une forte demande au sein des populations Rubané/V.S.G. implantées en Bassin parisien, sans vouloir ici parler des territoires encore plus à l'est. La sépulture 70 de l'habitat V.S.G. des Longues Raies (Jablines, Seine-et-Marne - Bulard et al., 1993) est à ce titre exemplaire : amphibolites, serpentinites et coquillages proviennent bien de l'Ouest de la France (analýses Querré et Taborin). Ce vaste réseau d’échanges, de compensations, de conciliations, d'alliances entre communautés, bien en place dès le Mésolithique d'Armorique, a bien sûr préparé le "lerrain" du procès dapparition de l'économie néolithique dans cette région. Mais qu'était-il obtenu en contrepartie?

\section{Le modèle d'implantation du site}

S`il est vrai que l'habitat V.S.G. comprend en général plusieurs unités d'habitations, et pourrait ainsi laisser croire que d'autres bâtiments sont encore préservés dans les terrains adjacents à la parcelle concernée par notre intervention, certaines études nécartent plus lidée que des fermes isolées aient pu s’établir, en rupture avec le modèle centre-curopéen de regroupement en villages (Lüning, 1982).

Si tel était le cas au Haut-Mée, nous serions probablement en présence d'un autre facteur d'évolution au sein du V.S.G.

Les différents sondages d'évaluation effectués près de Montours (Leroux et al., 1996) ont montré que d'autres vestiges du Néolithique ancien V.S.G. s’ajoutaient aux indices similaires déjà attestés par les prospections de P. Aussart (matériel céramique et lithique inédit), et qu’en conséquence un véritable "réseau" de sites séparés d’à peine 2 à $3 \mathrm{~km}$ était d’ores et déjà interprétable (lig. 1).

Il est en tous les cas certain que l'attrait des sols loessiques a encore joué à plein, et ce dans une région où ils ne sont repérés que par endroits. Cette variété du soussol armoricain, en particulier au niveau des zones à métamorphisme de contact, est une autre composante essentielle du mode d'exploration et dexploitation de l'environnement néolithique. 


\begin{tabular}{|l|l|l|c|c|}
\hline \multicolumn{1}{|c|}{ Structure } & \multicolumn{1}{|c|}{ Prélèvement } & \multicolumn{1}{c|}{ Réf. Labo } & B.P. & av. J.-C. \\
\hline Trou de poteau 121 & charbons & Ly-7662 & $5995 \pm 65$ & 5043,4742 \\
\hline Fosse 174 & charbons & Ly-7663 & $5765 \pm 60$ & 4761,4478 \\
\hline Fosse 76 & charbons & Ly-7661 & $5955 \pm 65$ & 4980,4711 \\
\hline Fosse 43 & charbons & Ly-7660 & $4900 \pm 55$ & 3796,3559 \\
\hline Fosse 2 & coquille noisette & Ly-356/A A-21673 & $5975 \pm 65$ & 5025,4727 \\
\hline
\end{tabular}

Gisements cités dans le texte

$\mathrm{MANCH}$

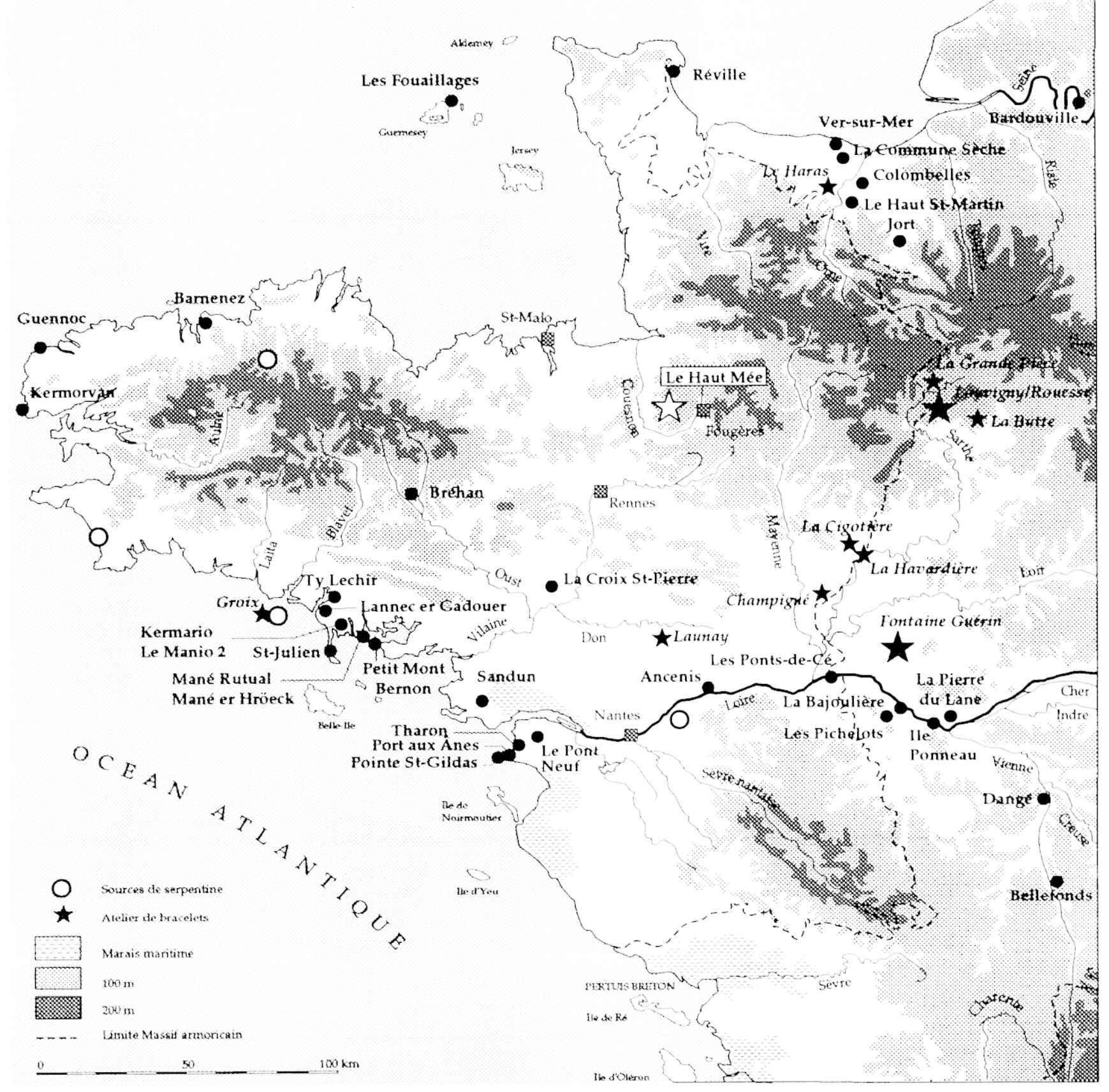

Fig. 14-Cartographic des gisements cités dans le texk (1).A.O. S. Casson). 


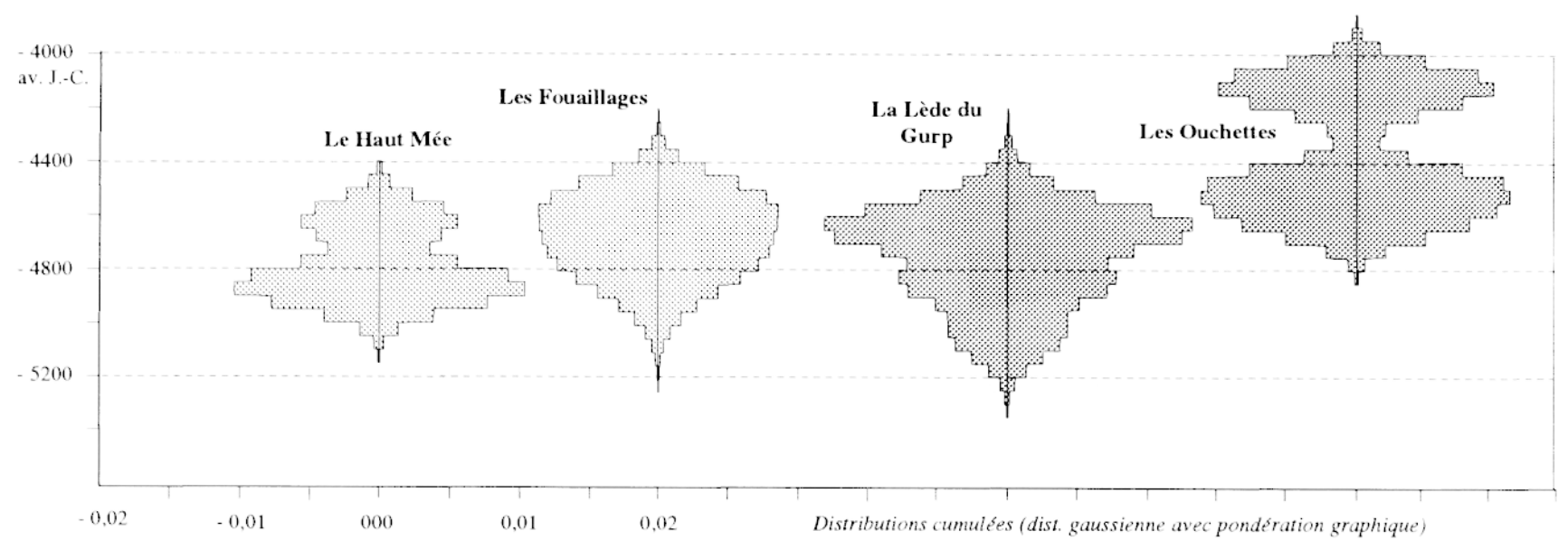

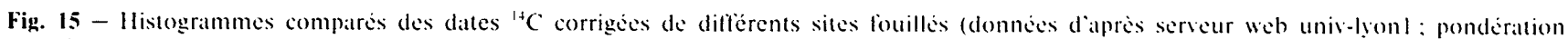
graphique atumatique selon lintervalle de confiance d'apres Cassen \&'t al. 1996).

\section{La chronologie absolue}

Trois fosses à couche unique $(43,76,174)$ et un trou de poteau de la maison (121) contenant du matériel néolithique V.S.G. ont bénéficié de datations radiométriques au laboratoire de Lyon I ; une coquille de noisette carbonisée incluse dans un élément de torchis trouvé dans la fosse 2 fit l'objet d’une analyse par accélérateur au laboratoire de Tucson (U.S.A.).

Malgré l'abondance des charbons, la date trop récente de la fosse 43 peut être commentée a posteriori par un choix sans doute malheureux du contexte archéo-stratigraphique puisqu'un fossé de parcellaire historique la coupe en deux, provoquant la source de pollution qui peut expliquer ce résultat. Les quatre autres résultats cohérents - qui, de prime abord, paraîtront anciens aux yeux d'un analyste de la production céramique - partagent cependant une ligne chronologique commune placée vers 4700 ans av. J.-C., ordre de grandeur compatible avec les propositions typologiques. D'ailleurs, on ne peut ici passer sous silence la séric significative du site peu éloigné des Fouaillages, dans les îles anglonormandes (Kinnes, 1982), dont les résultats concordants, contemporains de ceux du Haut-Mée, renvoient finalement à l'horizon historique illustré par les tessons à décor pivotant au peigne (Constantin, conmunication orale) découverts au contact du monument funéraire (Pinacle/Castellic ancien) qui leur est postéricur. Un phénomène de juxtaposition comparable aux rares vestiges V.S.G. (décor pivotant) piégés dans le paléosol castellic de la Table des Marchand a Locmariaquer (L'Helgouach - Cassen, 1987). Quelques histogrammes cumulés de dates ${ }^{14} \mathrm{C}$ des sites les plus "parlants" du Néolithique le plus ancien de la zone atlantique (fig. 14) montrent enfin combien les données statistiques actuelles du radiocarbone ne peuvent toujours pas confirmer les conjectures radicales de la précédente décennie quant ì une très précoce diffusion sud-nord du procès de la néolithisation par cette voie géographique.

\section{En perspective}

Plusicurs indices matériels, depuis de nombreuses années, laissaient penser que le premier néolithique dans l'Ouest de la France ne débutait pas avec les vestiges contenus dans les tombes à couloir. Des bracelets en pierre, certains motif's décoratifs poinçonnés sur la céramique, des spectres polliniques, plus récemment des armatures microlithiques "évoluées", des tessons imprimés au peigne pivotant, des vases à ouverture déformée incitaient les chercheurs à concevoir une étape chronologique plus ancienne dont un pan fut rattaché à l'horizon Cerny.

La découverte du Haut-Mée confirme un mouvement dominant d'influence orientale en Bretagne, durant le $V^{\prime}$ millénaire, qui n’écarte pourtant pas du champ des explications d’autres stimuli comme ceux décelables dans l'industrie lithique, au voisinage de la Loire, dès le $V^{E}$ millénaire (Marchand, à paraître). Quoi qu’il en soit, ces témoignages inédits impliquent dans l'immédiat une meilleure compréhension du "phénomène mégalithique", monumentalisme funćraire et religieux; à commencer par son cadre chrono-culturel dès lors que nous identifions deux étapes successives attestées en Armorique (V.S.G. et Cerny-Chambon) avant que ne s’affermissent les références propres au Néolithique moyen "historique", entre 4300 et 3700 ans av. J.-C.

\section{NOTE}

(1) Pour plus de clarté, et solon unc proche terminologic en usage des 1825 (Nahei). systematiséc par (". Boujot en 1993. k tertre sapplique dans nos studes a la masse de terre bien delimitée recourant le plus sourent des scipultures a contour ferme : le tumulus est par lesymologie du mot un apport distingue de terre el de pierre (cf. tumulus carnacén): k cairn (k "galgal” des Antiquaires) est un imoncellement de pierre architecturé sur une structure funeraire incerne, par exemple de ype tombe à couloir el chambre differencies. 


\section{REFERENCES BIBI.IOGRAPHIOLES}

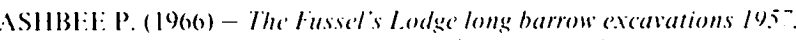
(Mlord. Society of Antiquaries of London, 1966.

ASHBB:I: P. (1970) - The Lasfem long barrow in Britain, London, Dent (5) Sons I.td, 1970 .

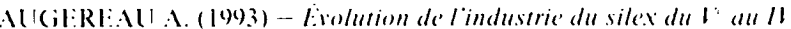
millenaire as. J.-C: dans. le' sud-e'st du Bassin parision. Organisa-

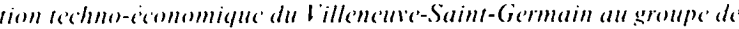

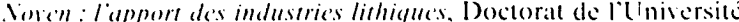
de Paris I (Panthion-Sorbonne), 3 vol., 451 p.. 12 pl.. 59 tabl

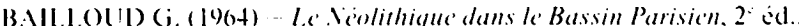
Paris, C.N.R.S.. 1974. suppl. a (iallia Prihistoirc. 2. 443 p.

BAILLO)(I) (i. el (OORD)II:R (i. (1987) - Le Néolithicue ancien el moren de la vallé de la Brisse (L.oir-et-Cher), R.t.c.. 26. 2. p. $117-163$

BNILLOUI) G BOUJOT C CASSIN S CL LE ROLIX C.-T. (1995) Carnac. Les Premieres architectures de pierre. Paris. Ed. du ('N.R.S., C.N.M.H.S. (Patrimoine au présent), et $126 \mathrm{p}$.

BARIBII:R S. VIAU Y. a DUBILLOT X. (1995) - Brion. la (roix Boizard. D.I.S. de satuvetage urgent. Autoroute $A$ S5. AngersTours. Nantes, S.R.A. Pays de Loire.

BI:RHIENS H. a SCHRÖTIER F. (1980) - Siedlunge'mund cirähar der lrichterheckerkultur und Sehmurkeramik bei Halle (Salde) Verölflenlichungen des l.andesmuscums tür Vorgeschichte in Halle. Bcrlin. 1980

BIG(OT B a LI: ( IRDIINER J (1987) - L.Habitat prehistoricue du chatcau de lougires, in: Jounce Preihist. at Protohist de Brefusnc. Rennes, Laboratoirc d'Anthropologie, 1987, p. 32-33.

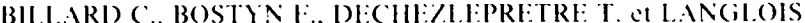
J.-Y. (1996) - Poses, "Sur la Mare". Bilan sicientificue l995. S.R.A. de Hatule-Normandic. 1996, p. $+1-44$

BIRI:E: P. (1995) - Rapport de prospection diathronicule. S.R.A. des Pays de Loire, Nantes, 1995

BOCJUCKI P. et GRY(jIIL. R. (1993) - Noolithic sites in the polish lowlands: research al Br/sc Kujawski, 1933 to 198t, in: (ase studies in Europesu Prehistorn. ed. Bogucki, Boca Raton, C.R.C. Press, p. 147.180

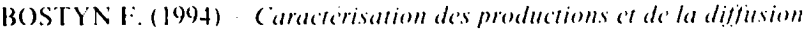

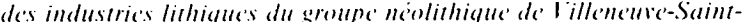
(icrmain. These de Docturat. liniversité de Paris X-Nanterre. 2 iol. $745 \mathrm{p}$.

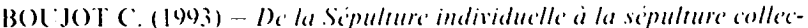

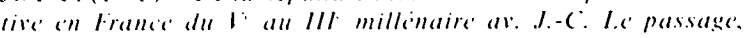
Doctorat de l'tniversiti de Paris I (Pantheon-Sorbonne). 3 vol.

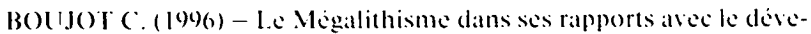
loppement des sépulutes collectives neolithiques. Apports d'une synthese a lechelle de la liance. B.S.P.l. t. 93. 3. p. $327-341$.

BOUJOT (. el ( ASSFN S. (1992) - le Developpement des premieres archiledures funcraires monumentales en france

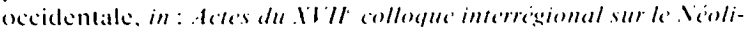

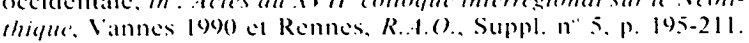

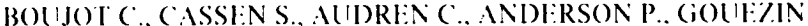
P. a MAR(HAN1) (j. (1994) Prolude a létude des lertres funcraires de Armorique-sud. Notes sur le monument de lannes

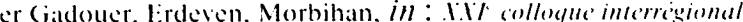
sur le .eolithique. Poitiers, 1994, résumé des communications. Ackes a paraitre.

BOLiJoT ( C. ASI:N S. (1997) - Néolithisation et monumentalite luncraire : explorations du tertre de Lannec er Gadouer à Frderen (Morbihan. France), in: RODRIGUEZ CASAL (Ed.). O Violiticon atlantico e as arive's do . Megalinismo. Actas do coloquio internacional. Santiago de (ompostcla. 1996. p. 211-232. Santiago de compostcla : l.I.S.P.P.. (Iniversite de Santiago, 1997.

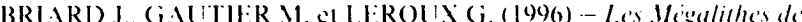
Saint-Just, Paris, ed. du C.T.II.S.

( ARRI H.. I)OUSSON J. A P()U'I.AIN P. (1958) - Habital neolithique dans les alluvions Yomne et Cure de la platine de SaintePalliace. B.S.P.I. p. 13.3-1.34

(ARRE H.. DOUSSON J. at POLLAIN P. (1959) - Satinte-Pallati. (iallia-prihistoire. Informations archéologiques, (irconscription de I)ijon. P. I03-106.

(ARRE: 11. (1990) - Passy (Yonne) et sal céramique : sites habités el

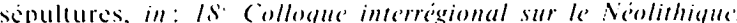
Dijon 1491, R.t.t.., 1t suppl.. p. 3(07-338.

(ASSI:N S. (1987) - le C'mere-Ouest de la France au ll' millenaire atam .1.-. . Osford 1987. B.4.R., 3+2. Internaltional séries. $385 \mathrm{p}$.

(ASSLX S. (1993) - Matcrial culture and chronology of the Middle

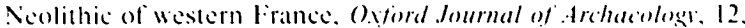
2. 1. 197-208

CASSIEN S. a MliLLER M. (1992) - Vestiges ciramigues de thorizon (ermy en Ar/on (Morbihan), B.S.P.1/. 118, p. $215-218$.

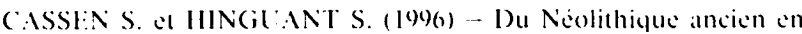
Brelange, B.S.P.I., 1.93, p. 147-148

( ASSEN S., GARNIIER B. a ROJO) (ILIERR.I M. (l9)(6) - l'n Programme informatique pour la representation graphicue des scries de dates "C corrigees : application aux sépultures monumentales nélithiques de la péninsule iberique, in : $1 / S$ (ompres Vational des socicites historiques et sciemtitiques, Pau. 199)3 pró- et Protohistoire, Paris, éd. du C.T.H.S. P. $4(4)-520$.

CASSIEN S., IINGUANT S., LANNUZILL (i. M MARCHANI) (i

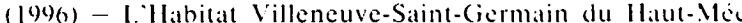
(Satint-Ftienne-en-Cogles, Ille-et-Vilaine), Internio 1, p. 45-50).

(HAMBON P. E MORDANT P. (1996) - Monumentalisme L sÉpultures collectives a Balloy (Seine-et-Mlarne), B.S.P.I. 1.93.3. p. 39$)(1-402$

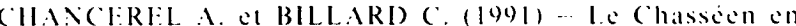
Normandie, in: Identiti du Chassien. Actes du colloyue International de Nemours, 1989, Nemours, A.P.R.A.1.1:. 1991 (.18moires du musce de Prihistoire d"lle-de-lrance, n" th. ค. $165-173$

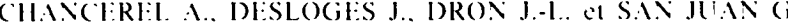
(1992) - Le Debut du Neolithique en Basse-Normandic, in :

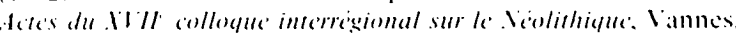
1990, Remnes, R.t.0. p. 153-176.

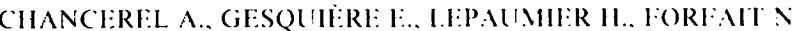
et L.FCLERC G. (1995) - Nouvelles implantations du Ville neure-Saint-Germatin en Basse-Normandice in: Actes da 1.1

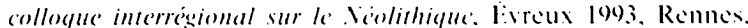
R.A.O. p. $43-56$

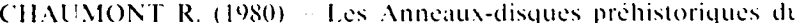
Maine, la Province du Maime. 3.3. sp.

CHILDE (

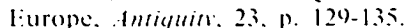

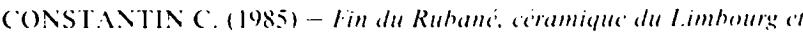

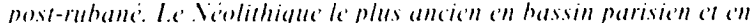
Hainatat. Oxford. B.A.R. International Series. 273 p.

(ONSTANTIN C. at MNNOI.AKAKIS L. (1901) I.e (iroupo

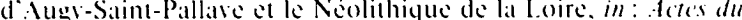

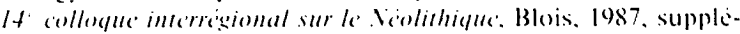

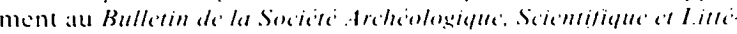
raire du l'ondimois. p. $+5-52$

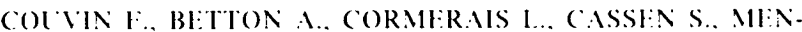

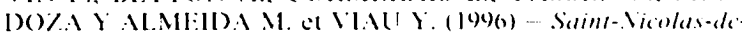

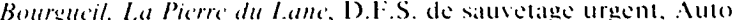
route i s. Orkins, S.R.A. Contre, 1990. 
CORCORAN J.X.W.P. (1969) - The Cotswold-Severn Group, in: Megalithic enquiries in the west of Britain. Liverpool, Liverpool University Press, p. 73-106.

CZERNIAK L. (1980) - Rozwoj spoleczenstw Kultury Póznej Ceramih Ustegowej na Kujawach, Poznan, Université de Poznan, Séries archeologiques 16, 1980

DADET P., BEURRIER M. et LAUTRIDOU J.-P. (1984) - Notice explicative de la feuille Saint-Hilaire-du-Harcouët à $1 / 50000$. B.R.G.M., carte $n 247$.

DESLOGES J. (1989) - Découverte d’une nécropole néolithique au lieu-dit la Haute-Bonny, commune de Rots (Calvados), in: Journée Préhistorique de Bretagne, Rennes. Résumé des communications. Rennes. C.N.R.S., Universite de Rennes I.

FOUERE P. (1994) - Les Industries en silex entre néolithique moven et campaniforme dans le nord du Bassin aquitain. Approche methodologique, implications culturelles de léconomie des matieres premieres et du débitage. Thèse de doctorat de l'universite de Bordeaux 1, 2 vol.

GHESQUIERE E. et MARCIGNY C. (1995)-Deux occupations du Néolithique ancien a l'ouest du Pavs de Cau (Seine-Maritime). R. 4.0., 12, p. 43-56.

GLOB P.V. (1949) - Barker. Danmarks aldste landsby, Nationalmuseets Arbeidsmark. p. 1-12

GOULETQUER P. (1991) - Barnenez-ar-Zant et ses symboles, in : Ia Bretagne linguistique. Centre de Recherche Bretonne et Celtique. 7. p. $103-133$.

GRUET M. (1986) - Le Sol d'habitat neolithique Augy-Saint-Pallaye de la Bajouliere (Maine-et-Loire), in: I colloque Interregional sur le Neolithicule de Caen. /983. Rennes. Suppl a la R.A.O. 1. p. $137-141$.

GRUET M. (1991)-Du Cardial en Anjou : Les Pichelots in : Actes du It colloque interregional sur le Neolithique. Blois, 1987, supplement au Bulletin de la Société Archéologique. Scientifique et Litheraire du Vendomois, p. 37-44

HAMON G. (1995) - Installations domestiques du Néolithique ancien et moyen I a Nohant-en-Graçay (Cher) et a Brion (Indre). R.A.C. 34, p. $157-176$.

HODDER I. (1984) - Burials, houses, women and men in the european Neolithic, in: New directions in archacology, D. Miller, C. Tilley dir., Cambridge. Cambridge University Press, p. 51-68.

JEUNESSE C. (1995) - Contribution à l'étude de la variabilité régionale au sein du Rubane. L'exemple du sud de la plaine du Rhin supérieur. Cah. Ass. Prom. Rech. Archeo. A/sace, 11, p, 1-22.

JOL Y F.et BESSAC-GIRAUDET J.(1986)-Carte geomorphologique de la France, Gip Reclus, C.N.R.S. I.G.N

JORGENSEN E. (1977) - Hagebrogard-Vroue-Koldhur Veolitische Gräberfeld aus Nordwest-Jütland, Copenhagen. Nhademik Forlag.

JORGENSEN E. (1993) - Jutlandic stonepacking graves, in : Digging into the past. 25 years of Archaeology in Denmark, Has et Storgaard (Eds), Aarhus, Aarhus Universitetsforlag.

JOUSSAUME R. (1986) - La Néolithisation du Centre-Ouest, in: I Veolithique de la France: Hommage à Bailloud, Guilaine J. Demoule J.-P., dir. Paris, Picard, p. 161-179

KINNES I. (1982) - Les Fouaillages and megalithic origins, Antiquits. 56, p. $24-30$

LANCHON Y.(1984) - Le Neolithique damubien et de tradition danubienne dans / Est du Bassin parisien. Memoire de maîtrise. Université de Paris I (Panthéon-Sorbonne), 2 vol.

LFCORNEC J. (1994) - Le Petit-Wont. Arzon, Morhihan, Document Archéologiques de l'Ouest, Rennes, P.E.A.O. 109 p.

LEROUX G. (1996) - Saint-Etienne-en-Cogles, te Haut-Mee, Site d'habitat du Neotithique ancien. D.F.S. de diagnostic, 1995/1996, Rennes, S.R.A. Bretagne.
LEROUX G.. AUBRY L. et PAITIER H. (1996) - Evaluation archeologique de l'A 84, sections / a 4. L'Autoroute des Estuaires, S.R.A de Bretagne, Rennes, 1996, 1

LE ROUX C.-T. et LECERF Y. (1971) - Découverte d'anneaus disques à Gévezé (Ille-et-Vilaine), Annales de Bretagne, 78. p. $13-23$

LE ROUZIC 7. (1899)-Carnac, fouilles faites dans la région, 1898 1899. B.S.P.M. p. 7-16.

LE ROUZIC Z. (1965)-Inventaire des monuments mégalithiques de la region de Carnac, Vannes, B.S.P.M.

LETTERLE F., LE GOUESTRE D. et LE MEUR N. (1991) - L. Chronologie du Néolithique moven en Armorique à la lumière du site de Sandun à Guérande (Loire-Atlantique), in: Actes du If Colloque Interregional sur le Neolithique, Blois, 1987. suppl. au Bulletin de la Societe trcheologique. Scientitique et Litueraire dn lendomois, p. 149-158

L'HELGOUAC'H J. (1983) - Les Idoles qu'on abat. B.S.P.Y., 110 p. 57-68.

L'HELGOUAC'H J. et CASSEN S. (1987) - Locmariaquer. La Table des Marchands. Campagne de fouilles, 1987. Rapport intermédiaire de fouille programmee, S.R.A. Bretagne, Rennes, 1987.

LE PONTOIS G. (1929) - Le Finistère préhistorique Institut International d'Anthropologie, n 3. Paris, Lib. E. Nourry.

LE ROUZIC Z., PEQUART SI-J. el PEQUART M. (1923) - Carnac. foulles faites dans la region. Campagne 1922. Paris, BergerLevrault. 1923

LÜNING J. (1982) - Research into the Bankeramik setlement of the Aldenhovener Platte in the Rhineland Analecta Prachistorid Leidensia, 15, p. 1-29

MAHE J. (1825) - Essai sur les Antiquites du departement du Morbihan. Vannes. Imp. Galles, 1825

MAISONNEUVE B. (1983) - Les Signaux graves dans les tombes à couloir en Amorique. Mémoire de maitrise, Universite de Paris I.

MANOLAKAKIS L. (1991) - Eléments néolithiques VilleneuveSaint-Germain et Cerny du nord et du sud de la Beauco (Essonne, Loiret), R.A.C. 30. 1991, p. 31-46.

MARCHAND G. (1994) - Microlithes et ceramiques à l'embouchure de la Loire, in: $\mathrm{XXl}$ colloque interregional sur le Neolithique. Poitiers, 1994, résumé des communications. Actes à paraître.

MERIMEE P. (1835) - Notes d'un vorage dans l'Ouest de la France. Paris, ed. Adam Biro, 1989

MIDGLEY S.-M. (1985) - The Origin and fonction of the earthen lons barrows of northern Europe. Oxford, B.A.R. International Series 259

MILN J. (1881) - Foulles faites a Carnace Les alignements do Kemario, Rennes, Typographie Oberthur.

MODDERMANN P.I.R. (1985) - Die Bandkeramik im Graetheidegebiet. Niederländish-Limburg. Bericht der Römish-Germanischen Kommission, 66, p. 25-121.

NEVOUX Y.(1993.1995)-Rappon de prospection-inventaire. S.R.A des Pays de Loire, Nantes, 1993, 1995.

PATTE E. (1971) - Sépultures du Poitou du Mésolithique au Bronze moyen, Gallia Préhistoire. XIV, p. 139-244.

PELFGRIN J. (1991) - Sur une recherche experimentale des techniques de débitage lamimaire in : Archeologie auiourd'tur tetes du Colloque lntemational "Experimentation en archeologie : bilan et perspectives" (Archéodrome de Beaune). t. 2, p. 118-128

PHILIBERT S. (1996) - Approche techno-fonctionnelle des outit lages du Néolithique ancien et moyen dans le Bassin Parisien. Les gisements du Moulin de Lettrée (Neauphle-le-Vieux. Yvelines) et de Louviers-la-Villette (Eure): premiers résultats. Intemeo. 1. Paris. Association pour les Ftudes interrégionales sur le Neolithique, p. 33-44 
PHILIPPE J. (1928) - Anneau-disque en jadéite de la ballastière du Breuilpont (Eure), Bull. Soc. Normande d'Et. Prehist., 26. p. $69-80$.

PICO C. LAPORTE L CAMMAS C. FABRE L. GRUET Y. el VELLA C. (1994) - Les Ouchettes à Plassay (Charente-Maritime). une occupation de fond de vallon au Néolithique, 89 p. dactylo., ill.

PRESTREAU M. et THEVENOT J.-P. (1996) - L'Axe YonneArmançon-Saône au Néolithique moyen : cadre chronologique et interpretations culturelles, in: 18 Colloque Interregional sur he Neolithique. Dijon, 1991. R.A.E. 14 suppl., p. 383-395

RENAULT V. (1994) - Mondeville, Le Haut-Saint-Martin, in : Bilan scientifique 1093. Ministere de la Culture, S.R.A. de BasseNormandie, Caen, p. 33-35.

ROUSSOT-LARROQUE I VILLES A (1988) - Fouilles pré-et protohistoriques à la Lède du Gurp (Grayan-et-L'Hôpital. Gironde), Rev. Archéo. de Bordeaux, p. 19-60.

SIMONIN D. (1988) - L'Habitat néolithique des Dépendances de Digny 1 a Echilleuse (Loiret), in: Du Neolithique moven // au Neolithique final au nord-ouest des Alpes, 12 Colloque interrégional sur le Neolithique. Lons-le-Saunier, 1985, Lons-le-Saunier. Musée d'Archéologie.

SIMONIN D. (1996) - Nouvelles données sur le Néolithique ancien et moven dans le sud-ouest de la Seine-et-Marne. Bulletin du Group. Archeo. de Seine-et-Marne, 32-34 (1991-1993), p. 57-84.

SPROCKOFF E. (1938) - Die nordische Megalithkultur. Berlin.

VERRON G. (1976) - Les Civilisations Néolithiques en Normandie. in: La Prehistoire Francaise, t. 2, Paris, C.N.R.S., p. 387-401.

VILLES A. (1984) - Le Néolithique ancien et le début du Néolithique moyen dans les pays de la Loire Moyenne. Etat de la question. in: Influences meridionales dans l'Est et le Centre-Est de la France au Néolithique. Actes du 8 Colloque Interregional sur le Néoli thique Le Puy-en-Velay, 1981. Clermont-Ferrand. Centre de Recherches et d'Etudes Préhistoriques de l'Auvergne, p. 57-93.
Ibréviations :

B.A.R. : British Archacological Report.

B.S.P.F. : Bullerin de la Socicié Prihistorique Francaise:

B.S.P..Y. : Bullerin de la Socitite Polvmatiaus du Morhihan.

R.A.C. : Revu' Archeologique du ('intre de la France.

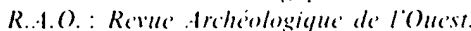

Serge CASSEN

Laboratoire de Préhistoire armoricaine U.M.R. 6566 du C.N.R.S., Université de Nantes B.P. 81 227, 44312 Nantes Cedex 3 cassen.s@humana.univ-nantes.fi

Claude AUDREN

Géosciences C.N.R.S., Université de Rennes, Laboratoire de techtono-physique Campus de Bealulieu, 35044 Rennes Cedex tahar.aifd@univrennesl.fi

Stéphan HINGUANT

A.F.A.N., U.M.R. 6566

Laboratoire d'Anthropologic

Campus de Beaulieu, 35044 Rennes Cedex

Gaëlle LANNUZEL

A.F.A.N., U.M.R. 6566

Laboratoire d'Anthropologic

Campus de Beaulieu, 35044 Rennes Cedex

Gregor MARCHAND

U.M.R. 6566 du C.N.R.S.

23, rue des Roses, 44000 Nantes marchand.g@humana.univ-nantes.fi 